\title{
The Brazilian Society of Cardiology and Brazilian Society of Exercise and Sports Medicine Updated Guidelines for Sports and Exercise Cardiology - 2019
}

Development: The Brazilian Society of Cardiology (Sociedade Brasileira de Cardiologia - SBC) and the Brazilian Society of Exercise and Sports Medicine (Sociedade Brasileira de Medicina do Exercício e do Esporte - SBMEE)

Norms and Guidelines Council: Fernando Bacal, Leandro Ioschpe Zimerman, Paulo Ricardo Avancini Caramori and Pedro Alves Lemos Neto

Norms and Guidelines Coordinator: Ludhmila Abrahão Hajjar

President of the Department of Ergometry, Exercise, Nuclear Cardiology and Cardiovascular Rehabilitation (Departamento de Ergometria, Exercício, Cardiologia Nuclear e Reabilitação Cardiovascular - DERC): Tales de Carvalho

President of the Group of Studies of Sports Cardiology (Grupo de Estudos de Cardiologia do Esporte GECESP): Antonio Carlos Avanza Jr.

President of SBMEE: Marcelo Bichels Leitão

Editors: Nabil Ghorayeb and Ricardo Stein

Associate Editors: Daniel Jogaib Daher, Anderson Donelli da Silveira and Japy Angelini Oliveira Filho

Authors: Nabil Ghorayeb, * Ricardo Stein, * Daniel Jogaib Daher, Anderson Donelli da Silveira, Japy Angelini Oliveira Filho, Luiz Eduardo Fonteles Ritt, Daniel Fernando Pellegrino dos Santos, Ana Paula Rennó Sierra, Artur Haddad Herdy, Claúdio Gil Soares de Araújo, Cléa Simone Sabino de Souza Colombo, Daniel Arkader Kopiler, Filipe Ferrari Ribeiro de Lacerda, José Kawazoe Lazzoli, Luciana Diniz Nagem Janot de Matos, Marcelo Bichels Leitão, Ricardo Contesini Francisco, Rodrigo Otávio Bougleux Alô, Sérgio Timerman, Tales de Carvalho, Thiago Ghorayeb Garcia, Antonio Claudio Lucas da Nobrega, Luiz Gustavo Marin Emed, Roberto Vital

* Both authors contributed equally as first author.

Guideline Authors: Nabil Ghorayeb, 1,2,3,4 Ricardo Stein, ${ }^{5,6,7}$ Daniel Jogaib Daher, ${ }^{2}$ Anderson Donelli da Silveira, ${ }^{5,6,7}$ Japy Angelini Oliveira Filho, ${ }^{3}$ Luiz Eduardo Fonteles Ritt, ${ }^{8,9}$ Daniel Fernando Pellegrino dos Santos, ${ }^{2}$ Ana Paula Rennó Sierra, ${ }^{10}$ Artur Haddad Herdy, ${ }^{11,12}$ Claúdio Gil Soares de Araújo, ${ }^{13}$ Cléa Simone Sabino de Souza Colombo, ${ }^{2,14}$ Daniel Arkader Kopiler, ${ }^{15,16}$ Filipe Ferrari Ribeiro de Lacerda, ${ }^{5}$ José Kawazoe Lazzoli, ${ }^{15,17}$ Luciana Diniz Nagem Janot de Matos, ${ }^{18}$ Marcelo Bichels Leitão, ${ }^{15}$ Ricardo Contesini Francisco, ${ }^{1,2}$ Rodrigo Otávio Bougleux Alô, $, 1,19$ Sérgio Timerman, ${ }^{20,21}$ Tales de Carvalho, ${ }^{12,22,23}$ Thiago Ghorayeb Garcia, ${ }^{1,2}$ Antonio Claudio Lucas da Nobrega, ${ }^{24}$ Luiz Gustavo Marin Emed, ${ }^{25}$ Roberto Vital ${ }^{26,27}$

Instituto Dante Pazzanese de Cardiologia, ${ }^{1}$ São Paulo, SP - Brazil

Hospital do Coração (HCor), Associação do Sanatório Sírio, ${ }^{2}$ São Paulo, SP - Brazil

Programa de Pós-Graduação em Medicina do Esporte da Universidade Federal de São Paulo (UNIFESP), ${ }^{3}$ São Paulo, SP - Brazil

Instituto de Assistência Médica ao Servidor Público Estadual (IAMSPE), ${ }^{4}$ São Paulo, SP - Brazil

Programa de Pós-Graduação em Cardiologia e Ciências Cardiovasculares da Universidade Federal do Rio Grande do Sul (UFRGS), ${ }^{5}$ Porto

Alegre, RS - Brazil

Hospital de Clínicas de Porto Alegre, Universidade Federal do Rio Grande do Sul (HCPA/UFRGS), ${ }^{6}$ Porto Alegre, RS - Brazil

Vitta Centro de Bem Estar Físico, ${ }^{7}$ Porto Alegre, RS - Brazil

Hospital Cárdio Pulmonar, ${ }^{8}$ Salvador, BA - Brazil

DOI: 10.5935/abc.20190048 
Escola Bahiana de Medicina e Saúde Pública, ${ }^{9}$ Salvador, BA - Brazil

Universidade de São Paulo (USP), ${ }^{10}$ São Paulo, SP - Brazil

Instituto de Cardiologia de Santa Catarina, ${ }^{11}$ Florianópolis, SC - Brazil

Clínica Cardiosport de Prevenção e Reabilitação, ${ }^{12}$ Florianópolis, SC - Brazil

Clínica de Medicina do Exercício, Clinimex, ${ }^{13}$ Rio de Janeiro, $R J-$ Brazil

Sports Cardiology, Cardiology Clinical Academic Group - St George's University of London, ${ }^{14}$ London - UK

Sociedade Brasileira de Medicina do Esporte e do Exercício (SBMEE), ${ }^{15}$ São Paulo, SP - Brazil

Instituto Nacional de Cardiologia (INC), ${ }^{16}$ Rio de Janeiro, RJ - Brazil

Federação Internacional de Medicina do Esporte (FIMS), ${ }^{17}$ Lausanne - Switzerland

Hospital Israelita Albert Einstein, ${ }^{18}$ São Paulo, SP - Brazil

Hospital Geral de São Mateus, ${ }^{19}$ São Paulo, SP - Brazil

Instituto do Coração da Faculdade de Medicina da Universidade de São Paulo (InCor-FMUSP), ${ }^{20}$ São Paulo, SP - Brazil

Universidade Anhembi Morumbi, Laureate International Universities, ${ }^{21}$ São Paulo, SP - Brazil

Departamento de Ergometria e Reabilitação Cardiovascular da Sociedade Brasileira de Cardiologia (DERC/SBC), ${ }^{22}$ Rio de Janeiro, RJ - Brazil

Universidade do Estado de Santa Catarina (UDESC), ${ }^{23}$ Florianópolis, SC - Brazil

Universidade Federal Fluminense, ${ }^{24}$ Rio de Janeiro, $R J-$ Brazil

Hospital Cardiológico Costantini, ${ }^{25}$ Curitiba, $P R$ - Brazil

Comitê Paralímpico Brasileiro (CPB), ${ }^{26}$ São Paulo, SP - Brazil

Universidade Federal do Rio Grande do Norte (UFRN), ${ }^{27}$ Natal, RN - Brazil

\section{This Guideline should be cited as:}

Ghorayeb N, Stein R, Daher DJ, Silveira AD, Ritt LEF, Santos, DFP et al. The Brazilian Society of Cardiology and Brazilian Society of Exercise and Sports Medicine's Updated Guidelines for Sports and Exercise Cardiology - 2019. Arq Bras Cardiol. 2019; 112(3):326-368.

Note: These Guidelines are for information purposes and are not to replace the clinical judgment of a physician, who must ultimately determine the appropriate treatment for each patient.

Correspondence: Sociedade Brasileira de Cardiologia - Av. Marechal Câmara, 360/330 - Centro - Rio de Janeiro - Postal Code: $20020-907$. E-mail:sbc@cardiol.br. 
Declaration of potential conflict of interest of authors/collaborators of The Brazilian Society of Cardiology and Brazilian Society of Exercise and Sports Medicine Updated Guidelines for Sports and Exercise Cardiology - 2019

\begin{tabular}{|c|c|c|c|c|c|c|c|}
\hline \multicolumn{8}{|c|}{ If the last three years the author/developer of the Guidelines: } \\
\hline $\begin{array}{l}\text { Names Members } \\
\text { of the Policy }\end{array}$ & $\begin{array}{l}\text { Participated in clinical } \\
\text { studies and/or experimental } \\
\text { trials supported by } \\
\text { pharmaceutical or } \\
\text { equipment related to the } \\
\text { guideline in question }\end{array}$ & $\begin{array}{c}\text { Has spoken at } \\
\text { events or activities } \\
\text { sponsored by } \\
\text { industry related } \\
\text { to the guideline in } \\
\text { question }\end{array}$ & $\begin{array}{l}\text { It was (is) } \\
\text { advisory board } \\
\text { member or } \\
\text { director of a } \\
\text { pharmaceutical or } \\
\text { equipment }\end{array}$ & $\begin{array}{l}\text { Committees } \\
\text { participated } \\
\text { in completion } \\
\text { of research } \\
\text { sponsored by } \\
\text { industry }\end{array}$ & $\begin{array}{l}\text { Personal or } \\
\text { institutional aid } \\
\text { received from } \\
\text { industry }\end{array}$ & $\begin{array}{l}\text { Produced } \\
\text { scientific } \\
\text { papers in } \\
\text { journals } \\
\text { sponsored by } \\
\text { industry }\end{array}$ & $\begin{array}{c}\text { It shares } \\
\text { the } \\
\text { industry }\end{array}$ \\
\hline Anderson Donelli da Silveira & No & No & No & No & No & No & No \\
\hline Artur Haddad Herdy & No & No & No & No & No & No & No \\
\hline Claúdio Gil Soares de Araújo & No & No & No & No & Inbramed & No & No \\
\hline $\begin{array}{l}\text { Cléa Simone Sabino de } \\
\text { Souza Colombo }\end{array}$ & No & No & No & No & No & No & No \\
\hline Daniel Jogaib Daher & No & No & No & No & No & No & No \\
\hline Daniel Arkader Kopiler & No & No & No & No & No & No & No \\
\hline $\begin{array}{l}\text { Filipe Ferrari Ribeiro de } \\
\text { Lacerda }\end{array}$ & No & No & No & No & No & No & No \\
\hline José Kawazoe Lazzoli & No & No & No & No & No & No & No \\
\hline $\begin{array}{l}\text { Luciana Diniz Nagem Janot } \\
\text { de Matos }\end{array}$ & No & No & No & No & No & No & No \\
\hline Luiz Eduardo Fonteles Ritt & No & No & No & No & No & No & No \\
\hline Marcelo Bichels Leitão & No & No & No & No & No & No & No \\
\hline Nabil Ghorayeb & No & No & No & No & No & No & No \\
\hline Rodrigo Otávio Bougleux Alô & No & No & No & No & No & No & No \\
\hline Sérgio Timerman & No & No & No & No & No & No & No \\
\hline Tales de Carvalho & UDESC & No & No & No & No & No & No \\
\hline Thiago Ghorayeb Garcia & No & No & No & No & No & No & No \\
\hline
\end{tabular}




\section{Content}

1. Presentation and Introduction .330

2. Pre-Participation Screening ……………………….......................330

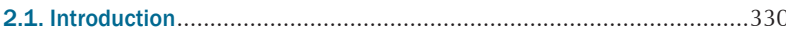

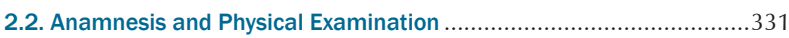

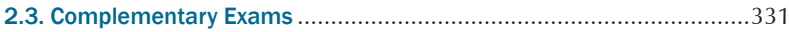

2.3.1. Twelve-Lead Electrocardiogram ....................................................332

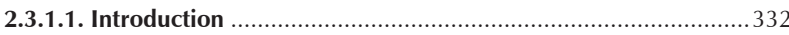

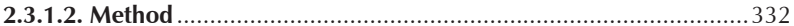

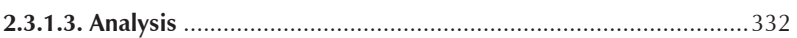

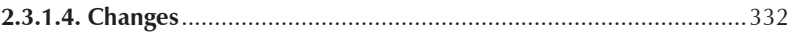

2.3.2. Electrocardiogram: Physiological Changes vs. Changes Suggestive

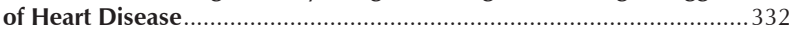

2.3.3. Exercise Stress Testing.................................................................. 334

2.3.3.1. Variables to be Evaluated in an Exercise Stress Testing .............334

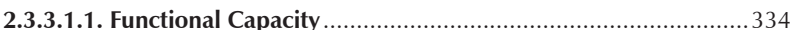

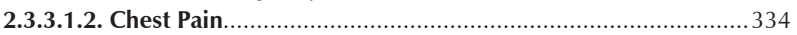

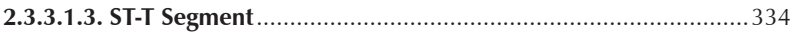

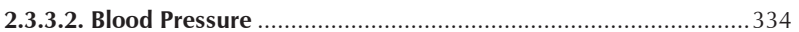

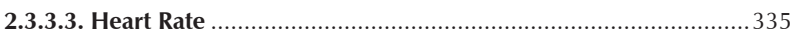

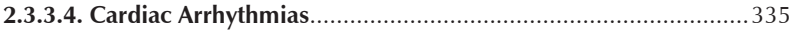

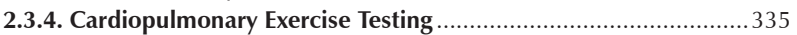

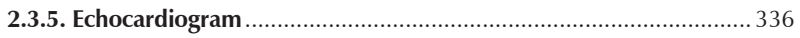

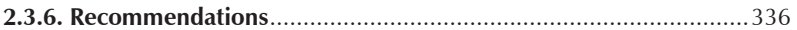

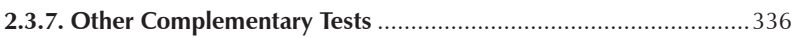

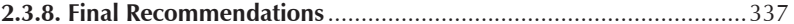

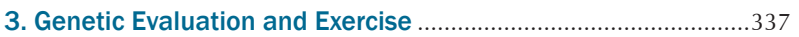

3.1. Positive Genotype and Negative Phenotype.....................................337

4. Individuals with Cardiomyopathies and Myocarditis..................338

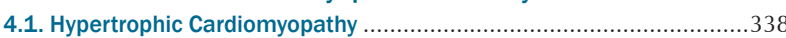

4.1.1. Genetics and Hypertrophic Cardiomyopathy ..............................339

4.1.2. Complementary Exams in Hypertrophic Cardiomyopathy ...........339

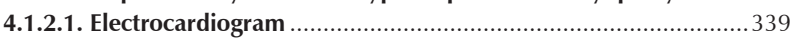

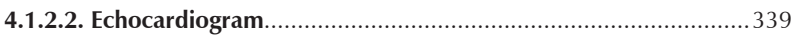

4.1.2.2.1. Transthoracic Doppler Echocardiogram..................................339

4.1.2.2.2. Transesophageal Doppler Echocardiogram..............................340

4.1.2.3. Cardiac Magnetic Resonance Imaging ........................................ 340

4.1.2.4. Exercise Tests and Hypertrophic Cardiomyopathy ................... 340

4.1.2.4.1. Exercise Testing Recommendations for Patients with

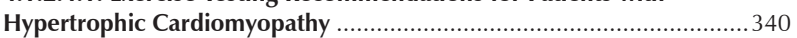

4.1.2.4.2. The Role of Maximal Cardiopulmonary Exercise Testing in

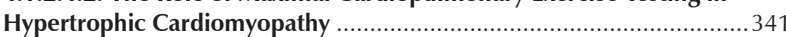

4.1.3. Sports and Hypertrophic Cardiomyopathy ……………............... 341

4.2. Arrhythmogenic Right Ventricular Dysplasia ......................................341

4.2.1. Diagnosis and Management of Athletes with Suspected

Arrhythmogenic Right Ventricular Dysplasia ........................................ 342

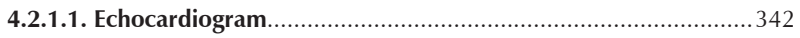

4.2.1.2. Cardiac Magnetic Resonance Imaging ..................................... 342

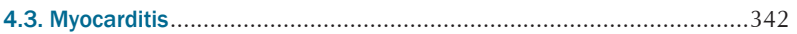

4.3.1. Recommendations for Athletes with Myocarditis ......................... 342

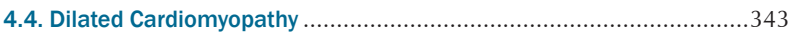

4.4.1. Complementary Exams for Dilated Cardiomyopathy ................... 343

4.4.1.1. Exercise Stress Testing and Cardiopulmonary Exercise Testing... 343

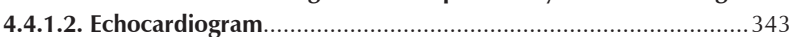

4.4.1.3. Cardiac Magnetic Resonance Imaging ........................................ 343

4.4.2. Sports and Dilated Cardiomyopathy...........................................343

4.4.2.1. Recommendations for Athletes Diagnosed with Dilated

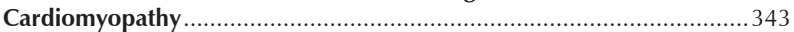

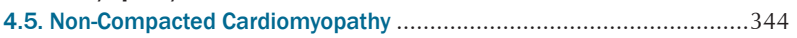

4.5.1. Sports and Non-Compacted Cardiomyopathy .............................. 344

4.5.1.1. Recommendations for Athletes Diagnosed with Non-Compacted

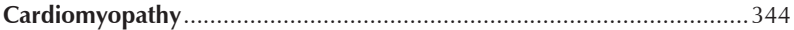

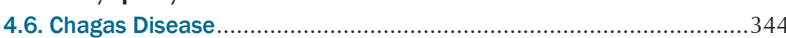

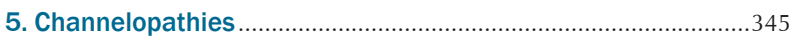

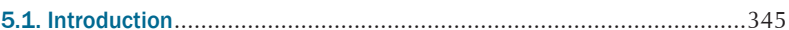

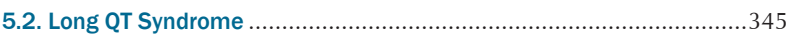

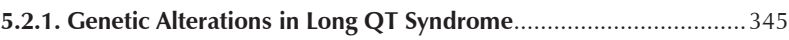

5.2.2. Risk Stratification in Long QT Syndrome .....................................345

5.2.3. Recommendations for Athletes with Long QT Syndrome .............. 345

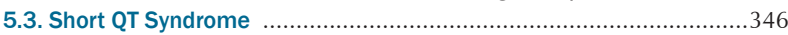

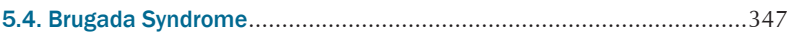

5.5. Catecholaminergic Polymorphic Ventricular Tachycardia ...................347

6. Athletes with Valvular Heart Disease .............................................348

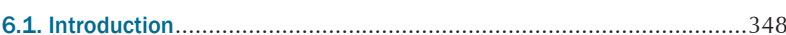

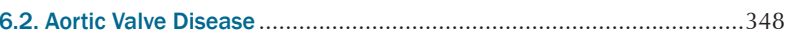

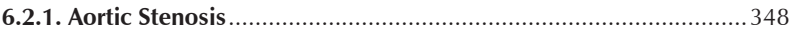

6.2.1.1. Recommendations and Evidence Level ....................................349

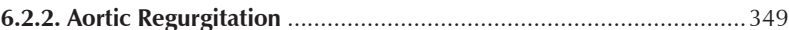

6.2.2.1. Recommendations and Evidence Level .....................................349

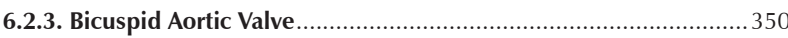

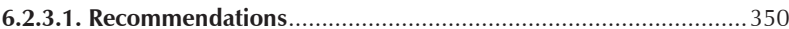

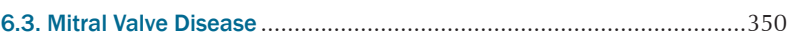

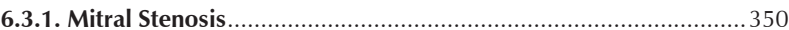

6.3.1.1. Recommendations and Evidence Level ...................................... 350

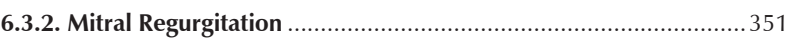

6.3.2.1. Recommendations and Evidence Level ....................................351

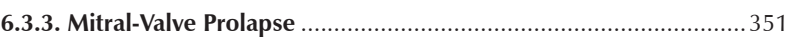

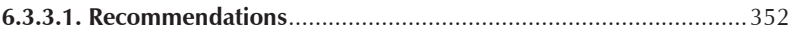

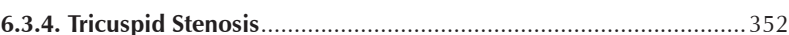

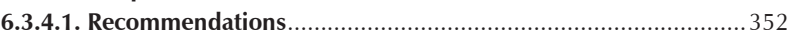

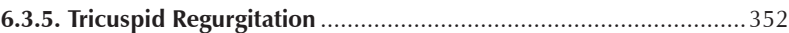

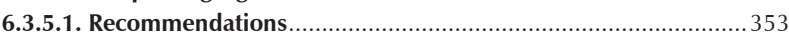

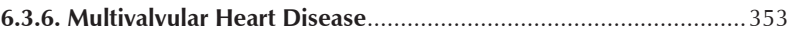

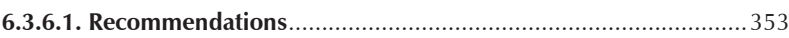

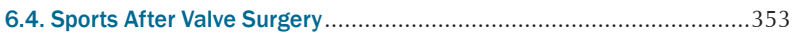

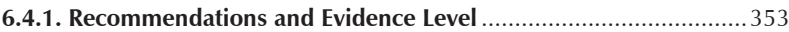

6.4.2. Transcatheter Aortic Valve Implantation ...................................... 353

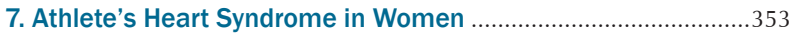

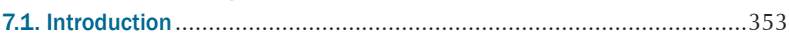

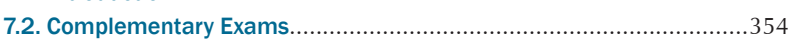

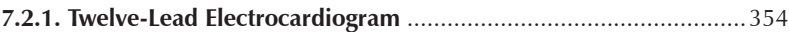

7.2.1.1. Electrocardiogram: Physiological Changes vs. Changes Suggestive of Heart Disease .

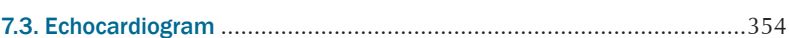

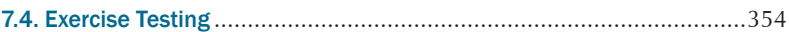

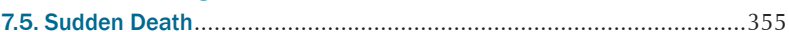

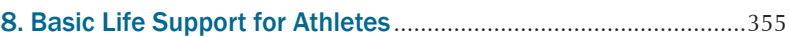

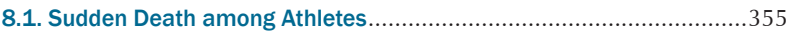

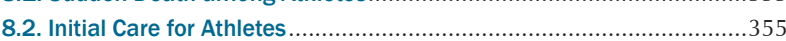

8.3. Special Aspects in Preventing Exercise/Sports-Related Sudden

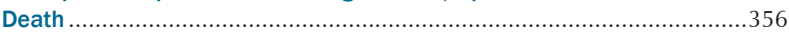

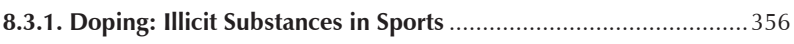

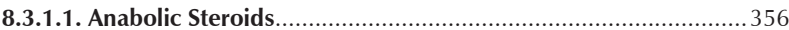

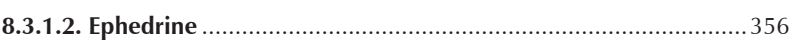

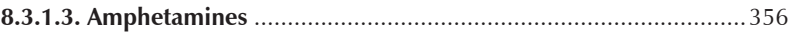

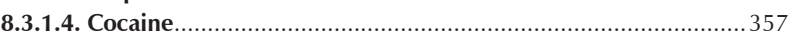

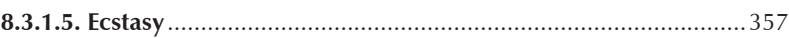

8.4. Evaluating Athletes and the Organization and Planning of

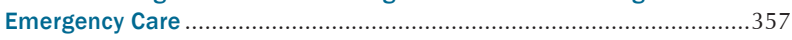

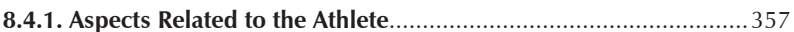

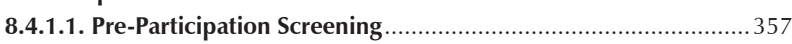

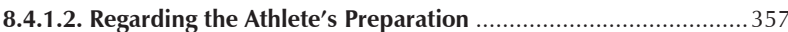

8.4.2. Aspects Related to Training Venues and Competition .......................357

8.4.2.1. Emergency Care and Medical Contingency Planning ..................357

8.4.2.2. Automatic External Defibrillators................................................ 357

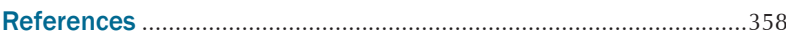




\section{Presentation and Introduction}

Movement is a part of daily life for humans, who must get from one place to another, pick up and carry things, relate to others or simply move for the pleasure of moving. Caspersen et al.'s, ${ }^{1}$ classic definition (1985) will be used in this Update, in which all body movement produced by the skeletal muscles that results in energy expenditure is considered physical activity. Physical exercise can be conceptualized as a special type of physical activity that is planned, structured and repetitive, whose ultimate or intermediate goal is to maintain or improve health, physical conditioning, body aesthetics or performance in competition. ${ }^{1}$

Although sports are often associated with leisure, they can also be a person's main activity: individuals can characterize themselves as professional athletes when it becomes their means of livelihood or an important source of income. Recently, the concept of athlete was formally defined as someone who simultaneously meets the following four criteria: (a) trains to improve sports performance or results; (b) actively participates in sports competitions; (c) is formally recognized at a local, regional or national level; (d) regards competition as a main activity (way of life) or as a focus of personal interest, devoting several hours to training every day or most days, exceeding the time allocated to other professional or leisure activities. ${ }^{2}$ Those who exercise regularly and but only compete occasionally, such as in marathons or other mass sports events, should be called amateur athletes. ${ }^{2}$ Thus, although primarily directed to professional athletes, many aspects covered in this Update also apply to amateurs and some apply to non-athletes who exercise regularly.

These updated guidelines for sports and exercise cardiology will address the following topics: pre-participation screening, structural and non-structural heart diseases, genetic aspects of these pathologies, valvular disease, the hearts of female athletes, as well as basic life support for athletes. Some topics in the 2013 Guidelines ${ }^{3}$ will be covered in future publications or can be consulted in other specific Guidelines.

In summary, this document serves as a de facto update for this field of knowledge and can be applied in clinical practice.

\section{Pre-Participation Screening}

\subsection{Introduction}

Clinical pre-participation screening (PPS) for sports activities should be understood as a standardized systematic medical evaluation that can cover a broad population of professional and amateur athletes before participating in regular moderate-to-intense exercise. Its purpose is to identify cardiovascular diseases that are incompatible with certain types of exercise. The main objective of this screening, which is conducted prior to initiating training and periodically afterwards, is the prevention of cardiovascular diseases and the early detection of diseases that cause sudden cardiac death (SD). This can be achieved by temporarily or permanently suspending the exercise or by treating the potentially fatal conditions that it could trigger. The American
Heart Association, ${ }^{4}$ the European Society of Cardiology ${ }^{5}$ and the Brazilian Society of Exercise and Sports Medicine ${ }^{3}$ recommend PPS for all professional athletes. PPS can also be recommended for correctly prescribing moderate-to-high intensity exercise for non-professionals.

Corrado et al. ${ }^{6}$ demonstrated the importance of PPS for preventing SD. Over a 26-year period during which PPS was introduced as a federal law in Italy (1979-2004), the incidence of SD in screened athletes was reduced by $89 \%$ : from 3.6 per 100,000 person-years in 1979-1980 to 0.4 per 100,000 person-years in 2003-2004. At present, one of the main issues in PPS is cost-effectiveness. Some societies, such as the American Heart Association, advocate screening with only a questionnaire and a physical examination, believing that the financial and psychological costs associated with false positive results in complementary examinations, such as electrocardiograms (ECG), do not justify the potential benefits. ${ }^{4}$ However, the European Society of Cardiology and numerous sporting associations (e.g., FIFA, the NBA), support the use of resting $E C G$, since it has been shown to affect the incidence of SD among athletes. ${ }^{7,8}$

Although we do not have randomized studies comparing the two models of evaluation, we suggest that PPS for professional athletes should include 12-lead resting ECG, since, first, it helps guarantee their safety and, second, the investments involved in their training. ${ }^{9-11}$ These issues will be addressed in this document, which aims to establish norms for PPS in our country.

For didactic purposes, as well as due to clinical, physiological, and epidemiological differences, we have chosen to divide PPS candidates into two groups: amateur athletes and professional athletes. When considering various aspects of exercise, such as intensity, training frequency and volume, a zone of intersection will always exist between these groups. Nevertheless, the medical evaluator's good judgment and individual experience will be fundamental in choosing a way forward in these cases. In light of such divisions, it is of fundamental importance to understand the distinction this Guideline determines between amateur and professional athletes:

Amateurs: adults who participate in regular, moderateto-high intensity sports activities who occasionally compete, although without professional ties to the sport.

Professionals: ${ }^{2}$

- Individuals who train to improve their sports performance

- Individuals who actively participate in competitions

- Individuals who train and compete as their main activity or as a focus of personal interest. They devote a number of hours on most days to training, exceeding the time spent in other professional or leisure activities.

However, professional athletes can also be classified according to age:

- Young athletes - 12 to 17 years.

- Adult athletes - 18 to 35 years.

- Master athletes - 35 years or older. 


\subsection{Anamnesis and Physical Examination}

Ideally, all candidates for moderate-to-high intensity exercise should undergo PPS, which can identify risk factors and signs and symptoms suggestive of cardiovascular, pulmonary, metabolic or locomotor disorders. ${ }^{12-14}$ In anamnesis, issues related to exercise, including family history of disease or sports-related cardiovascular events, should be prioritized. However, a detailed investigation of family history with respect to heart disease or other SD-related diseases must be performed. To do this, adequate knowledge of these medical conditions and a cardiological approach are important. ${ }^{10,15,16}$

In PPS it should be considered that cardiac adaptations to physical exercise are frequency, intensity, and duration dependent and vary among different sports and training systems, as well as among individuals. ${ }^{17}$ Due to the latter aspect, different adaptations can be found in individuals involved in similar physical activities. It should be pointed out that the modifications involved in what is referred to as "athlete's heart syndrome" should initially be considered as normal physiological adaptations to exercise, of a transient nature and without negative repercussions on an individual's health. ${ }^{18}$

The Physical Activity Readiness Questionnaire can be applied systematically during anamnesis. This questionnaire, developed in Canada, should be combined with basic questions asked by a physician (Table 1) about cases of SD or inherited heart diseases, family history of sickle cell disease or other hemoglobinopathies, as well as the patient's origin. Determining the patient's origin is important, since certain regions have endemic diseases, such Chagas' disease, or have a higher prevalence of congenital diseases, such as the Veneto region of Italy, where there is a higher prevalence of arrhythmogenic right ventricular dysplasia (ARVD). ${ }^{19,20}$ Particular care should be taken when obtaining information about licit or illicit drug use that could be considered as doping or that could be harmful to health (i.e., which could cause SD or other undesirable events). ${ }^{21,22}$ Important symptoms include: palpitations, syncope, chest pain or discomfort, exertional dyspnea, dizziness/asthenia, or any other symptom triggered by exercise. Accurate sensitivity is needed to determine whether mentioned symptoms indicate a disease state or are merely the consequence of more intense training or competition. For both amateur and professional athletes, if syncope occurs during exercise rather than post-effort, a detailed investigation should be conducted to discard a primary arrhythmic event. ${ }^{23}$

The physical examination should include inspection for certain clinical conditions, such as anemia, posture changes, infectious foci (e.g., dental), severe systemic or infectious diseases, bronchial asthma, obesity, diabetes mellitus, systemic arterial hypertension, and changes in pulmonary or cardiovascular auscultation. A search for signs related to possible cardiovascular disease should be prioritized, such as: heart murmur, third and fourth heart sounds, valve clicks, pulse changes in the upper and lower limbs, signs of Marfan syndrome or other aortic diseases (e.g., Loeys-Dietz syndrome), as well as adequate blood pressure (BP) in both arms at the first evaluation. ${ }^{14,24,25}$

\begin{tabular}{lcc}
\hline $\begin{array}{l}\text { Recommendation for anamnesis and } \\
\text { physical examination }\end{array}$ & $\begin{array}{c}\text { Recommendation } \\
\text { grade }\end{array}$ & $\begin{array}{c}\text { Evidence } \\
\text { level }\end{array}$ \\
\hline Amateur athletes & $\mathrm{I}$ & $\mathrm{C}$ \\
Professional athletes & $\mathrm{I}$ & $\mathrm{A}$ \\
\hline
\end{tabular}

\subsection{Complementary Exams}

Laboratory tests, in principle, are unnecessary: requests for them should be based on clinical data, especially cardiocirculatory issues. Routine laboratory tests include: complete blood count, fasting glucose, urea, creatinine, sodium

Table 1 - Details to be included in a personal and family history assessment for athletes

Has any doctor ever told you that you have a heart problem?

Precordial pain or discomfort on exertion or at rest

Pre-syncope or syncope, especially if related to exertion

Arrhythmias

Previously diagnosed pathologies

Do you have any bone or joint problems that could be made worse by physical activity?

Is there any other reason why you should not perform physical activity?
Have there been cases of sudden death or heart disease in your family?

Do you feel chest pain when exercise?

Do you lose your balance due to dizziness and/or loss of consciousness? Are there cases of heart disease, sudden death before age 50 or cardiac arrhythmias In your family?

Observe palpitations (skipped beats or heart racing)

Previous history of heart murmur

Previous history of hypertension

Previous history of metabolic disease

Use of performance enhancing substances/ use of any medication

Live/lived in an area with endemic Chagas disease

Do you currently take some type of medication? Question directly about anti-hypertensive, NSAID, anabolics, illicit drugs, and alcohol consumption

Family members with genetic diseases; hypertrophic cardiomyopathy, dilated cardiomyopathy, channelopathies, arrhythmias, Marfan syndrome

NSAID: nonsteroidal anti-inflammatory drug. 
and potassium, complete lipid profile, uric acid, glutamicoxalacetic transaminase, glutamic-pyruvic transaminase, gamma-glutamyl transpeptidase, bilirubin, prothrombin time/ international normalized ratio, and common urine testing.

Recommendation grade: I.

Evidence level: $B$.

For individuals who exercise or compete at altitudes over 2,000 meters, it is important to perform hemoglobin electrophoresis to rule out the possibility of hemoglobinopathies (e.g., sickle cell anemia). In our country, especially in regions of higher incidence, serology for Chagas' disease may also be recommended. ${ }^{3}$ Chest radiography may also be requested in many cases.

\subsubsection{Resting 12-Lead Electrocardiogram}

\subsubsection{Introduction}

Use of this examination in groups of younger athletes is controversial. Although the American Heart Association (American College of Cardiology/American College of Sports Medicine) does not include ECG in PPS, the European Society of Cardiology, in addition to numerous sports organizations, recommend it. 4,5 For master athletes, resting ECG is mandatory, since older adults have a higher prevalence of cardiovascular diseases, especially coronary artery disease (CAD). ${ }^{26,27}$

\subsubsection{Method}

Conventional 12-lead ECG should be performed with the individual in the supine position, recorded at a velocity of 25 $\mathrm{mm} / \mathrm{s}$ and ideally obtained 24 hours after the last sporting activity. At least 5 minutes of rest is recommended before the examination. ${ }^{3,28}$

\subsubsection{Analysis}

Since there are peculiarities among the resting ECG results of athletes, examinations should be interpreted by physicians with experience in the area. This recommendation is important, because it will prevent common alterations of the athlete's heart from being confused with heart disease. However, in most countries medical knowledge regarding the interpretation of athletes' ECG is still limited, which prohibits broader application of this method. ${ }^{29}$

\subsubsection{Changes}

Regular intense exercise can cause physiological changes to the heart at structural, functional and electrical levels. The ECG findings of more than $80 \%$ of high-performance athletes reflect exercise-induced cardiac adaptations as a result of intrinsic changes in automaticity and atrioventricular conduction, ${ }^{30}$ as well as of increased vagal tone and cardiac remodeling.

Due to the establishment of criteria that allow a distinction between heart diseases and athlete's heart syndrome, interpretations of athletes' ECG are becoming more uniform. ${ }^{28,31}$ It is understood that the false positives associated with athletes' ECG depend on the criteria used in their interpretation, as well as our current understanding of variations of normality. Thus, new criteria represent a major effort to refine the analysis and interpretation of ECG, making it more specific without losing sensitivity. Variations in the prevalence of these criteria are related to gender (higher in males), age (genetic/congenital diseases in young athletes and CAD in master athletes), ethnicity (black athletes have more left ventricular overload and repolarization changes than athletes of other races), training level (variation is more frequent in professional athletes than amateurs) and type of sport (predominantly regarding the dynamic component). ${ }^{28}$ It can be especially difficult to differentiate between physiological and pathological adaptations in black athletes, since they have a tendency to develop more hypertrophy in response to exercise than whites. We should also point out that more than $10 \%$ of black athletes may have a wall thickness $>12 \mathrm{~mm}$ in the echocardiogram. ${ }^{32}$

Failure to distinguish between the physiological and the pathological can have harmful consequences. Athletes can be unnecessarily disqualified from competition due to ECG changes that could be considered normal. Likewise, they may undergo unnecessary examinations, which greatly increase their costs. On the other hand, signs of life-threatening cardiovascular disease may be erroneously interpreted as normal variants of an athlete's ECG, which could put the individual at risk of SD.

Changes in the athlete's ECG can be divided into two groups: common and/or related to training; or uncommon and/or suggestive of heart disease (Table 2). ECG is most useful when performed as part of PPS, when it can identify unexpected changes, such as previous myocardial infarction (in older age groups), arrhythmias, conduction disorders, etc. An ECG may also help diagnose less prevalent diseases, such as hypertrophic cardiomyopathy (HCM), long QT syndrome, short QT syndrome, Brugada syndrome, Wolff-ParkinsonWhite syndrome (or other pre-excitation syndrome), in addition to arrythmogenic right ventricular dysplasia (ARVD). A 12-lead ECG may also facilitate assessment of significant atrioventricular and intraventricular conduction and rhythm disturbances. It can also detect ST-segment changes, such as early repolarization, T-wave inversion in precordial and/ or peripheral leads, and voltage criteria suggestive of left ventricular hypertrophy $(\mathrm{LVH}) .^{28,31}$

There may be variations in the prevalence of EGC changes, which are more frequent in men than women. In relation to age, we found a higher frequency of inverted T-waves in precordial and/or peripheral leads in master athletes and older adults, as well as criteria for LVH, in addition to conduction disturbances (Table 3). There are also significant variations in 12-lead ECG results in different types of sports.

Recommendation grade: I.

Evidence level: A.

\subsubsection{Electrocardiogram: Physiological Changes vs. Changes Suggestive of Heart Disease}

Athletes frequently show ECG changes (up to $80 \%$ in some series), including: bradycardia/sinus arrhythmia (13\% to $69 \%)$, first degree atrioventricular block (35\%), and early 
Table 2 - Electrocardiogram: changes due to exercise vs. changes suggestive of heart disease

\begin{tabular}{|c|c|}
\hline Physiological ECG findings in athletes & Abnormal ECG findings in athletes \\
\hline Sinus Bradycardia (HR > 30bpm) & T-wave inversion $>1 \mathrm{~mm}$ in 2 or more leads (except DIII, aVR and V1) \\
\hline Sinus arrhythmia & ST-segment depression $>0.5 \mathrm{~mm}$ in 2 or more leads \\
\hline Ectopic atrial rhythm & Pathological $Q$ waves $>3 \mathrm{~mm}$ or $>40 \mathrm{~ms}$ in 2 or more leads (except DIII and aVR) \\
\hline Junctional escape rhythm & Complete left bundle branch block \\
\hline $1^{\text {st }}$ degree BAV (PR interval > $200 \mathrm{~ms}$ ) & Nonspecific conduction delay with QRS > $140 \mathrm{~ms}$ \\
\hline $2^{\text {nd }}$ degree AVB Mobitz I (Wenckebach) & Deviation of the electrical axis from $-30^{\circ}$ to $90^{\circ}$ \\
\hline Incomplete right bundle branch block & Left atrial overload \\
\hline \multirow{2}{*}{ Isolated QRS voltage criterion for $\mathrm{LVH}$} & Right ventricular hypertrophy pattern with RV $1+$ SV $5>10.5 \mathrm{~mm}$ and axis deviation $>120^{\circ}$ \\
\hline & Ventricular pre-excitation \\
\hline Early repolarization & QT interval $>470 \mathrm{~ms}$ in men and $>480 \mathrm{~ms}$ in women \\
\hline \multirow{6}{*}{$\begin{array}{l}\text { ST-segment elevation accompanied by T-wave inversion in leads V1 to } \\
\text { V4 in Black athletes }\end{array}$} & QT interval $<320 \mathrm{~ms}$ \\
\hline & Brugada pattern \\
\hline & Sinus bradycardia $<30 \mathrm{bpm}$ or sinus pauses $>3 \mathrm{~s}$ \\
\hline & Atrial tachyarrhythmia \\
\hline & Ventricular extrasystoles with 2 or more 10 -second ECG episodes \\
\hline & Paired ventricular extrasystoles and NSVT \\
\hline
\end{tabular}

AVB: atrioventricular block; BPM: beats per minute; ECG: electrocardiogram; HR: heart rate; LVH: left ventricular hypertrophy; NSVT: nonsustained ventricular tachycardia.

Table 3 - Different types of electrocardiographic abnormalities in relation to age found in an unselected European population of 32,652 subjects who underwent sports pre-participation screening

\begin{tabular}{lccc}
\hline & $\begin{array}{c}<20 \text { years } \\
(\mathrm{n}=\mathbf{2 . 4 3 0})\end{array}$ & $\begin{array}{c}\mathbf{2 0 - 2 9} \text { years } \\
(\mathrm{n}=\mathbf{2 . 4 3 0})\end{array}$ & $\begin{array}{c}>\mathbf{3 0} \text { years } \\
(\mathrm{n}=\mathbf{2 . 4 3 0} \%\end{array}$ \\
\hline Incomplete RBBB, increased PR interval, early repolarization pattern & 73.1 & 37.9 & 30.1 \\
Inverted T-waves & 9.5 & 38.6 & 37.9 \\
R/S wave voltage increase & 3.1 & 4.6 & 7.2 \\
RBBB & 10.9 & 12.1 & 10.9 \\
LAHB, LBBB & 2.1 & 5.7 & 13.3 \\
Pre-excitation pattern & 1.3 & 1.1 & 0.6 \\
\hline
\end{tabular}

LAHB: left anterior hemiblock; RBBD: right bundle branch block; LBBB: left bundle branch block. Adapted from Pelliccia et al. ${ }^{73}$

repolarization (50\% to $80 \%$ ). Such findings are usually due to physiological adaptations related to athlete's heart syndrome. ${ }^{33}$ Athletes may also present voltage criteria for $\mathrm{LVH}$, which reflects remodeling of this cavity, although without pathological Q-waves, electrical axis deviation, atrial overload or repolarization changes. ${ }^{31,32}$ These physiological changes in ECG should be clearly separated from patterns suggestive of heart disease, which can be recognized by repolarization changes, pathological Q waves, marked intraventricular conduction defects, pre-excitation, short or long QT intervals, and Brugada syndrome. These findings are rare (less than $5 \%$ ) but may express some cardiomyopathy or channelopathy that could predispose the athlete to SD. ${ }^{33}$ Another important point concerns atrial dilation (resulting from regular training) to meet increased cardiac demand during exercise, although this is not fully understood. Nevertheless, despite this dilation, atrial function seems to be preserved in athletes, but not in patients with structural heart disease. ${ }^{34}$

Other less common findings that can be identified in athletes are sinus pauses < 3 s (mainly during sleep) and second-degree bicuspid aortic valve (BAV) type I (Wenckebach). Such findings generally disappear during effort and with the administration of substances. Changes that can be considered cardiac adaptations to physical exertion should not cause alarm, and participation in competitive sports should not be prohibited without further evaluation. On the other hand, findings suggestive of heart disease, even if asymptomatic, should be investigated, especially in the absence of a positive 
family history or the presence of abnormal findings during physical examination. ${ }^{35,36}$

\section{Recommendation grade: $I$.}

Evidence level: A.

\subsubsection{Exercise Stress Testing}

As part of a strategy for early cardiovascular disease identification, an exercise stress testing can be recommended for the initial evaluation of amateur or professional athletes of any age group. This test can contribute to the prognosis of asymptomatic patients or when there are symptoms potentially indicative of some pathological condition. ${ }^{37,38}$ Its may also be used to evaluate cardiorespiratory fitness during training for certain sports, especially those with a predominantly aerobic component. ${ }^{39,40}$

Asymptomatic individuals with no cardiovascular risk factors can be cleared without this examination. However, an exercise stress testing may be recommended in other conditions. ${ }^{41}$ After 35 years of age, CAD is the main cause of mortality. An exercise stress testing is recommended for individuals in this age range, mainly to identify myocardial ischemia, since the results can indicate the probable presence of the disease. In asymptomatic individuals, and even in those with known CAD, exercise stress testing is used for prescribing an adequate level of physical activity.

Changes in resting ECG, often due to physiological $\mathrm{LVH}$, reduce the method's accuracy for diagnosing myocardial ischemia. Simultaneous analysis of other examination variables contributes to a more global assessment. ${ }^{42}$ When a patient mentions having palpitations during physical activity, this should be investigated with an exercise stress testing to reproduce the conditions of the complaint in a controlled environment.

\subsubsection{Variables to be Evaluated in an Exercise Stress Testing}

\subsection{Functional Capacity}

Low functional capacity indicates a poor prognosis. A number of observational studies have demonstrated an inverse association between the metabolic equivalents reached in the exercise stress testing and mortality. ${ }^{43-45}$ When an individual's functional capacity is low compared to predicted values for his or her gender and age group, additional investigation may be necessary. ${ }^{46}$

\subsection{Chest Pain}

An exercise stress testing can reproduce the conditions of chest pain or discomfort during exercise and allows a probable diagnosis of myocardial ischemia due to CAD, which should lead to further investigation and suspension of training. When an exercise stress testing leads to non-ischemic pain similar to that which motivated the test, but there are no changes in any of the test variables, the probability of CAD is low and the athlete can return to competition. ${ }^{47} \mathrm{O}$ the other hand, chest pain characteristic of angina, even if unaccompanied by STsegment changes, is usually associated with a poor prognosis.
Proper interpretation of an exercise stress testing requires prior knowledge of normal findings for young athletes. Determining whether ST-segment depression in master athletes is related to CAD can be challenging. The possibility of a false positive result related to $\mathrm{LVH}$ cannot be ruled out, but ischemia of atherosclerotic origin should always be discarded. Additional investigation may be required before returning to practice and competition. ${ }^{48}$

\subsection{ST-T Segment}

ST-segment depression $>1 \mathrm{~mm}$ is suggestive of CAD, especially when in a horizontal or descending pattern. Such alterations have higher values when occurring concomitantly with chest pain or other manifestations that contribute to a diagnosis of myocardial ischemia. ${ }^{49}$ ST-segment elevation $\geq 1 \mathrm{~mm}$ at $60 \mathrm{~ms}$ after J-point, when not observed in a Q-wave area (inactive zone), is very suggestive of subepicardial (or transmural) injury, ${ }^{50}$ indicates ischemia and must be managed as such.

In asymptomatic athletes, when ST alterations occur during an exercise stress testing, even if unaccompanied by chest pain, or when they occur with high double product values and high exercise capacity, especially if associated with frequent cardiac arrhythmias, training should be suspended (temporarily or not). In such cases, it is of fundamental importance to continue investigation into cardiovascular disease. Such an approach is based on the increased cardiovascular demand and increased risk of events during exercise, especially in individuals over 35 years of age or when one or more CAD risk factors are present.

ST-segment analysis should consider:

- Morphological characteristics, i.e., descending is more serious than horizontal, which is more serious than slow ascending. ${ }^{51}$

- Early onset during exercise and persistent changes late in the recovery phase indicate greater risk and severity. ${ }^{52}$

- ST-segment depression greater than $10 \%$ in relation to the immediately preceding R-wave amplitude. This adjustment in ST-segment evaluation should be considered due to recurring high-amplitude R-waves, which can express physiological LVH. ${ }^{53}$

Furthermore, regarding the ventricular repolarization phase, it is important to point out that when starting from an altered ECG, normalization during exercise can indicate a good prognosis (if not accompanied by symptoms). ${ }^{54,55}$

\subsubsection{Blood Pressure}

Excessively high BP during an exercise stress testing in patients who have not been diagnosed with hypertension and who have normal resting levels could be a warning sign, because there is a significantly greater risk of developing hypertension in subsequent years. In patients with newly diagnosed hypertension, laboratory investigation and treatment should begin immediately. However, if there is a progressive decrease in systolic BP during an exercise stress testing, especially when it falls below the pre-effort value, subsequent investigation for heart disease should be carried out, especially in cases of stress-induced systolic dysfunction. 


\subsubsection{Heart Rate}

Chronotropic incompetence indicates a poor prognosis and has been associated with endothelial dysfunction, altered autonomic modulation, elevated inflammatory markers and CAD. An inadequate HR response can be considered as the inability to achieve $85 \%$ of the estimated maximum HR. The following equation can be used to predict maximum HR: 208 - (age $\times 0.70)$. A chronotropic index $<80 \%$ is another way to identify chronotropic incompetence, which has prognostic value. It is obtained by the following ratio: (HR reserve obtained/estimated $\mathrm{HR}$ reserve) $\times 100 .^{56}$

Vagal modulation of $H R$ can be inferred from HR reduction in the first minute of recovery in relation to $H R$ at peak exertion. This observation was initially identified when comparing athletes with heart failure (HF) patients. ${ }^{57,58}$ Reductions $\leq 12$ beats per minute have been associated with higher mortality rates. ${ }^{59}$

\subsubsection{Cardiac Arrhythmias}

Less complex cardiac arrhythmias, such as occasional ventricular extrasystoles during an exercise stress testing, often express an increase in sympathetic autonomic modulation due to graduated exercise. Such conditions alone, without other alterations, do not justify limiting the activity of asymptomatic individuals, nor do they require further investigation. Symptomatic or asymptomatic patients who develop complex ventricular arrhythmias, such as ventricular tachycardia (whether sustained or not), must be investigated before they return to training.

For mild-to-moderate intensity leisure activities in asymptomatic individuals with a cardiovascular risk factor: perform an exercise stress testing at the beginning of participation.

\section{Recommendation grade: III.}

\section{Evidence level: $\mathrm{C}$.}

For amateur athletes participating in high-intensity sports and competition: perform exercise stress testing at the beginning of training.

\section{Recommendation grade: Ila. \\ Evidence level: A.}

For professional athletes participating in high-intensity athletic activity and competition: perform an exercise stress testing at the beginning of the season.

\section{Recommendation grade: I.}

\section{Evidence level: $\mathrm{C}$.}

Any time:

When a patient refers to chest pain or discomfort, fatigue or dyspnea of unknown cause, palpitations, or when previously non-existent arrhythmias, exercise-related pre-syncope or syncope or elevated resting BP (with or without compromise a target organ) are identified: perform an exercise stress testing.

Recommendation grade: I.

Evidence level: A.

\subsubsection{Cardiopulmonary Exercise Testing}

For a long time (including in Brazil), athletes and individuals participating in high-performance activities have undergone cardiopulmonary exercise testing (CPET) to evaluate performance and prescribe aerobic training. ${ }^{60}$ As described in Table 4, CPET differs from an exercise stress testing by adding measures and analyses of expired gases. ${ }^{61}$ Unlike in exercise tests for clinical diagnosis, when CPET is performed in apparently healthy athletes BP is often not measured and even ECG is often not performed, and $\mathrm{HR}$ is obtained by frequency meter. With so much equipment available (e.g., in laboratories, clinics, hospitals, clubs and sports centers) to perform these measures, there is little sense in evaluating an athlete's aerobic condition through a exercise stress testing, which has an error rate of approximately $20 \%$ when estimates based on formulas developed for clinical protocols involving treadmills or cycle ergometers are used.

In certain clinical settings and for certain groups of athletes, including a CPET in PPS may be recommended (or even critical for) individual risk stratification, especially due to the data collected from expired gas measurement and analysis. This could be relevant in master athletes, in individuals with cardiovascular and/or pulmonary diseases who are involved in recreational competition (e.g. half-marathons, marathons, mountain climbing, cycling, water sports, etc.), as well as in professional athletes. In these circumstances and whenever possible, it is best to use an exercise stress testing that closely approximates the patient's sport.

Among the additional clinical information that CPET can reveal about athletes or active, healthy individuals, two types stand out: (a) more precise and objective identification of limiting factor(s) for maximum effort (cardiovascular, respiratory and muscular or metabolic) and (b) evaluation of systolic volume behavior, which is obtained by analysis of the curves and maximal values of oxygen pulse $\left(\mathrm{VO}_{2} / \mathrm{HR}\right)$

Table 4 - Main differences between exercise stress testing and cardiopulmonary exercise testing

\begin{tabular}{lcc}
\hline & Exercise testing & \\
\hline Variable & $\begin{array}{c}\text { Exercise stress } \\
\text { testing }\end{array}$ & $\begin{array}{c}\text { Cardiopulmonary } \\
\text { exercise testing }\end{array}$ \\
\hline Functional capacity & Measured & Measured \\
Maximum aerobic power & Estimated & Measured \\
Anaerobic threshold & Undetermined & Determined \\
V/Q Ratio & Not evaluated & Evaluated \\
Inotropic response & Limited evaluation & Excellent evaluation \\
Mechanical Efficiency & Presumed & Measured \\
Protocol & More dependent & Less dependent \\
True maximum & Presumed & Probable/identified \\
cardiorespiratory capacity & Unidentified & Probable/identified \\
Etiology of dyspnea &
\end{tabular}

$V / Q$ ratio: ventilation/perfusion ratio. 
and ventilatory equivalents $\left.\left(\mathrm{VE} / \mathrm{VO}{ }_{2} \text { and } \mathrm{VE} / \mathrm{VCO}\right)_{2}\right)^{62} \mathrm{CPET}$ is already included in cardiological evaluation of $\mathrm{HF}$ patients, ${ }^{63}$ in identifying the etiology of effort dyspnea ${ }^{64}$, and has more recently been considered capable of identifying myocardial ischemia ${ }^{65,66}$ or abnormal responses after cardiac surgery. ${ }^{67}$ In patients with chest pain, changes in the oxygen pulse during CPET make its diagnostic and predictive accuracy greater than an exercise stress testing for detecting or excluding myocardial ischemia. ${ }^{68}$ It is the procedure of choice when a valid and precise measurement of an athlete's aerobic condition is required and $\mathrm{HR}$ thresholds must be determined for exercise prescription.

\begin{tabular}{lcc}
\hline Recommendation & $\begin{array}{c}\text { Recommendation } \\
\text { grade }\end{array}$ & $\begin{array}{c}\text { Evidence } \\
\text { level }\end{array}$ \\
\hline Amateur athletes & Ila & $\mathrm{C}$ \\
$\begin{array}{l}\text { Professional athletes } \\
\begin{array}{l}\text { For more precise stratification of } \\
\text { exercise-limiting factors }\end{array}\end{array}$ & $\mathrm{I}$ & $\mathrm{B}$ \\
\hline
\end{tabular}

CPET should be used when there is a change in resting ECG that may interfere in its interpretation or when there are suspicious hemodynamic responses.

Recommendation grade: Ila.

Evidence level: B.

The routine use of CPET to stratify risk of sudden death in apparently healthy children and adolescents does not seem especially useful.

Recommendation grade: III.

Evidence level: $B$.

\subsubsection{Echocardiogram}

An echocardiogram may play a relevant role in PPS since it can diagnose the main diseases involved in SD in athletes (Table 5). It can also help distinguish between physiological alterations in the athlete's heart and HCM painlessly, quickly and at a relatively low cost. However, it should be reserved for cases where there is a clinical/family history of heart disease or when a physical examination gives suspicious results, as well as when changes in resting ECG indicate cardiomyopathy. ${ }^{69}$ Furthermore, in known cases of congenital heart disease, especially those of low complexity, when physical activity and even high-performance sports are not contraindicated, a periodic ECG helps evaluate the evolution of the condition in question and its correct management. Doppler echocardiogram associated with physical effort is important when verifying cardiac function during exercise, and it can aid in diagnosis and determining the course of treatment, especially for HCM patients. ${ }^{28}$

\subsubsection{Recommendations}

The European Society of Cardiology, in light of the findings of Corrado et al..$^{6}$ (the previously mentioned 25-year Italian follow up of athletes), has established a screening program
Table 5 - Main causes of sudden death in athletes

\begin{tabular}{lc}
\hline Age $<35$ & Age $>35$ \\
\hline Hypertrophic cardiomyopathy & Coronary artery disease \\
Arrhythmogenic right ventricular dysplasia & \\
Anomalous origin of coronary arteries & \\
Myocarditis & \\
Valve disease & \\
Pre-excitation syndrome & \\
Conduction system disease & \\
\hline
\end{tabular}

for individuals between 12 and 35 years of age that includes an initial examination consisting of family history, a physical examination, and 12-lead ECG. Additional tests will only be performed after positive findings in initial evaluation. ${ }^{70}$ Using ECG in programs for young asymptomatic athletes (12 to 35 years of age) has proven to be a high-cost strategy, and no population studies with adequate follow-up have proven its efficacy. Although this test is considered the most practical method for detecting cardiac structural changes, its use as a screening tool is generally reserved for elite athletes, especially in clubs or teams with the necessary financial resources. ECG may indicate the presence of congenital abnormalities in athletes, even when the results are normal. However, since most of these changes are not implicated in the genesis of $\mathrm{SD}$, its use has not been routinely recommended, especially given that its diagnostic power in asymptomatic athletes with normal physical examination results is very low. ${ }^{71}$

When CAD is suspected in the initial evaluation, further investigation should be carried out with more accurate examinations: ECG with physical or pharmacological stress, myocardial scintigraphy with physical or pharmacological stress or dynamic cardiac MRI. Studies have suggested introducing a limited echocardiogram that is restricted to the two-dimensional mode, which can be performed in 5 minutes. The results showed good sensitivity and specificity for diagnosing various SD-related conditions in athletes, especially $\mathrm{HCM}{ }^{72}$ which is implicated in more than $30 \%$ of SD cases in young athletes. At the present time, ECG is considered a confirmatory diagnostic modality to be performed after suspicious results are found in PPS.

Recommendation grade: I.

\section{Evidence level: A.}

There is no evidence to support the use of routine ECG in population screening programs for asymptomatic individuals.

\section{Recommendation grade: III.}

\subsubsection{Other Complementary Tests}

The use of other diagnostic tools, whether laboratory, graphic, imaging, invasive or non-invasive, should comply with clinical criteria and scientific evidence already established in the literature, depending on the PPS findings. 


\subsubsection{Final Recommendations}

The recommendations in Table 6 can be used as a population screening research strategy. Associations and governing councils of professional athletes currently have their own protocols, given the legal and economic issues involved. PPS based on initial clinical consultation and 12-lead ECG can help identify athletes at greater risk of SD.

\section{Genetic Evaluation and Exercise}

According to consensus and expert opinion, genetic assessment is not routinely recommended for athletes. If the question of whether a 12-lead resting ECG should be included in routine PPS is still being discussed, it follows that there must be a pressing reason for genetic investigation of an athlete.

There are two occasions when genetic evaluation is especially well indicated when: ${ }^{74}$

a) there is a family history of hereditary heart disease (cardiomyopathy, channelopathies, aortic diseases) or suspicion thereof (episodes of syncope, arrhythmias, cardiac arrest/SD). In such cases, it is important to point out that genetic study must first be performed on the individual or an effected family member. When a causal mutation has been detected, then the other family members should be studied (including the athlete if not initially tested);

b) the athlete has a phenotype that strongly indicates an inherited disease (signs, symptoms and/or test results suggestive or compatible with a specific disease). ${ }^{75,76}$

Clinical genetic assessment should always be the first step before genetic testing is conducted. This assessment should include a thorough anamnesis of family history as well as a complete physical examination. Family history should include aspects such as the age of symptom onset, the activities that triggered the symptoms, diagnosed diseases, and the number of affected relatives and degree of kinship. Thus, a thorough understanding the family tree or "family pedigree" will guide the investigation toward the affected side of the family. When there are no suspect first-degree relatives, the study should be extended to another generation if there is a great suspicion of inherited heart disease.

More recent studies have highlighted the role of genetic study in the "molecular autopsy" of individuals without anatomical changes who died suddenly. ${ }^{77-79}$ A comprehensive analysis of genes related to SD in subjects who died suddenly during exercise has identified potential causative variants. However, the effects of many genetic variants are still undetermined and further study is needed to understand their clinical significance. However, comprehensive genetic analysis of individuals who died during exercise could determine potential causative variants and help identify relatives at risk. ${ }^{77}$ Specific recommendations about genetic analysis are addressed in the sections on inherited diseases in this Guideline.

\subsection{Positive Genotype and Negative Phenotype}

Individuals can be considered to have positive genotype/ negative phenotype when:

- They have a potentially pathogenic mutation.

- Complementary exams indicate no clinical manifestations or structural/electrical changes in the heart.

The question is whether these subjects are at increased risk of SD, even without the signs of structural heart disease. This is of paramount importance because in certain cases the adrenergic stress of intense or competitive exercise can trigger complications and SD. Reviewing the family history of inherited heart disease can be a great challenge, which is mainly due to variable expressivity (i.e., severity frequently varies, even within the same family), as well as to reduced penetrance (i.e., some patients may never develop the disease).$^{80}$ Many investigated diseases are autosomal dominant, although some are due to de novo mutations. The age of onset may also vary, with patients remaining asymptomatic over a long period of the disease, which makes initial clinical diagnosis difficult. ${ }^{76}$

When faced with this diagnostic challenge, we must determine that the phenotype is truly negative. A thorough cardiologic investigation with ECG, echocardiogram, cardiac magnetic resonance, Holter monitoring, and provocative tests (exercise or drugs) should be performed when genetic disease is suspected. ${ }^{81}$ The current European PPS recommendations state that after a detailed questionnaire (including symptoms and family history) and clinical examination, priority should be given to 12-lead ECG. Athletes with two or more "borderline ECG findings" or any "abnormal ECG findings" require further investigation. ${ }^{76}$

Table 6 - Recommendations by age group and competitive level

\begin{tabular}{lcccc}
\hline & Leisure & Amateurs & Professionals \\
\hline Children/adolescents & Initial evaluation + 12-lead ECG & Initial evaluation + 12-lead ECG & Initial evaluation + 12-lead ECG \\
18-35 years & Initial evaluation + 12-lead ECG & Initial evaluation + 12-lead ECG & Initial evaluation + 12-lead ECG \\
& Initial evaluation + CAD risk evaluation + & Initial evaluation + CAD risk evaluation + & Initial evaluation + CAD risk evaluation + \\
35-59 years & 12-lead ECG + (consider functional test) & 12-lead ECG + (consider functional test) & 12-lead ECG + (consider functional test) \\
& Initial evaluation + 12-lead ECG + & Initial evaluation + 12-lead ECG + & Initial evaluation + 12-lead ECG + \\
functional test & functional test & funal test &
\end{tabular}

12-lead ECG: resting 12-lead electrocardiogram; CAD: coronary artery disease. 
The European Society of Cardiology reported that SD occurs three times more in athletes (2.3 per 100,000 individuals) than non-athletes ( 0.9 per 100,000 individuals) ${ }^{76}$ There have been a limited number of SD cases in asymptomatic HCM patients. Five cases of premature SD have been reported in which the autopsy revealed no macroscopic HCM or mutation of the TNNT2 gene. ${ }^{82}$ Two patients were found with ventricular fibrillation and normal hearts who subsequently developed HCM and MYH7 gene mutation. ${ }^{83}$ In one ARVD case, a 13-year-old mutation carrier in the non-clinically affected DSP (desmo- toquine) gene suffered SD two years after the genetic study. ${ }^{84}$ In an Italian study of 12,500 athletes, only one case of SD due to ARVD was not clinically detected. ${ }^{85}$ In the context of dilated cardiomyopathies, a case of SD was also described in a 35-year-old female with LMNA gene (c908-909delCT) mutation in whom no structural disease or conduction disorder was detected. ${ }^{86}$

In assessing positive genotype/negative phenotype in the early development of cardiomyopathy, it is important to remember that intense sports activity can worsen the prognosis for mutation carriers, as in ARVD and HCM..$^{87,88}$

The current recommendations are controversial, being based on expert consensus and the available few longitudinal studies. Table 7 shows general differences between U.S. and European recommendations. For example, the American Heart Association and American College of Cardiology state that patients with HCM-positive genotypes may participate in competitive sports, as long as two-dimensional echocardiogram indicates they are asymptomatic and without evidence of LVH and they have no family history of HCM-related SD (Class Ila; Evidence level C). However, athletes with clinically expressed and diagnosed HCM should not participate in most competitive sports. ${ }^{89}$ It is our opinion that future studies should evaluate the pathogenic potential and negative effects of intense exercise on individuals with positive genotypes. Finally, we believe that disqualification should only be used as a final intervention and that adequate information and decision-making (by the family, athlete, coach, sponsor, etc.) should be sought.

\section{Individuals with Cardiomyopathies and Myocarditis}

\subsection{Hypertrophic Cardiomyopathy}

$\mathrm{HCM}$ is one of the major causes of sports-related SD in individuals under 35 years of age. .0,91 $^{90}$ The U.S. National Registry of Sudden Death in Athletes evaluated the causes of SD in competitive athletes between 1980 and 2011. Of 2,406 total deaths identified in young athletes (mean age: 19 years), 842 had some cardiovascular diagnosis. HCM was the most common cause of SD, occurring in $36 \%$ of the cases. ${ }^{92}$ However, its contribution to SD in athletes has been systematically overestimated. Recent evidence from a metaanalysis ${ }^{92}$ indicates that HCM caused $10.3 \%$ of athlete deaths, while $27.5 \%$ had structurally normal hearts.

$\mathrm{HCM}$ is an autosomal dominant genetic disease characterized by myofibrillar disarray in myocytes, accompanied by hypercontractility and asymmetrical hypertrophy (with or without obstruction of the outflow tract), which are unexplained by pressure, volume overload, or another underlying systemic condition. Ventricular hypertrophy (determined by an imaging method) $>15 \mathrm{~mm}$ in any segment with no other apparent cause is highly suggestive of $\mathrm{HCM} .{ }^{93}$ For hypertrophy between 13 and $14 \mathrm{~mm}$, other factors, such as family history, specific ECG changes, symptoms, another imaging method and even genetic evaluation should be considered in the differential diagnosis. ${ }^{94}$ In first-degree relatives of a HCM patient, hypertrophy greater than 13 $\mathrm{mm}$ is also highly indicative of this disease. ${ }^{91}$ Hypertrophy related to pressure overload, physical training and basal septal hypertrophy in the elderly should be considered in the differential diagnosis.

HCM patients may be totally asymptomatic or present symptoms such as lipothymia, syncope, dyspnea, palpitations or angina, especially when related to increased myocardial demand or obstruction of the outflow tract, as occurs during exercise. SD in these patients occurs primarily due to ventricular arrhythmias, although other complications such as supraventricular arrhythmias (with or without pre-excitation),

Table 7 - U.S. vs. European recommendations for athletes with positive genotypes

\begin{tabular}{|c|c|c|}
\hline Heart Disease & $\begin{array}{c}\text { American Heart Association/American College of } \\
\text { Cardiology }\end{array}$ & European Society of Cardiology \\
\hline Cardiomyopathies (HCM, DCM, ARVD) & $\begin{array}{l}\text { No restrictions (e.g., asymptomatic and without left } \\
\text { ventricular hypertrophy) }\end{array}$ & $\begin{array}{c}\text { Competitive sports prohibited: only non-competitive sports } \\
\text { and leisure activities permitted }\end{array}$ \\
\hline Long QT & No restrictions (except QTL1 and swimming) & $\begin{array}{c}\text { Competitive sports prohibited: only non-competitive sports } \\
\text { and leisure activities permitted }\end{array}$ \\
\hline Catecholaminergic tachycardia & Competitive sports prohibited & Competitive sports prohibited \\
\hline Brugada syndrome & No restrictions & No restrictions \\
\hline Marfan Syndrome & $\begin{array}{l}\text { Mild-to-moderate activity only (no family history of aortic } \\
\text { dissection or SD) }\end{array}$ & Competitive sports prohibited \\
\hline
\end{tabular}

HCM: hypertrophic cardiomyopathy; DCM: dilated cardiomyopathy; ARVD: arrhythmogenic right ventricular dysplasia. 
advanced atrioventricular block, asystole, and myocardial infarction may also be the cause of this undesired event.

\subsubsection{Genetics and Hypertrophic Cardiomyopathy}

At present, at least 20 genes have been implicated in the genesis of this disease, ${ }^{95}$ and more than 1,700 mutations related to contractile myocardial protein have been discovered. Mutations in at least 11 different genes that code for sarcomeric proteins have been identified in up to $70 \%$ of family cases. ${ }^{96,97}$ Mutations of genes in the beta-myosin heavy chain (MYH7) and myosin-binding protein C (MYBPC3) are the most frequent. Together, MYBPC3 and MYH7 account for up to half of all clinically recognized cases of HCM, and make up at least $75 \%$ of the index cases in which a mutation is identified. ${ }^{98}$ Other less frequent mutations are related to the troponin I and troponin T genes (TNNI3, TNNT2) and alpha-tropomyosin-1 (TPM1), whose frequency is often less than $5 \%$. Still less common (less than $1 \%$ ) are mutations of muscle LIM protein (CSRP3), troponin C (TNNC1) and titin (TTN). Genetic phenotypes such as Fabry disease, amyloidosis, Danon disease and Friedreich ataxia should also be considered. ${ }^{95}$ Mutations in troponin genes, although less common (15\% to $30 \%$ ), have been most closely associated with SD, ${ }^{99}$ including, in some reports, individuals with no phenotypic manifestations of the disease.

Genetic counseling by a multidisciplinary team experienced in genetically determined heart disease is recommended for individuals with HCM.

Recommendation grade: I.

Evidence level: $\mathrm{C}$.

Genetic sequencing study for patients with clinically diagnosed HCM (index cases).

\section{Recommendation grade: $I$.}

\section{Evidence level: $B$.}

Assessment for specific mutations in direct relatives of patients diagnosed with genetically determined HCM.

\section{Recommendation grade: $I$.}

Evidence level: $B$.

\subsubsection{Complementary Exams in Hypertrophic Cardiomyopathy}

\subsubsection{Electrocardiogram}

ECG should be performed in all patients with suspected HCM.

\section{Recommendation grade: I.}

\section{Evidence level: $B$.}

About $90 \%$ of patients with HCM have ECG changes, with ST-segment and T-wave being the most common. Athletes with HCM have a higher prevalence of T-wave changes (especially deep T-wave inversion in the lateral leads) and
ST-segment changes than non-athletes with the disease. In addition to these changes, there is left atrial enlargement, which is identified by a prolonged P-wave duration ( $>120$ ms) in leads I or II with a negative P-wave portion $\geq 1 \mathrm{~mm}$ in depth and $\geq 40 \mathrm{~ms}$ in duration in the V1 lead. Complete left bundle branch block may also be suggestive of HCM. In the past, some ECG changes in athletes were considered potentially pathological, such as: left atrial enlargement and left axis deviation, $\mathrm{T}$-wave inversion confined to $\mathrm{V} 1-\mathrm{V} 4$ preceded by J-point elevation (especially in blacks), Q-waves $\geq 3$ to 4 $\mathrm{mm}$ (with an amplitude less than one-quarter of the R-wave and a duration $<0.04 \mathrm{~s}$ ). However, such changes are now considered physiological responses in the athlete's heart, and do not require additional clinical evaluation. ${ }^{100,101}$

\subsubsection{Echocardiogram}

This exam play a fundamental role in HCM assessment. In addition to the degree of hypertrophy, they can determine the gradient between the left ventricle (LV) and the aorta, as well as the presence of mitral valve abnormalities: systolic anterior motion and altered patterns of diastolic function..$^{93,102}$ Echocardiograms also have an important role in differentiating between hypertrophy due to HCM and that due to physical training (ventricular hypertrophy in the athlete's heart). A variety information, such as the pattern and distribution of hypertrophy, parietal thickening, cavity size, assessment of diastolic function by tissue Doppler imaging, and family history are required. ${ }^{103}$ When not clinically differentiated, ECG, echocardiograph, functional or other imaging methods, such as serial ECG, may be useful when evaluating athletes with suspected HCM before and after a detraining period (Table 8). ${ }^{104}$ Regarding prognosis, LV wall thickness $>30 \mathrm{~mm}$ is a major risk factor for SD, especially in adolescents and young adults. ${ }^{105}$ A gradient above 50 $\mathrm{mmHg}$ between the LV and the aorta is also associated with worse prognosis. ${ }^{106}$

When comparing athletes and non-athletes with HCM from an echocardiographic point of view, athletes present the following characteristics: lower LV wall thickness, higher left ventricular end-final diastolic diameter and higher ejection fraction.

\subsection{Transthoracic Doppler Echocardiogram}

Confirm clinical suspicions of HCM by determining parietal thickening and whether there is a dynamic gradient.

Recommendation grade: $I$.

Evidence level: $B$.

Investigate the presence of HCM in first-degree relatives.

Reassessment of clinical evolution, as well as therapeutic interventions.

Recommendation grade: Ila.

Evidence level: $\mathrm{C}$.

Annual reassessment of family members of HCM patients aged 12 to 18 years. 
Table 8 - Factors indicative of athlete's heart syndrome (vs. HCM) in athletes with left ventricular hypertrophy in the "gray zone" (i.e., wall thickness: $13-15 \mathrm{~mm}$ )

\begin{tabular}{l}
\hline Clinical \\
\hline No family history \\
Absence of diffuse T-wave inversion in ECG \\
\hline Nuclear magnetic resonance \\
\hline Homogeneous distribution of left ventricular hypertrophy \\
No late gadolinium enhancement (fibrosis) \\
\hline Echocardiogram \\
\hline Increased left ventricular diameter (LVDD > 55 mm) \\
Symmetrical hypertrophy (septum, posterior wall, apex and base) \\
Normal diastolic function (E/A ratio > 1, peak velocity to $E^{\prime}>11.5 \mathrm{~cm} / \mathrm{s}$ ) \\
Hypertrophy regression after detraining \\
No HCM-causing mutations found in genetic analysis
\end{tabular}

LVDD: left ventricular diastolic diameter; ECG: electrocardiogram; HCM: hypertrophic cardiomyopathy.

In individuals over 21 years of age, reevaluation should be done every 5 years.

Tissue Doppler imaging should be performed to differentiate HCM from physiological or pathological cardiac hypertrophy (e.g. hypertension).

An exercise echo stress test should be used in asymptomatic patients who do not show significant gradients at rest or with the Valsalva maneuver.

Recommendation grade: Ila.

Evidence level: $\mathrm{C}$.

\subsection{Transesophageal Doppler Echocardiogram}

Patients with an inadequate transthoracic window.

Transesophageal Doppler echocardiogram is used to assess valve damage and the mechanism and magnitude of mitral regurgitation when this is unclear after transthoracic ECG.

Intraoperative evaluation for myomectomy and alcohol septal ablation.

Recommendation grade: $I$.

Evidence level: $B$.

To clarify the mechanism of atypical mitral regurgitation.

\section{Recommendation grade: Ila.}

Evidence level: $B$.

\subsubsection{Cardiac Magnetic Resonance Imaging}

Cardiac magnetic resonance imaging $(\mathrm{CMRI})$ is used to evaluate patients with suspected HCM when an ECG is inconclusive. Although ECG is the first imaging choice for patients with suspected HCM, this method may be limited by poor acoustic windows, particularly for areas such as the cardiac apex. ${ }^{107}$ CMRI can also be used in highly suspicious cases that are not confirmed by ECG. Its excellent spatial resolution provides exclusive information about cardiac muscle and tissue, helping in the differential diagnosis of secondary causes of hypertrophy, such as amyloidosis and sarcoidosis. This examination allows the visualization of subtle changes in the thickness and contractility of the LV over time, as well as the detection of fibrotic areas, and recent studies have reported the presence and amount of fibrosis with prognosis. ${ }^{107,108}$

CMRI is used to evaluate athletes with ECG abnormalities that are suspicious of HCM and inconclusive ECG findings.

Recommendation grade: $\mathbf{I}$.

Evidence level: $B$.

CMRI should be used for myocardial fibrosis screening in every athlete with suspected HCM.

Recommendation grade: Ila.

Evidence level: $B$.

\subsubsection{Exercise Tests and Hypertrophic Cardiomyopathy}

The exercise stress testing is an independent means of identifying patients at increased risk of SD. Since the presence of marked ST-segment changes in HCM patients may indicate ischemia but not necessarily heart disease, the exercise stress testing has little diagnostic value. However, it could be a prognostic marker to be taken into consideration, especially when associated with expired gas measurements (CPET). ${ }^{109,110}$

For these patients, a ramp protocol should be used first. This test avoids sudden changes in the recruitment of neuromuscular motor units and the metabolic changes associated with incremental protocols due to the constant and continuous increase of external work. The slope of the ramp should be individualized to last, preferably, from 8 to 12 minutes. ${ }^{109}$

4.1.2.4.1. Exercise Testing Recommendations for Patients with Hypertrophic Cardiomyopathy

The exercise stress testing is recommended for asymptomatic HCM patients who do not present high risk criteria as an associated element in prognostic stratification.

Exercise stress testing is recommended for asymptomatic patients without high risk criteria, but who wish to participate in recreational physical activity.

It is an additional element in differential diagnosis between athlete's heart syndrome and HCM.

Recommendation grade: $I$.

Evidence level: $B$.

The exercise stress testing can be used for patients with doubtful symptoms that are not associated with other high-risk criteria (preferably CPET). 
It can be used to assess functional capacity and heart rate response to exercise in patients with an implanted defibrillator who wish to participate in low-intensity physical activity.

\section{Recommendation grade: Ila.}

Evidence level: $\mathrm{C}$.

In athletes with high risk criteria (symptomatic), it can facilitate differential diagnosis between HCM and physiological hypertrophy.

Recommendation grade: III.

4.1.2.4.2. The Role of Maximal Cardiopulmonary Exercise Testing in Hypertrophic Cardiomyopathy

A maximal CPET can stratify HCM patients regarding cardiovascular morbidity and mortality, helping guide treatment. In athletes who are in the "gray zone" between physiological hypertrophy and the pathological hypertrophy of HCM, measuring oxygen consumption and peak oxygen pulse with a CPET can be of great assistance. In general, highly trained athletes have values between 55 and $70 \mathrm{~mL} \cdot \mathrm{kg}^{-1} \cdot \mathrm{min}^{-1}$. Sharma et al. ${ }^{111}$ demonstrated that healthy athletes can actually achieve significantly higher peak oxygen consumption than athletes with $\mathrm{HCM}\left(66.2 \mathrm{~mL} . \mathrm{kg}^{-1}\right.$. $\mathrm{min}^{-1}$ vs. $34.3 \mathrm{~mL} \cdot \mathrm{kg}^{-1}$. $\left.\mathrm{min}^{-1}\right)$. Since there was no overlap between groups, the researchers postulated a cutoff of $50 \mathrm{~mL} \cdot \mathrm{kg}^{-1} \cdot \mathrm{min}^{-1}$ to discriminate between the pathological hypertrophy of HCM from the dynamic component of the athlete's heart.

Finally, since there are conflicting data regarding CPET and specific predictions of SD in patients with $\mathrm{HCM}$ based on VE/VCO slope, neither VE/VCO slope nor peak $\mathrm{VO}_{2}$ are currently used in risk stratification. ${ }^{12}$

\section{Recommendation grade: Ila.}

\section{Evidence level: $\mathbf{B}$.}

\subsubsection{Sports and Hypertrophic Cardiomyopathy}

Why is there a low prevalence of HCM among high-level athletes? The response seems to be related to a natural selection process that excludes individuals with HCMrelated functional and structural alterations from the highintensity training required to become a professional. So, is being a competitive athlete with HCM synonymous with SD? The answer is no. We all know cases of athletes who were diagnosed with this disease well into their professional careers or after they had already retired. The problem is that intense exercise can trigger severe arrhythmias, increased left ventricular outflow obstruction and/or ischemic compression in small blood vessels (possible fibrosis due to repetitive ischemia) during training and competition.

Based on the premise that strenuous exercise can be an important trigger for SD, athletes with a probable or unequivocal diagnosis of HCM should be excluded from most competitive sports. However, it should be pointed out that only a minority of HCM patients have SD or cardiac arrest during exercise. ${ }^{113}$ This recommendation is independent of age, sex, phenotype, symptoms, LV outflow tract obstruction, drug treatment, septal ablation, or pacemaker or implanted defibrillator. ${ }^{89}$ Although criteria have been suggested ${ }^{114,115}$ for establishing SD risk factors in HCM patients (Table 9), it should be pointed out that such criteria should be used with caution, since they do not take important HCM-related aspects into account, such as genetics and CMRI results.

Individuals classified as low risk (especially those without a gradient at rest or during effort) ${ }^{116}$ may participate in sports such as golf, billiards, bowling and shooting (group IA). Recreational sports that require high intensity or abrupt changes of intensity are not recommended. Individuals with positive genotype/negative phenotype (without clinical evidence of disease) may participate in sports, provided they are assessed periodically, since the chance of SD is directly related to the presence of hypertrophy and fibrosis. A recent study evaluated vigorous exercise in HCM patients and individuals with positive genotype/negative phenotype. Exercise was associated with higher cardiac volumes and better diastolic function, but not with a higher incidence of ventricular arrhythmias. ${ }^{117}$

Participation in competitive sports for clinically diagnosed HCM patients.

\section{Recommendation grade: III.}

\section{Evidence level: $B$.}

\subsection{Arrhythmogenic Right Ventricular Dysplasia}

ARVD is a cardiac muscle disease of genetic origin characterized by changes during the formation of desmosomes. It is clinically manifested by the replacement of myocardial tissue with fatty and/or fibrous tissue, generally affecting the right ventricle and with more pronounced clinical manifestations when the apical septum of the LV is affected. Mutations in non-desmosomal genes have also been identified, such as filamin C, TMEM43 and phospholambam, especially in cases involving the LV. ${ }^{118,119}$ Among athletes from the Veneto region of Italy, ARVD is a major cause of SD: one study found a five-fold increase in SD risk for young athletes who participated in competitive sports. ${ }^{120}$ Based on recent data, ARVD is ranked as the third most frequent cause of SD the United Kingdom. ${ }^{88}$ ARVD is a rare condition in the

\section{Table 9 - Risk factors for sudden death in HCM patients}

\begin{tabular}{l}
\hline Greater risk factors \\
\hline Cardiorespiratory arrest survivor \\
Spontaneous sustained ventricular tachycardia \\
Family history of SD in patients < 40 years \\
Unexplained syncope or pre-syncope \\
Interventricular septum $>30$ mm \\
\hline Minor risk factors \\
\hline Abnormal blood pressure response to exercise \\
Patients under 30 years of age \\
Nonsustained ventricular tachycardia \\
\hline HCM: hypertrophic cardiomyopathy; SD: sudden death.
\end{tabular}


general population, with an estimated prevalence of 1 in 5,000 , although in some European countries, such as Italy and Germany, the prevalence is 1 in 2,000. ${ }^{121}$ Diagnosis can be challenging given the need to exclude other disorders that may present with similar signs and symptoms. ${ }^{122}$ The main clinical manifestations are palpitations, syncope, chest pain, complex ventricular arrhythmias and SD. Since highly trained athletes may have right ventricular (RV) hypertrophy, in addition to a variety of changes in depolarization, repolarization, and nerve conduction, a differential diagnosis between "athlete's heart syndrome" and ARVD should always be performed. Since an echocardiogram may have technical limitations with respect to RV images, its structural and functional analysis may be impaired. However, akinesia, dyskinesia or RV aneurysms associated with the dilation of this chamber are among the most important criteria in the revised classification. CMRI is a noninvasive imaging technique that has become the main tool for diagnosing ARVD. Segmental or global dysfunction of the RV or a substantial increase in this cardiac chamber, associated with myocardial thinning and presence of late enhancement (fibrosis and/or edema), supports a diagnosis of ARVD. ${ }^{121,123}$ A 12-lead resting ECG and Holter monitoring can help with diagnosis, principally by detecting arrhythmias such as branch block pattern ventricular tachycardia, inverted T-waves in the right precordial leads (V1 to V3) and epsilon waves (present in $30 \%$ of ARVD patients). Family history should always be investigated, and a confirmed case in a first degree relative is a major criterion. Thus, suspected firstdegree cases or confirmed second-degree cases are minor criteria. In especially difficult cases, a biopsy of the RV can be performed. The final clinical diagnosis may not be simple. The presence of two major criteria, one major and two minor criteria (different categories) or four minor criteria (different categories) confirm the diagnosis.

New evidence suggests that ECG adaptations, such as isolated right ventricular overload or T-wave inversion from V2 to V4 (associated with right axis right deviation in black athletes) are related to benign structural adaptations of the heart in competitive athletes. In these individuals careful investigation for the other criteria is necessary, and research on family history is of fundamental importance. ${ }^{124}$

\subsubsection{Diagnosis and Management of Athletes with Suspected Arrhythmogenic Right Ventricular Dysplasia}

\subsubsection{Echocardiography}

In athletes with a family history of ARVD or with ECG changes suggestive of ARVD.

Recommendation grade: $I$.

Evidence level: C.

\subsubsection{Cardiac Magnetic Resonance Imaging}

CRMI should be used when there is a strong suspicion, despite a non-diagnostic ECG or in cases where an echocardiogram could not adequately assess the RV.

Recommendation grade: $I$.

Evidence level: $\mathrm{C}$.
Competitive physical activity in patients with a definite or probable diagnosis of ARVD.

Recommendation grade: III.

Evidence level: $B$.

There is sufficient evidence that exercise can trigger SD in individuals with ARVD. Probable causes include: increased sympathetic tone and even greater dilation of the ventricular chambers during exercise, which, associated with myocardial fibrosis, leads to the appearance of complex arrhythmias. ${ }^{125,126}$ Adhesion between the cells could be compromised by genetic factors, and in the meantime, mechanical stress from exercise can lead to cardiomyocyte apoptosis and worsening of the disease. ${ }^{127,128}$ Group 1A sports can be allowed on an individual basis. More recent studies have confirmed the deleterious role of sustained vigorous physical activity ( $>6$ metabolic equivalents) in the occurrence of ventricular arrhythmias in ARVD patients, and reducing exercise after diagnosis is associated with a lower occurrence of severe arrhythmias. ${ }^{129,130}$

\subsection{Myocarditis}

Myocarditis has a heterogeneous clinical profile and, although not very prevalent, it is the probable cause of 5 to $22 \%$ of SD cases in athletes, depending on age and region. ${ }^{88,131}$ This disease is characterized by an inflammatory process with consequent non-ischemic degeneration and necrosis of the myocardium. Generally, myocarditis is the result of an infection (viruses, bacteria, fungi, protozoa), but it may be associated with substance use or autoimmune diseases. ${ }^{132}$ SD may occur in the acute phase (when a myocarditis patient does not abstain from sports for 6 months), or even in the chronic phase, when there is already scar tissue in the myocardium, which is a consequence of complex arrhythmias triggered by an unstable electrical substrate. In this phase, exercise may be the arrhythmogenic trigger due to increased venous return and muscle fiber stretching from physical activity. ${ }^{133,134}$

In athletes, the main symptoms are palpitations, precordialgia, dyspnea, fatigue and syncope. ECG changes include ventricular arrhythmias, ST-T segment changes, and rhythm and conduction disorders. It may evolve with left ventricular enlargement due to the disease, hypertrophy due to physical training or a combination of both. ${ }^{135,136} \mathrm{CMRI}$ and myocardial biopsy (although less common in our country) may facilitate diagnosis. Due to their prevalence in Brazil, we point out that myocarditis may also be caused by the dengue and HIV viruses, as well as by Chagas' disease.

\subsubsection{Recommendations for Athletes with Myocarditis}

Competitive physical activity for patients with active myocarditis.

Recommendation grade: III.

Evidence level: $B$.

Athletes diagnosed with myocarditis should be advised against practicing any competitive sports and should undergo a period of convalescence. Although there is no consensus, 
many experts recommend that this period be at least six months after the onset of clinical manifestations. However, some experts have been more "liberal", recommending shorter periods of convalescence.

These athletes may resume training and competition after:

- Left ventricular function, ventricular wall motion, and cardiac dimensions return to normal values (based on stress and resting echocardiography and radionuclide imaging).

- Complex or frequent forms of ventricular and supraventricular arrhythmias and clinically relevant arrhythmias are absent.

- Inflammatory and heart failure markers are normalized.

- Resting ECG is normalized, although the persistence of ST-segment changes alone should not impede the athlete's return to training and competition.

\subsection{Dilated Cardiomyopathy}

Dilated cardiomyopathy (DCM) has an estimated prevalence of 40 cases per 100,000 individuals. It is defined as a myocardial disease, characterized by LV dilation and global systolic dysfunction, and there may be overlapping segmental abnormalities with increased myocardial mass. DCM includes disorders of genetic origin, disorders due to infection, inflammation, exposure to toxic substances or metabolic diseases, and disorders of idiopathic origin (although at least $40 \%$ of disorders classified as idiopathic are, in fact, of genetic origin). Up to 40 genes have been identified, with proteins from several cellular structures being affected (sarcomere, sarcolemma and intercellular junction). ${ }^{137}$ DCM patients vary widely in clinical presentation and hemodynamics. ${ }^{138}$

Long-term aerobic training may lead to changes in cardiac morphology, including increased LV cavity size and mass. Increased cavity size may produce a greater systolic volume and thus, the resting ejection fraction may be at the lower limit of normal or slightly reduced. In this context, it is important to differentiate between LV increase due to systematic training and that due to DCM. ${ }^{138}$

\subsubsection{Complementary Examinations for Dilated Cardiomyopathy}

\subsubsection{Exercise Stress Testing and Cardiopulmonary Exercise Testing}

Although exercise performance may only be slightly reduced in young DCM patients, arrhythmias are usually present at a very early stage of the disease (including supraventricular and ventricular tachyarrhythmia, as well as conduction delays).

\begin{tabular}{lcc}
\hline $\begin{array}{l}\text { Recommendations for exercise stress } \\
\text { testing and CPET }\end{array}$ & $\begin{array}{c}\text { Recommendation } \\
\text { grade }\end{array}$ & $\begin{array}{c}\text { Evidence } \\
\text { level }\end{array}$ \\
\hline $\begin{array}{l}\text { Exercise stress testing or CPET to assess } \\
\text { individuals with known or suspected }\end{array}$ & & $\mathrm{C}$ \\
$\begin{array}{l}\text { ventricular arrhythmias during exercise, } \\
\text { regardless of age }\end{array}$ & $\mathrm{I}$ & \\
$\begin{array}{l}\text { Exercise stress testing to assess DCM } \\
\text { severity }\end{array}$ & $\mathrm{llb}$ & $\mathrm{B}$ \\
\hline
\end{tabular}

\begin{tabular}{llc}
\hline CPET to assess DCM severity & la & B \\
$\begin{array}{l}\text { Exercise stress testing to identify } \\
\text { pathophysiological mechanisms and clarify } \\
\text { symptoms }\end{array}$ & llb & B \\
$\begin{array}{l}\text { CPET to identify pathophysiological } \\
\text { mechanisms and clarify symptoms }\end{array}$ & । & B \\
\hline
\end{tabular}

CPET: cardiopulmonary exercise testing.

\subsubsection{Echocardiogram}

An echocardiogram is more sensitive than ECG for diagnosing LVH and accurately quantifies LV mass. Thus, cardiac abnormalities detected by an echocardiogram have additional predictive value. ${ }^{138,139}$

\begin{tabular}{lcc}
\hline $\begin{array}{l}\text { Recommendations for performing } \\
\text { ECHO }\end{array}$ & $\begin{array}{c}\text { Recommendation } \\
\text { grade }\end{array}$ & $\begin{array}{c}\text { Evidence } \\
\text { level }\end{array}$ \\
\hline $\begin{array}{l}\text { Assessment of patients with suspected } \\
\text { DCM or heart failure }\end{array}$ & I & B \\
$\begin{array}{l}\text { Assessment for differential diagnosis } \\
\text { between DCM and "athlete's heart } \\
\text { syndrome" }\end{array}$ & । & B \\
\hline
\end{tabular}

Echo: echocardiogram.

\subsubsection{Cardiac Magnetic Resonance Imaging}

CMRI can clearly and effectively demonstrate and quantify anatomical and functional changes in DCM. This examination has been found useful for evaluating HF patients by accurately calculating the function of both ventricles. It also helps distinguish idiopathic DCM from other forms of ventricular dysfunction, such as ventricular dysfunction caused by coronary artery disease. ${ }^{140}$ In addition, the method makes an important contribution to prognostic evaluation. Determining the presence and extent of fibrosis by myocardial late enhancement has good prognostic value, since it represents a substrate for arrhythmia and SD. Further research is needed to confirm the role of CMRI in the prognostic stratification of DCM, especially when defining the arrhythmic risk of these patients. ${ }^{141}$

\subsubsection{Sports and Dilated Cardiomyopathy}

DCM is an uncommon myocardial disease that deserves consideration because it is a potential cause of SD in athletes. ${ }^{142-144}$ In reality, there is little information on the risk of SD during physical activity or the relative risk of physical training for athletes with DCM. Thus, it is not clear whether asymptomatic DCM patients are at risk of SD during physical activity or competitive sports, since tachyarrhythmias are much more common in patients with more advanced disease, i.e., with explicit cardiac symptoms and reduced ejection fraction.

\subsubsection{Recommendations for Athletes Diagnosed with Dilated Cardiomyopathy}

Until further information is available, symptomatic DCM athletes should not participate in competitive sports except for those in class IA and selected cases. 


\section{Recommendation grade: III.}

\section{Evidence level: $B$.}

Athletes with a definite DCM diagnosis but a low risk profile (asymptomatic, no family history of SD, slightly reduced ejection fraction, normal pressure response to exercise and no complex ventricular arrhythmias) could participate in low-tomoderate intensity dynamic exercise and low-intensity static exercise (recommendations IA and IB).

These recommendations apply to competitive exercise. Physical activity of a therapeutic nature (cardiac rehabilitation) is indicated for all DCM and heart failure patients. ${ }^{145}$

\subsection{Non-Compacted Cardiomyopathy}

Non-compacted cardiomyopathy is a rare cardiac disease that has been recently recognized. It is due to embryonic interruption of myocardial compaction and is characterized by segmental thickening of the LV walls that consists of two layers: a compacted epicardial layer and an endocardial layer with marked trabeculations and deep intratrabecular recesses that are filled by blood flow. In non-compacted cardiomyopathy, left ventricular capacity is usually increased and the ejection fraction is reduced. ${ }^{146,147}$

Although considered a rare condition by some researchers, the incidence and prevalence of non-compacted cardiomyopathy are uncertain. Using echocardiography, a study at a large institution found a prevalence of $0.05 \%$. Among HF patients, the prevalence of non-compacted cardiomyopathy is $4 \% .{ }^{148}$ Diagnosis is quite difficult due to the lack of clear criteria, as well as the condition's heterogeneous clinical spectrum and the usual need for MRI for a reliable diagnosis.

This disease may be asymptomatic or present with $\mathrm{HF}$, ventricular and/or atrial arrhythmias, pre-excitation, thromboembolic events or SD. However, the risk of adverse consequences, including SD, seems to be associated with the degree of LV systolic dysfunction and/or ventricular tachycardia. ${ }^{149}$ There are no universally accepted criteria or precise guidelines for morphological diagnosis. However, a noncompacted/compacted myocardium ratio of $>2.1: 1$ at the end of systole in an echocardiogram or of 2.3:1 at the end of systole in CMRI is currently the most widely accepted criterion. ${ }^{150}$

Non-compacted cardiomyopathy can be found alone or combined with congenital heart defects, neuromuscular disorders or as part of genetic syndromes. ${ }^{149}$ It is a genetically heterogeneous disease, with familial or sporadic cases, and with pathogenic mutations involving the cytoskeleton, mitochondria, sarcomeres and z-line proteins. Therefore, different forms have been described: autosomal dominant, autosomal recessive, $\mathrm{X}$-linked, and with mitochondrial patterns of inheritance, although the most common form has an autosomal dominant trait. ${ }^{146}$

\subsubsection{Sports and Non-Compacted Cardiomyopathy}

Neither the extent to which physical training can alter non-compacted cardiomyopathy nor the prevalence of non- compacted LV morphology among healthy athletes have been determined. ${ }^{151,152}$ Since forensic reports of SD in young athletes do not include non-compacted cardiomyopathy as a possible cause, it is not possible to apply risk stratification strategies for new patients with this disease.

Recent studies have found a higher prevalence of increased LV trabeculation among athletes than controls (18.3\% vs. 7\%). It is believed that these abnormalities represent a non-specific epiphenomenon that increases with higher image resolution in echocardiography. In addition, increased LV trabeculation or isolated echocardiographic criteria for cardiomyopathies are likely to be of little significance and may be a part of the athlete's heart. ${ }^{153,154}$ Thus, not all athletes with isolated ventricular non-compaction should be diagnosed with non-compacted cardiomyopathy. Therefore, functional parameters such as ejection fraction must be considered in patient management. ${ }^{154}$

\subsubsection{Recommendations for Athletes Diagnosed with Non-Compacted Cardiomyopathy}

Athletes with an unequivocal diagnosis of non-compacted cardiomyopathy and compromised systolic function, major ventricular tachyarrhythmias in Holter monitoring or at an exercise testing or a history of syncope should not participate in competitive sports, with the possible exception of lowintensity sports (class IA), at least until more clinical information becomes available.

Recommendation grade: III.

Evidence level: $\mathrm{C}$.

\subsection{Chagas Disease}

Chagas disease continues to be one of the most important causes of non-ischemic cardiomyopathy in Latin America. Approximately 8-10 million people are estimated to be infected with Trypanosoma cruzi, ${ }^{155}$ and this protozoa is responsible for approximately 12,000 deaths per year. ${ }^{156}$ The disease usually manifests itself in $30 \%$ to $40 \%$ of those infected, and clinical findings usually appear 10 to 30 years after initial infection. ${ }^{157}$ Cardiac arrhythmias and SD are common and may occur at any stage of progression, even in individuals without significant structural disease. ${ }^{158,159}$ Sustained ventricular tachycardia is the main cause of SD, and is associated with LV dysfunction, syncope and non-sustained ventricular tachycardia in Holter monitoring or the exercise testing. ${ }^{160,161}$ In addition, sinus node dysfunction, atrioventricular and intraventricular conduction disorders are common findings in patients with Chagas disease and may progress to complete atrioventricular block. Few studies have evaluated the risk of SD in Chagas patients during intense exercise, and a lack of symptoms does not exclude the presence of cardiomyopathy, even in high-level athletes. ${ }^{162}$ Diagnosis involves epidemiological and serological evaluation (immunofluorescence). ECG and echocardiogram facilitate diagnosis of cardiomyopathy and conduction disorders. An exercise stress testing or a CPET, MRI, Holter monitoring and even electrophysiological study can more accurately assess the risk of SD. The exercise recommendations are similar to those for individuals with DCM. 


\section{Channelopathies}

\subsection{Introduction}

Channelopathies are inherited arrhythmogenic heart diseases that do not involve structural impairment and are caused by genetic changes that result in dysfunction of the cardiac ion channels, which leads to risk of SD. ${ }^{163}$ The most commonly known channelopathies are long QT syndrome, short QT syndrome, Brugada syndrome, and catecholaminergic polymorphic ventricular tachycardia (CPTV) ${ }^{75}$ Sinus node disease and Lenegre disease or conduction system disease are also examples of channelopathies.

Ion channels, the ion currents moving through these channels, proteins that attach to the membrane structure of myocardial cells, and the junctions between these structures are involved in electrical impulse formation and the synchronous transmission of these impulses throughout the heart, which generates cardiac action potential. ${ }^{164,165}$ The performance of each of these functions is determined by different genes. Mutations in related genes cause specific dysfunctions and cause channelopathies. ${ }^{166,167}$ The ion channels in the cell membrane allow ions to enter and exit following a voltage gradient. Genetic mutation in these channels can lead to gain or loss of function. With the recent increases in knowledge about these entities, defibrillator use and easier access to genetic evaluation, decisions shared between the medical team and the family have allowed a more permissive stance toward exercise in individuals with channelopathies. ${ }^{168}$ Detailed recommendations on the most prevalent syndromes are described below.

\subsection{Long QT Syndrome}

Long QT syndrome (LQTS) is the prototype channelopathy. First described more than 50 years ago as an autosomal recessive disease, Jervell and Lange-Nielsen syndrome ${ }^{169,170}$ includes congenital deafness, increased QTc intervals, and syncope or SD. Subsequently, an autosomal dominant form called Roman-Ward syndrome (prolonged QTC without deafness) was discovered. Several types of LQTS are currently known, which are determined by gene mutations that cause distinct changes in ventricular depolarization and repolarization.

The typical clinical features of LQTS include syncope or SD associated with increased QTC intervals and ventricular tachyarrhythmias such as torsade de pointes. ${ }^{171}$ Typically, certain factors trigger syncope in LQTS, which are related by subtype and genotype. The most common triggers are: adrenergic activity in SQTL1, sudden awakening and an acute auditory stimulus in SQTL2 and sleeping/resting in SQTL3. However, phenotypic presentations vary widely. Carriers can be asymptomatic, have no increase in QTc interval or have syncope or SD in the first days of life. Thus, diagnostic criteria were developed to score alterations, which are divided into three main groups: clinical history, family history and ECG. ${ }^{163}$

\subsubsection{Genetic Alterations in Long QT Syndrome}

Genetic alterations are known in approximately 60\% of the clinical cases of LQTS, and at least 17 genes have been associated with this clinical entity. Generally, patients have mutations in three specific genes: KCNQ1, KCNH2 or SCN5A. ${ }^{172}$ Hundreds of mutations have already been described, with the most prevalent type being cardiac. ${ }^{173}$ The most common mutation occurs in the KCNQ1 gene, which is responsible for more than $30 \%$ of the genetic variants and pathological mutations identified in LQTS and causes SQTL1. ${ }^{173}$ This type of mutation causes a loss of function in the IKs potassium current, ${ }^{166}$ which plays an important role in cell repolarization and QT interval adaptation to heart rate. SQTL5, a mutation caused by the KCNE1 gene, is much less frequent (considered rare) and is responsible for IKs loss-offunction. ${ }^{166}$ The $\mathrm{KCNH} 2$ (HERG) gene, which encodes the alpha subunit of the fast potassium channels, and KCNE2, which encodes the beta subunit, are responsible for the rapid entry of potassium during phase 3 of the action potential. ${ }^{174}$ Loss of alpha subunit function accounts for $40 \%$ of genotyped LQTS and is responsible for SQTL2. ${ }^{175}$ SQTL3 accounts for approximately $10 \%$ of all mutations diagnosed in LQTS, due to changes in the SCN5A gene, whose functional gain produces a continuous sodium input during the plateau phase, which facilitates early depolarization in cardiac cells. Although hundreds of other mutations have been described, treatment and follow-up of LQTS patients and families are restricted to the most known forms. ${ }^{176}$

\subsubsection{Risk Stratification in Long QT Syndrome}

Genetic analysis has been widely used for risk stratification and determining specific therapeutic interventions in LQTS patients and their relatives. Since LQTS is an uncommon clinical condition and data have only been obtained through cohort studies, the evidence level for recommendations about risk stratification and treatment strategies has been limited to B. The most robust risk marker of LQTS is a previous episode of aborted SD, and its most common cause is polymorphic ventricular tachycardia, degenerating or not into ventricular fibrillation. Patients who have experienced such a condition have a 13-fold increased risk of new SD episodes. Previous syncope is also an extremely unfavorable risk marker, which could double the risk. ${ }^{177}$

However, the risk of having an arrhythmic event is not the same for all patients. Evidence shows that individuals with SQTL2 and SQTL3 have a higher risk of events than those with the mutations that cause SQTL1. In addition, individuals with a QTC duration > $500 \mathrm{~ms}$ are at higher risk than those with shorter QTc durations. ${ }^{172}$ Mutations involving the gene segment that encodes the channel pore are also related to poorer prognosis. Therefore, once again, the value of genotyping in patients with this syndrome is clear. A family history of SD did not prove to be a higher risk marker for events. ${ }^{178}$

\subsubsection{Recommendations for Athletes with Long QT Syndrome}

A few years ago, LQTS patients were advised not to participate in competitive sports based on the understanding that they were exposed to an increased risk of SD. In 2015, Aziz et al. ${ }^{179}$ studied more than 100 patients with a positive LQTS genotype, all engaged in some type of sports program. 
Of these, $25 \%$ practiced competitive sports. Interestingly, the authors found no disease-related symptoms during sports, confirming that no event or SD had been described in those undergoing proper treatment. ${ }^{179}$ This and other evidence led to a revision of the recommendation to universally restrict LQTS patients from competitive sports. Thus, the American Heart Association/American College of Cardiology published new eligibility recommendations for athletes with channelopathies. ${ }^{180}$ Participation in competitive sports was reconsidered for athletes with LQTS due to a lack of evidence that asymptomatic athletes with positive genotype/negative phenotype may be at increased risk of malignant arrhythmias during sports. However, athletes must be under treatment and asymptomatic for 3 months before returning to training. Furthermore, precautionary measures, such as an automatic external defibrillator (Table 10), are advisable. However, it is important to stress that water sports are contraindicated for athletes with SQTL1.

Recommendation grade: IIb.

Evidence level: C.

Regarding water sports, Ackerman et al. ${ }^{180}$ described the follow up of swimmers diagnosed with SQTL1 and treated with beta-blockers, many with an implantable cardioverterdefibrillator (ICD), who chose to continue competing. The incidence of events was low, with only two events (both in the same individual) among 74 patients diagnosed with LQTS. It should be noted that this individual had a history of aborted SD and was not using beta-blockers.

Beta-blockers are the basis for managing LQTS, and are indicated for all symptomatic or asymptomatic individuals with a QTc interval $\geq 470 \mathrm{~ms}$. Therefore, all patients with a prolonged QT interval should receive beta-blockers, although protection is incomplete for patients with LQTS2 and 3 (class I intervention). For patients with a mutation (positive genotype) but a normal QT interval, prophylactic use of beta-blockers is also recommended, given their good tolerability and the fact that at least $10 \%$ of asymptomatic individuals will develop symptoms over time. ${ }^{181,182}$

Recommendation grade: Ila.

Evidence level: $B$.

An ICD is recommended for all cardiac arrest survivors with good functional status and life expectancy $>1$ year.

Table 10 - Precautionary measures for patients with channelopathies

Avoid substances that prolong the QT interval (www.crediblemeds.org)

Avoid substances that exacerbate Brugada syndrome (www.brugadadrugs.org)

Hydration and replacement of electrolytes: avoid dehydration (trigger)

Avoid hyperthermia, whether due to fever or excessive heat in athletes with long QT and Brugada syndrome

An external automatic defibrillator should be part of the athlete's equipment

Establish an emergency action plan
Recommendation grade: I.

Evidence level: $B$.

Patients who develop syncope despite the use of betablockers may also benefit from ICD.

Recommendation grade: Ila.

Evidence level: $B$.

An ICD can be considered in patients at high risk of SD, such as those with SQTL3, even if asymptomatic. Individuals with a QTc interval > 500 ms present a very high risk. ${ }^{183}$

Recommendation grade: IIb.

Evidence level: $B$.

Sympathetic denervation may be considered for patients with syncope or CPTV who are already using betablockers. ${ }^{181,184}$

Recommendation grade: IIb.

Evidence level: $B$.

\subsection{Short QT Syndrome}

Short QT syndrome is a very rare condition that has been known for less than 20 years. ${ }^{185}$ In this disease, shortening of repolarization occurs, which favors the development of ventricular arrhythmias by reentry. It is characterized by a short QT interval (QTc < $320 \mathrm{~ms}$ ) with peaked T-waves (that could have increased amplitude) with a normal ascending phase and a rapid descending phase. ${ }^{186,187}$ A QTC interval $\leq 340 \mathrm{~ms}$ is a risk marker. Short QT syndrome should also be considered when the patient has a QTc interval $\leq$ $360 \mathrm{~ms}$ in association with a confirmed genetic mutation, a family history of short QT syndrome, a family history of SD in individuals under 40 years of age and/or in survivors of cardiorespiratory arrest. ${ }^{188}$ Since the clinical parameters are still unclear, genetic analysis is useful to confirm the diagnosis in suspected cases. Mutations in three genes that encode potassium channels have been described: $\mathrm{KCNH} 2$, $\mathrm{KCNQ} 1$ and $\mathrm{KCNJ} 2$, all resulting in function gains in the IKr, IKs and IK1 channels, respectively, and determining short QT syndrome types 1, 2 and $3 .{ }^{187}$ Three other genes that encode calcium channels, CACNA1C (short QT syndrome type 4), CACNB2 (short QT syndrome type 5) and CACNA2D1 (short QT syndrome type 6) were also identified. ${ }^{188}$ Given that the number of patients with a confirmed diagnosis is very small, it has not yet been determined whether any specific type of mutation determines a worse prognosis. Moreover, new generation sequencing does not identify any genetic cause in up to $40 \%$ of individuals with a clear phenotype. ${ }^{188}$ Risk factors for arrhythmias are also not known. Treatment for this condition is still controversial: in patients with a $\mathrm{KCNH} 2$ gene mutation, quinidine has been shown to prolong refractoriness and suppress the induction of arrhythmias during an electrophysiological study, ${ }_{1}^{189}$ although for other mutations its usefulness has not been established. The disease appears to be highly lethal, but there may be a diagnostic bias toward severe cases. Although the use of ICD may be considered, 
inappropriate shocks may occur due to the double-counting phenomenon (QRS complexes and T-waves). ${ }^{190,191}$

Regarding exercise recommendations, participation in competitive sports may be considered for short QT patients as long as they are asymptomatic, have been under treatment for 3 months and precautionary measures are taken (automatic external defibrillator).

Recommendation grade: Ila.

Evidence level: $\mathrm{C}$.

\subsection{Brugada Syndrome}

This syndrome is characterized by the occurrence of syncope or SD caused by polymorphic ventricular tachycardia in structurally normal hearts. Its diagnosis may be based on a specific EGC pattern, defined as an ST-segment elevation $\geq 2 \mathrm{~mm}(0.2 \mathrm{mV})$ in the right precordial leads. However, this diagnosis may be unstable. ${ }^{192}$ Its most peculiar aspect is J-spot elevation in the right precordial leads (V1 to V3), although this phenomenon has also been described in lower leads. ${ }^{193-195}$ However, the ECG results may be unimpressive, requiring the use of sodium channel blockers to unmask the condition. The tracking and proper identification of these patients are essential, since SD is rarely the first symptom. ${ }^{192}$

This syndrome is highly influenced by gender, since $90 \%$ of cases occur in men. To date, only functional loss mutations in SCN5A, present in about $20 \%$ of those affected, have been identified. Currently, a total of 23 genes have been implicated in Brugada syndrome (BrS1-BrS23), and the vast majority of them are very rare. ${ }^{196}$ Clinically, the disease manifests with syncope or SD, predominantly in the third or fourth decade of life, with fever as a trigger for arrhythmias.

In risk stratification, individuals with spontaneous J-point elevation have a worse prognosis than those in whom the typical pattern was observed only after infusion of flecainide, procainamide or ajmaline. The occurrence of syncope, associated with spontaneous J-point elevation, increases the risk of SD by up to 6 times. Neither a family history of SD nor detecting a mutation in the SCN5A gene proved useful for risk stratification. ${ }^{197,198}$

Sports have not been described as a SD risk factor in Brugada syndrome. However, since there is a greater risk of events related to parasympathetic activity in this syndrome, arrhythmias can occur after exercise/training, a point in which there is vagal recovery and sympathetic withdrawal. In addition, significant elevations in body temperature due to intense physical activity in unfavorable environments may also trigger SD.

Defibrillators are recommended for:

Aborted SD patients.

Recommendation grade: I.

Evidence level: $\mathbf{B}$.

Patients with spontaneous J-point elevation and syncope, or with previously documented ventricular tachycardia.

Recommendation grade: Ila.

Evidence level: $\mathrm{B}$.
Exercise and competitive sports may be considered for Brugada patients, provided they are asymptomatic and have been undergoing treatment for 3 months.

\section{Recommendation grade: Ila.}

Evidence level: $\mathrm{C}$.

\subsection{Catecholaminergic Polymorphic Ventricular Tachycardia}

Catecholaminergic polymorphic ventricular tachycardia (CPVT) is triggered by physical exertion or emotional stress in children and young adults with structurally normal hearts. ${ }^{199,200}$ The patient's resting ECG will appear normal, except for relative bradycardia for age and frequent $U$-waves. The disease manifests clinically as syncope. ${ }^{199}$

At least four mutations have been described in several genes (RyR2, CASQ2, TRDN, CALM1) that potentially cause CPVT. The most common cause is functional gain mutation in RyR2 (about $60 \%$ to $75 \%$ of cases), the gene that encodes type 2 ryanodine receptor, which is the protein responsible for releasing calcium from the sarcoplasmic reticulum. Anomalies in the CASQ2, the gene that encodes cardiac calsequestrin, which is a calcium-binding protein in the sarcoplasmic reticulum, account for up to $5 \%$ of CPVT cases. The CALM1 gene encodes calmodulin, a protein that binds to calcium and stabilizes the RyR2 channel, and accounts for less than $1 \%$ of the cases. Finally, there is also the TRDN gene (identified in two families with CPVT), which encodes triadin, a protein that binds RyR2 and calsequestrin to the sarcoplasmic reticulum. ${ }^{201-203}$ Genetic analysis does not contribute to risk stratification, but it is important for identifying mutation carriers that have not yet manifested symptoms. The initial presentation of about $30 \%$ of patients is SD, and up to half of the patients suffer cardiac arrest between the ages of 20 and 30 years. ${ }^{204}$ CPVT is a penetrating disease, and the prevalence of "silent" cases could be up to $20 \%{ }^{205}$ However, cardiac events may occur even in this subgroup of individuals, who should be treated according to current guidelines. In these cases, genetic analysis plays a central role. ${ }^{206,207}$

Arrhythmias during exercise are the typical manifestation, frequently 120 to 130 beats per minute, beginning with isolated ventricular extrasystoles and progressing to episodes of unsustained and sustained ventricular tachycardia if effort is continued, usually with $180^{\circ}$ rotation in the front plane (bidirectional). Atrial arrhythmias, atrial fibrillation and supraventricular tachycardia are also common in the syndrome. Beta-blockers, the main therapeutic pillar for CPVT, ${ }^{208,209}$ are very effective and are recommended for:

Patients with clinical manifestations.

Recommendation grade: $I$.

Evidence level: $B$.

Asymptomatic mutation carriers.

Recommendation grade: Ila.

Evidence level: $\mathrm{B}$. 
An ICD is recommended for individuals with aborted SD.

\section{Recommendation grade: $\mathrm{I}$.}

Evidence level: B.

Individuals with sustained syncope or ventricular tachycardia despite the use of beta-blockers.

\section{Recommendation grade: Ila. \\ Evidence level: B.}

Recommendations about competitive sports in this disease are quite restrictive: athletes with symptomatic or asymptomatic CPVT should not participate in competitive sports (except class IA).

\section{Recommendation grade: III.}

Evidence level: $\mathrm{C}$.

\section{Athletes with Valvular Heart Disease}

\subsection{Introduction}

The assessment and follow-up of physically active individuals with valve disease are important pillars of sports cardiology. For athletes with valvular heart disease, eligibility criteria are based on cohort studies and expert consensus. However, randomized clinical trials with prospective data are scarce.

Athletes with intermediate degrees of valve disease are the most challenging group. Serial evaluation and stratification of disease severity are fundamental. As new symptoms develop, they should be treated promptly.

To qualify for competition, athletes must initially be classified according to symptoms, degree of valvular damage and left ventricular dysfunction.

Stage A: Asymptomatic athletes at risk of developing stenosis or significant valve regurgitation, e.g., mitral valve prolapse or BAV, as well as individuals whose physical examination is consistent with the underlying pathology (mitral, aortic ejection), but not classic valve dysfunction.

Stage B: Asymptomatic athletes with mild-to-moderate valve disease with preserved LV function.

Stage C: Asymptomatic athletes with severe valve disease with preserved LV systolic function (C1) or LV systolic dysfunction (C2).

Stage D: Symptomatic athletes with severe valve disease (with or without LV dysfunction).

\subsection{Aortic Valve Disease}

Aortic impairment is usually degenerative and is a result of aortic stenosis in middle-aged/elderly athletes and BAV in younger athletes. In Brazil, rheumatic etiology should be considered. Primary aortic diseases are common causes of aortic regurgitation, although there are also rheumatic and congenital causes (e.g., BAV). ${ }^{210,211}$

\subsubsection{Aortic Stenosis}

Aortic stenosis is considered a progressive disease and survival during the asymptomatic phase has been found similar to that of age-matched controls. ${ }^{212}$ In 2010, approximately 40 million people worldwide aged 65 or older had aortic stenosis, and this number is expected to reach 72 million by $2030 .{ }^{213}$ Lower exercise tolerance, effort dyspnea, and angina in athletes with systolic murmur are suggestive of clinically important aortic stenosis. Dyspnea is due to increased LV filling pressure or an inability to increase cardiac output with exercise.

Aortic stenosis is also recognized as responsible for $\mathrm{SD}$ in young athletes, although the prevalence of less than $4 \% .{ }^{214}$ It is important to point out that almost 70\% of SD episodes in subjects with severe aortic stenosis were not preceded by any of the classic symptoms of the disease. ${ }^{212}$

Echocardiography with Doppler color flow mapping is the method of choice for diagnosis, classification and evaluation of aortic stenosis ${ }^{215}$ (Table 11).

Transthoracic echocardiography provides evidence of aortic valve anatomy (e.g., the number of cusps and the extent of calcification), as well as valve hemodynamics (to confirm severity) and their consequences on LV function. Pulmonary hypertension, concomitant valvular disease and aortic root dilation can also be evaluated. ${ }^{216}$

Cardiac MRI is useful for patients with an unfavorable transthoracic window and/or when there is disagreement between two-dimensional echocardiographic parameters. ${ }^{217}$ Computed tomography of the heart can be used to quantify valve calcification. A calcium score of less than 700 Agatston units excludes severe aortic stenosis and has a high negative predictive value. On the other hand, scores over 2,000 Agatston units suggest severe aortic stenosis. ${ }^{213}$

Due to potential progressive aortic valve narrowing, athletes with mild or moderate (stage B) aortic stenosis should be assessed annually.

In asymptomatic or oligosymptomatic patients, exercise testing (exercise stress testing or CPET) could reveal those with low functional capacity, intraoperative hypotension and/or electrocardiographic changes during exercise. Such findings will conflict with the recommendations about sports participation. Recently, Saeed et al. ${ }^{218}$ analyzed almost 800 exercise tests and found that patients with moderate-to-severe asymptomatic aortic stenosis can perform the test safely and with good tolerability. In addition, event-free survival at 1 year was almost $90 \%$ in asymptomatic patients, but less than $70 \%$ in those who reported symptoms during exercise.

BAV patients without stenosis (stage A) should have an annual physical examination to detect new heart murmurs. Athletes with mild-to-moderate aortic stenosis (stage B) should

Table 11 - Aortic stenosis severity rating

\begin{tabular}{lccc}
\hline $\begin{array}{l}\text { Impairment } \\
\text { (degree) }\end{array}$ & $\begin{array}{c}\text { Jet velocity } \\
(\mathrm{m} / \mathrm{s})\end{array}$ & $\begin{array}{c}\text { Medium } \\
\text { gradient } \\
(\mathrm{mmHg})\end{array}$ & $\begin{array}{c}\text { Aortic valve area } \\
\left(\mathrm{cm}^{2}\right)\end{array}$ \\
\hline Mild & $<3$ & $<25$ & $>1.5$ \\
Moderate & $3-4$ & $25-40$ & $1.0-1.5$ \\
Severe & $>4$ & $>40$ & $<1.0\left(<0.6 \mathrm{~cm}^{2} / \mathrm{m}^{2}\right)$ \\
\hline
\end{tabular}


undergo anamnesis, a physical examination, echocardiography (to evaluate disease progression), and exercise testing to ensure that their exercise tolerance is compatible with their physical activity, that no episodes of hypotension occur during exercise, and that there is no electrocardiographic evidence of complex ischemia/arrhythmia.

\subsubsection{Recommendations and Evidence Level}

Athletes with aortic stenosis should be evaluated annually to continue participating in sports.

\section{Recommendation grade: I.}

\section{Evidence level: $\mathrm{C}$.}

Athletes with discrete aortic stenosis (stage B) and an appropriate physiological response to a maximal exercise testing may participate in any sport.

\section{Recommendation grade: Ila.}

Evidence level: $\mathrm{C}$.

Athletes with moderate aortic stenosis (stage B) can participate in competitive sports with low-to-moderate static and dynamic components (classes IA, IB and IIA) if the exercise testing results are sufficient for the activity level required in competition, with clinical, hemodynamic and ECG responses to exercise and without ventricular tachyarrhythmias.

\section{Recommendation grade: Ila.}

Evidence level: $\mathrm{C}$.

Asymptomatic athletes with severe aortic stenosis (stage C) should not participate in competitive sports, except for those with low static and dynamic components (class IA).

Symptomatic athletes with aortic stenosis (stage D) should not participate in competitive sports.

\section{Recommendation grade: III.}

\section{Evidence level: $\mathrm{C}$.}

\subsubsection{Aortic Regurgitation}

The prevalence of aortic regurgitation increases with age, although it is very low (1\%) in individuals less than 70 years of age. After that age, its prevalence increases to over $2 \% .{ }^{219}$ In the native valve, aortic regurgitation may be the result of abnormalities of the valve leaflets, the aortic root or both. The main causes of aortic regurgitation are diseases that affect the aortic ring or root without directly involving the aortic valve: BAV, connective tissue genetic disorders (Marfan, Ehlers-Danlos and Loeys-Dietz syndromes), inflammatory diseases (in particular syphilitic aortitis, Takayasu arteritis and giant cell arteritis), rheumatic heart disease and hypertensive dilation. In fact, so-called "idiopathic" aneurysms of the ascending aorta have a genetic diagnosis in at least 30\% of the cases. ${ }^{210,219}$ Aortic regurgitation is invariably well tolerated and asymptomatic for years; however, eccentric hypertrophy progressively develops and LV systolic and diastolic volumes increase, which could lead to LV systolic dysfunction.
Aortic regurgitation is diagnosed in asymptomatic athletes when physical examination reveals wide arterial pulse pressure, a diastolic murmur in the aortic area or Erb's point, or a systolic murmur related to increased systolic volume. An echocardiogram is definitive for diagnostic confirmation and classifying aortic regurgitation. With color Doppler echocardiography, the size of the regurgitant jet and the flow convergence can be determined, allowing the regurgitant orifice area to be calculated..$^{210,220}$

CMRI may be used as a complement to echocardiography when quantifying aortic regurgitation. In fact, it has been reported that quantitative volume and regurgitant fraction can be calculated with better reproducibility through CRMI than echocardiography. 221,222

Because the pathophysiology of aortic regurgitation leads to LV dilation in elite athletes, it must be differentiated from the physiological alterations in athlete's heart syndrome. Therefore, when evaluating increased LV volume in elite athletes with suspected or diagnosed aortic regurgitation, only LV volumes that exceed normal physiological response to sports training should be considered.

Although up to $45 \%$ of male athletes have a LV end-diastolic diameter (LVDD) $>55 \mathrm{~mm}$, only $14 \%$ of elite male athletes have a LVDD > $60 \mathrm{~mm}$, and LVDD rarely exceeds $70 \mathrm{~mm}$. A LVDD > $55 \mathrm{~mm}$ occurs in $<10 \%$ of elite female athletes, while only $1 \%$ have a LVDD $>60 \mathrm{~mm} .^{223-225}$ The same is true for LV end-systolic diameter (LVSD): in elite athletes, the upper limit for LVSD is $49 \mathrm{~mm}$ for males and $38 \mathrm{~mm}$ for females. Only index data on body surface area and height are available regarding LVDD, which indicate upper limits of $35.3 \mathrm{~mm} / \mathrm{m}^{2}$ and $40.8 \mathrm{~mm} / \mathrm{m}^{2}$ for male female athletes, respectively. ${ }^{223-226}$

A normal LV ejection fraction response to exercise is observed in aortic regurgitation patients until there is significant LV dilation. When evaluating the progressive effects of severe aortic impairment in athletes with normal LV ejection fraction, serial analysis of LVSD is of great value. The American Heart Association/American College of Cardiology define preserved systolic function (stage C1) in patients with significant aortic impairment as a LV ejection fraction $\geq 50 \%$ and LVSD $\leq 50 \mathrm{~mm}$ or index LVSD $\leq 25 \mathrm{~mL} / \mathrm{m}^{2}{ }^{210,227}$ Thus, in athletes with significant aortic impairment and a LVDD that exceeds the abovementioned reference values. There is a higher probability that severe aortic impairment contributes to LV dilation. Such athletes require a more careful evaluation to verify that no ventricular increase has occurred and whether signs and/or symptoms occur during exercise, such as dyspnea on exertion or reduced functional capacity.

\subsubsection{Recommendations and Evidence Level}

Athletes with aortic regurgitation should be evaluated annually to continue participating in sports.

To confirm that athletes with aortic regurgitation are truly asymptomatic, they should undergo an exercise testing involving at least the activity level achieved during training and competition and have a physiological hemodynamic response.

Athletes with mild-to-moderate aortic impairment (stage B), a physiological response to a maximal exercise testing, normal 
or discretely dilated LV and a normal ejection fraction may participate in any sport (with frequent reassessment).

Recommendation grade: $I$.

Evidence level: $\mathrm{C}$.

Athletes with mild to moderate aortic regurgitation (stage B), a physiological response to a maximal exercise testing, a moderately dilated LV (LVSD $<50 \mathrm{~mm}$ [men], < $40 \mathrm{~mm}$ [women] or $<25 \mathrm{~mm} / \mathrm{m}^{2}$ [both sexes]) and a normal ejection fraction may participate in any sport (with frequent reassessment).

\section{Recommendation grade: Ila.}

Evidence level: $\mathrm{C}$.

Athletes with severe aortic regurgitation (stage $\mathrm{C} 1$ ), a physiological response to a maximal exercise testing, a moderately dilated LV (LVSD < $50 \mathrm{~mm}$ [men], < $40 \mathrm{~mm}$ [women] or $<25 \mathrm{~mm} / \mathrm{m}^{2}$ [both sexes]), a normal ejection fraction and no progression of aortic impairment or LV regurgitation according to echocardiography may participate in any sport (with frequent reassessment).

Athletes with aortic regurgitation whose aortic diameters are 41 to $45 \mathrm{~mm}$ may participate in sports in which there is no risk of collision (with frequent reassessment).

\section{Recommendation grade: IIb.}

Evidence level: $\mathrm{C}$.

Symptomatic athletes with significant aortic regurgitation (stage D), LV systolic dysfunction with an ejection fraction < $50 \%$ (stage C2), LVSD > $50 \mathrm{~mm}$ or $>25 \mathrm{~mm} / \mathrm{m}^{2}$ (stage C2) or a significant increase in LVDD (> $70 \mathrm{~mm}$ or $\geq 35.3 \mathrm{~mm} /$ $\mathrm{m}^{2}$ [men], $>65 \mathrm{~mm}$ or $\geq 40.8 \mathrm{~mm} / \mathrm{m}^{2}$ [women]) should not participate in competitive sports.

\section{Recommendation grade: III.}

\section{Evidence level: $\mathrm{C}$.}

\subsubsection{Bicuspid Aortic Valve}

BAV is the most common congenital heart disease, affecting $1.3 \%$ of the population. ${ }^{228}$ There is already consensus that an association exists between BAV and changes in vascular connective tissue, and that dilation of the aortic root can occur, including a risk of dissection, even in the absence of hemodynamically significant aortic stenosis or aortic regurgitation. ${ }^{229,230}$

\subsubsection{Recommendations}

Athletes with BAV but not aortic root dilation (less than $40 \mathrm{~mm}$, or equivalent in children and adolescents according to body surface area), significant aortic stenosis, or aortic regurgitation may participate in any competitive sport.

Athletes with BAV and aortic root measurements between 40 and $45 \mathrm{~mm}$ may participate in competitive sports with a low-to-moderate static component or a low-to-moderate dynamic component (classes IA, IB, IIA and IIB) but should avoid sports that involve a risk of collision or trauma.
Athletes with BAV and aortic root dilation greater than 45 $\mathrm{mm}$ may participate only in competitive sports with low static and dynamic components (class IA).

\subsection{Mitral Valve Disease}

\subsubsection{Mitral Stenosis}

A mitral valve area of 4 to $6 \mathrm{~cm}^{2}$ is considered normal. Mitral stenosis affects women twice as frequently as men. ${ }^{231}$ As mitral stenosis progresses, particularly when the area becomes smaller than $2 \mathrm{~cm}^{2}$, a diastolic pressure gradient develops between the left atrium (LA) and the LV, causing elevation in LA pressures and decreased flow towards the $\mathrm{LV}^{232}$ Frequently of rheumatic origin, mitral stenosis rarely causes SD. However, exercise may lead to a marked increase in pulmonary and pulmonary capillary pressure, sometimes culminating in acute pulmonary edema. ${ }^{233}$ Athletes with mitral stenosis are more likely to develop atrial fibrillation as a result of strenuous exercise in an already enlarged atrium. Systemic embolization is the main complication, but there is no evidence that strenuous exercise increases risk. When atrial fibrillation occurs in an athlete with mitral stenosis, anticoagulant therapy should be applied.

As in other valvular heart diseases, the evaluation of athletes with mitral stenosis requires a well-documented anamnesis, as well as an echocardiogram (Table 12). ${ }^{215}$ This disease is considered severe when there is a resting mean transmitral gradient of 5 to $10 \mathrm{mmHg}$, which is dependent on transvalvular flow and the diastolic filling phase, factors that vary widely with increased heart rate during exercise. ${ }^{210}$

Athletes with mitral stenosis, whether asymptomatic or with minimal symptoms, should perform an exercise testing involving at least the activity level achieved during training/ competition, especially if the disease severity is uncertain. The intensity of physical activity should depend on the size of the left atrium and the severity of the defect. Pulmonary artery systolic pressure during exercise can be estimated noninvasively with an echocardiogram, which can be of great value in quantitative analysis of the safe training range for mitral stenosis patients. ${ }^{210}$

\subsubsection{Recommendations and Evidence Level}

Athletes with mitral stenosis should undergo an annual evaluation to continue participating in sports.

An exercise testing should be performed involving at least the activity level achieved during training/competition with a hemodynamic response to confirm the symptom status.

Table 12 - Echocardiographic features of severe mitral stenosis

Mitral valve area $<1.5 \mathrm{~cm}^{2}$
Mean left atrial/left ventricular diastolic gradient $\geq 10 \mathrm{mmHg}$
Pulmonary artery systolic pressure $\geq 50 \mathrm{mmHg}$ at rest
Pulmonary artery systolic pressure $\geq 60 \mathrm{mmHg}$ on effort




\section{Recommendation grade: $I$.}

\section{Evidence level: $\mathrm{C}$.}

Athletes with mild mitral stenosis (mitral valve area $>$ $2.0 \mathrm{~cm}^{2}$, mean gradient $<10 \mathrm{mmHg}$ at rest) in normal sinus rhythm may participate in any competitive sport.

\section{Recommendation grade: Ila.}

\section{Evidence level: $\mathrm{C}$.}

Athletes with significant mitral stenosis should not participate in competitive sports, with the possible exception of sports with low static and dynamic components (class IA).

Athletes with any degree of mitral stenosis and atrial fibrillation or who have a history of atrial fibrillation on anticoagulant therapy should not participate in competitive sports involving collision/trauma risk.

\section{Recommendation grade: III.}

\section{Evidence level: $\mathrm{C}$.}

\subsubsection{Mitral Regurgitation}

The prevalence of mitral regurgitation is age dependent, with a frequency $>6 \%$ in adults over 65 years of age. ${ }^{234}$ The pathogenesis varies from mitral-valve prolapse (sometimes with myxomatous degeneration) to rheumatic causes, connective tissue diseases (e.g., Marfan syndrome) and infective endocarditis, to secondary causes such as coronary artery disease and dilated cardiomyopathy. Diagnostic suspicion arises from auscultating a systolic murmur at the apex, which is confirmed and quantified by echocardiography. ${ }^{220}$ Generally, athletes with mild or moderate mitral regurgitation are asymptomatic (Stage B).

The severity of mitral regurgitation is related to LV regurgitant volume into the left atrium, with increased atrial pressure, increased ventricular diastolic volume and posterior LV dilation. ${ }^{235}$ Due to overestimation of the LV ejection fraction, LV systolic dysfunction in athletes with mitral insufficiency is defined as a LV ejection fraction $<60 \%$ or LVSD $>40 \mathrm{~mm}$. As in aortic regurgitation, it is difficult to distinguish LV dilation due to exercise from that caused by major mitral regurgitation when LVDD is $<60 \mathrm{~mm}$ (or $<40 \mathrm{~mm} / \mathrm{m}^{2}$ ). However, LVDD $>60 \mathrm{~mm}$ strongly suggests significant mitral regurgitation, thus justifying subsequent investigation. ${ }^{210}$

Dynamic exercise generally decreases the regurgitant fraction due to reduced systemic vascular resistance. On the other hand, static exercise with increased systemic BP, HR and systemic vascular resistance increase regurgitant volume, which increases the pressure in pulmonary capillaries. The assessment of athletes with mitral regurgitation, which should occur at least annually, should include complete anamnesis and an echocardiogram. This test can noninvasively estimate pulmonary artery systolic pressure during exercise and is useful for decision making about the intensity of safe physical activity, especially in those with more severe mitral regurgitation. ${ }^{210}$

The recommendations listed below should be considered in patients with secondary causes of mitral regurgitation (e.g., infective endocarditis, rupture of the mitral valve chordae) due to a marked increase in LV systolic pressure, which could further damage valve tissue.

\subsubsection{Recommendations and Evidence Level}

Athletes with mitral regurgitation should be evaluated annually to continue participation in sports.

Athletes with mitral regurgitation should undergo an exercise stress testing or CPET involving at least the activity level achieved in during training and competition, with a hemodynamic response to confirm symptom status.

Athletes with mild-to-moderate mitral regurgitation, normal sinus rhythm, normal LV diameter and function, and normal pulmonary arterial pressures (stage B) may participate in any competitive sport.

Recommendation grade: $I$.

Evidence level: $\mathrm{C}$.

Athletes with moderate mitral regurgitation (stage B), normal sinus rhythm, normal LV ejection fraction, and moderate LV dilation (compatible with that resulting exclusively from exercise [LVDD $<60 \mathrm{~mm}$ or $<35 \mathrm{~mm} / \mathrm{m}^{2}$ in men or $<40$ $\mathrm{mm} / \mathrm{m}^{2}$ in women) may participate in any sport.

Recommendation grade: Ila.

Evidence level: $\mathrm{C}$.

Athletes with significant mitral regurgitation, normal sinus rhythm, a normal LV ejection fraction at rest, and mild LV dilation (compatible with that which can only result from exercise [LVDD $<60 \mathrm{~mm}$ or $<35.3 \mathrm{~mm} / \mathrm{m}^{2}$ in men or $<$ $40 \mathrm{~mm} / \mathrm{m}^{2}$ in women]) (stage C1) may participate in sports with a low-to-moderate static component and a low dynamic component, as well as in sports with a low static component and a moderate dynamic component (classes IA, IIA and IB ).

Recommendation grade: Ilb.

Evidence level: $\mathrm{C}$.

Athletes with mitral regurgitation and significant LV dilation (LVDD $\geq 65 \mathrm{~mm}$ or $\geq 35.3 \mathrm{~mm} / \mathrm{m}^{2}$ [men] or $\geq 40 \mathrm{~mm} / \mathrm{m}^{2}$ [women]), pulmonary hypertension and LV ejection fraction $<60 \%$ or LVSD > $40 \mathrm{~mm}$ should not participate in any competitive sport, with the possible exception of low static and dynamic component sports (class IA).

Athletes with mitral regurgitation and a history of atrial fibrillation and long-term anticoagulation therapy should not participate in sports that involve a risk of collision/trauma.

\section{Recommendation grade: III.}

Evidence level: $\mathrm{C}$.

\subsubsection{Mitral-Valve Prolapse}

This pathology, which has an estimated prevalence of $2 \%$ to $4 \%$ in the general population, appears to be more common in women. Diagnosed with echocardiography, it is defined as systolic displacement of one or both mitral leaflets $\geq 2 \mathrm{~mm}$ into the left atrium, as well as by the mitral annular plane in the 
parasternal cross-section of the long axis. ${ }^{235,236}$ It occurs in two forms: the classical form, with diffusely thickened leaflets ( $\geq 5$ $\mathrm{mm}$ ) with bileaflet prolapse; or the non-classical form, in which there is limited $(<5 \mathrm{~mm}$ ) or absent thickening and segmental prolapse. Classical prolapse can be further subdivided into symmetrical (when the leaflets meet at a common ring point) and asymmetrical (when one leaflet is moved further towards the atrium). ${ }^{237} \mathrm{~A}$ mitral valve leaflet thickness $>5 \mathrm{~mm}$ in the echocardiogram has been associated with an increased risk of $\mathrm{SD}$, stroke and endocarditis in patients with classic prolapse. ${ }^{236}$

The etiology can be primary (degenerative disease) or secondary (Marfan syndrome, Ehlers-Danlos syndromes, pseudoxanthoma elasticum). These patients can be identified through auscultation by the presence of a meso-telesystolic click and/or a mitral regurgitation murmur, as well as by chest pain, dyspnea, exercise intolerance, syncope and/or dizziness.

The major risks related to mitral-valve prolapse include severe progressive mitral regurgitation requiring valve surgery, infective endocarditis, embolic events, atrial and ventricular tachyarrhythmias and SD (which appears to be associated with structural abnormalities of the mitral valve, as in the classical form), with diffuse thickening, stretching and redundancy, and, in some cases, rupture of chordae tendineae.

The prognosis for mitral-valve prolapse is controversial. For example, the Framingham Heart Study ${ }^{238}$ described mitralvalve prolapse as a benign entity, but other studies indicate that a subgroup of patients may be at a greater risk of cardiac arrest, which is the most devastating consequence. Thus, the risk for serious adverse events secondary to mitral-valve prolapse remains uncertain. . $39,240^{2}$

SD associated with isolated mitral-valve prolapse is rare among young people, particularly with respect to exercise, and is also rare among professional athletes: its frequency in these groups is no greater than that of the general population. It predominantly occurs in patients over 50 years of age with severe mitral regurgitation and/or systolic dysfunction. However, Basso et al. ${ }^{241}$ have shown a growing interest in mitralvalve prolapse, highlighting this entity as a neglected cardiac abnormality that could be associated with severe cardiac events, including SD in youth and adults. Caselli et al. ${ }^{242}$ evaluated a large cohort of competitive athletes from 2000 to 2010, finding that mitral-valve prolapse was a relatively common finding, although predominantly benign. In addition, they recommend that detecting moderate-to-severe mitral regurgitation, as well as ventricular arrhythmias, may be useful for identifying athletes with mitral-valve prolapse who are at greater risk.

Some individuals with mitral-valve prolapse present a phenotype described as MASS (mitral valve, aorta, skeleton, and skin), which involves connective tissue changes, long limbs, deformity of the thoracic cage, and joint hypermobility). In such patients the risk of progression to aortic dilation/ dissection or SD is greater. The MASS phenotype only applies if the aortic diameter $z$-score is $<2$, the systemic score is $\geq$ 5 and the patient is at least 20 years old..$^{243-246}$

\subsubsection{Recommendations}

Athletes with mitral-valve prolapse but no prior syncope (especially if of arrhythmogenic origin), sustained supraventricular or unsustained tachycardia or complex ventricular tachycardia according to $24 \mathrm{~h}$ Holter monitoring, severe mitral regurgitation according to an echocardiogram, LV systolic dysfunction (LV ejection fraction $<50 \%$ ), previous embolic event or family history of SD related to mitral-valve prolapse may participate in any competitive sport.

Athletes with mitral-valve prolapse who exhibit any of the above characteristics may participate in competitive sports with low static and dynamic components (class IA).

Recommendations for athletes with mitral-valve prolapse and hemodynamic overload secondary to moderate-to-severe mitral regurgitation should be guided by the mitral regurgitation.

\subsubsection{Tricuspid Stenosis}

In isolation, tricuspid stenosis is rare. It is mainly caused by rheumatic disease and is usually associated with mitral stenosis. Although less common, tricuspid stenosis may result from congenital/genetic abnormalities, such as Ebstein's anomaly, Fabry disease, Whipple disease, or active infective endocarditis. ${ }^{247}$ In summary, tricuspid stenosis patients should be considered according to degree of severity (Table 13). ${ }^{215}$

\subsubsection{Recommendations}

Asymptomatic athletes may participate in any competitive sport. An exercise testing involving at least the activity level achieved during training and competition should be performed.

\subsubsection{Tricuspid Regurgitation}

Tricuspid regurgitation is reported as the most common heart valve disease, affecting up to $85 \%$ of the population. ${ }^{248}$ It is divided into two categories: primary (or organic) and secondary tricuspid regurgitation, which is the most common form. Namely, only $8 \%$ to $10 \%$ of tricuspid regurgitation cases are primary, ${ }^{246}$ being associated with rheumatic heart disease, pacemaker electrode and defibrillator leads (iatrogenic complications) myxomatous degeneration, myocardial degeneration, tricuspid valve prolapse, infectious diseases (e.g., endocarditis) and congenital heart diseases (e.g., Ebstein's anomaly). It may also be related to postoperative complications. Physical examination and chest X-ray may help estimate tricuspid regurgitation, but echocardiogram is the gold standard for assessing the mechanism and severity of the condition. Three-dimensional echocardiography is even more sensitive, allowing a simultaneous view of all the leaflets. ${ }^{249}$ If RV function cannot be adequately evaluated with this method, CMRI, due to its capacity to quantify RV volumes and ejection fraction, is an important introductory step. ${ }^{248}$ If these measures

\section{Table 13 - Echocardiographic features of severe tricuspid stenosis}

Tricuspid valve area $\leq 1.0 \mathrm{~cm}^{2}$
Mean diastolic gradient right atrium/right ventricle $\geq 5 \mathrm{mmHg}$
Isolated right atrial enlargement
Tricuspid pressure half-time $\geq 190 \mathrm{~ms}$


cannot be estimated/determined non-invasively, right cardiac catheterization is used for such evaluation.

"Physiological" tricuspid regurgitation can be detected by echocardiography in approximately $80 \%$ of healthy athletes and does not imply any structural valve abnormality. ${ }^{231}$

\subsubsection{Recommendations}

Athletes with primary tricuspid regurgitation, regardless of severity, and normal RV function, in the absence of right atrial pressure $>20 \mathrm{mmHg}$ or elevated RV systolic pressure, may participate in any competitive sport.

\subsubsection{Multivalvular Heart Disease}

Multivalvular heart disease, a combination of stenotic and/ or regurgitant lesions of two or more heart valves, is a highly prevalent clinical condition among patients with valvular heart disease. It occurrence is mainly due to rheumatic heart disease, although the incidence of this etiological factor has decreased dramatically in the last five decades. ${ }^{250}$ Myxomatous valvulopathy and infective endocarditis are also associated with multivalvular disease. Diagnosis is through physical examination, echocardiogram (the main imaging mode for diagnosis and follow-up), and sometimes cardiac/ coronary angiography.

\subsubsection{Recommendations}

The cumulative effects of multiple significant valve lesions on an individual's physiological response to exercise may be difficult to predict, and multiple moderate lesions may also have physiological effects on the somatosensory system. Generally speaking, athletes with moderate-tosevere multivalvular disease should not participate in competitive sports.

\subsection{Sports after Valve Surgery}

Although much progress has been made in cardiac surgery, mortality after valve replacement is still higher than that of the general population of the same age group.

Mechanical heart valve prosthesis requires anticoagulant therapy and transvalvular gradients of varying degrees, which could be exacerbated by exercise. Thus, for athletes who have had a valve replacement, such factors determine their adequacy for competitive sports. ${ }^{251}$

An exercise stress testing or CPET involving at least at the activity level achieved during training and competition is of great value for analyzing the functional capacity of the athletes who have undergone valve replacement/repair.

\subsubsection{Recommendations and Evidence Level}

Athletes with an aortic or mitral bioprosthesis who are not on anticoagulant therapy and have normal LV ejection fraction and valvular function may participate in competitive sports (class IA, IB, IC and IIA).

Athletes with an aortic or mitral mechanical heart valve prosthesis who are undergoing anticoagulant therapy and have normal LV ejection fraction and valvar function may participate in competitive sports (class IA, IB and IIA) if there is no risk of collision/trauma.

Athletes who have undergone successful mitral balloon valvuloplasty or surgical commissurotomy may participate in competitive sports based on the severity of their residual mitral regurgitation or aortic stenosis and their pulmonary arterial pressure during rest and exercise.

Athletes who have undergone mitral valve surgery to correct mitral regurgitation or aortic valve repair, having no residual or moderate mitral regurgitation and having normal LV ejection fraction, may participate in sports (class IA, IB and IIA), but only at the discretion of the attending physician and if there is no risk of collision/trauma.

Recommendation grade: Ila.

Evidence level: $\mathrm{C}$.

\subsubsection{Transcatheter Aortic Valve Implantation}

Transcatheter aortic valve implantation is a minimally invasive percutaneous procedure that was performed for the first time in 2002. It is considered the gold standard for patients with aortic stenosis who are at high surgical risk, especially older adults. ${ }^{252}$ Since these patients often have low functional capacity, therapeutic exercise intervention can improve their physical integrity and performance in activities of daily living.

Several recent studies have confirmed the benefits of exercise in patients who have undergone transcatheter aortic valve implantation. They are unanimous in reporting improved functional capacity (as measured by CPET or the 6-minute walk test). ${ }^{253-256}$ Altisent et al., ${ }^{257}$ in a 4-year follow-up, found that an increase $<20 \%$ in the 6 -minute walk test 6 months after the procedure correlates with an all-cause mortality of $65 \%$. Therefore, exercise increases the functional capacity of these individuals, improving prognosis and quality of life. It should be pointed out that we are not aware of any studies on athletes who have undergone transcatheter aortic valve implantation.

\section{Athlete's Heart Syndrome in Women}

\subsection{Introduction}

Since the passage of Title IX in 1972, women's participation in sports has increased dramatically. During the 2014-2015 school year, approximately 8 million United State. high school students participated in sports, over $40 \%$ of whom were girls. ${ }^{258}$ Female athletes have been historically underrepresented in research that has guided exercise and sports cardiology. However, in the last three decades there has been an exponential increase in the number of women participating in competitive sports. Thus, female gender should be considered an important biological variable in this context.

As in men, the body of female athletes also undergoes physiological adaptations to physical training and may present structural and electrical changes compatible with athlete's heart syndrome. Such adaptations can occur in all athletes, but their magnitude depends on several factors, including gender. There are anthropometric, physiological 
and biochemical differences between men and women, including smaller stature, lower body mass, smaller LV diameter, less testosterone and a different physical work capacity. ${ }^{259}$ In hemodynamic terms, higher resting HR have been observed, although maximum levels during exercise are reached in a manner similar to men. Systolic BP and systolic volume increase less on effort, and maximal $\mathrm{O}_{2}$ consumption $\left(\mathrm{VO}_{2}\right.$ max) is lower. Nevertheless, female cardiac output is $5 \%$ to $10 \%$ higher than that of males at any level of submaximal oxygen consumption. ${ }^{260}$ In absolute values, female work capacity is lower, but when assessed at the same intensity percentage, the cardiovascular performance of men and women are similar.

Since physical training can result in a series of cardiovascular system modifications and adaptations, knowing how to differentiate physiological responses due to regular exercise from pathological ones can be a challenge when performing detailed clinical evaluations of athletes.

\subsection{Complementary Exams}

\subsubsection{Twelve-Lead Electrocardiogram}

\subsubsection{Electrocardiogram: Physiological Changes vs. Changes Suggestive of Heart Disease}

Both physiological and pathological adaptations may differ between female and male athletes in ECG. However, data on specific ECG differences between genders are limited. Using the criteria of Pelliccia et al. (2000), ${ }^{261}$ women had a higher prevalence of normal ECG than men $(78 \%$ vs. 55\%) in a cohort of European Olympic athletes. On the other hand, according to the latest Seattle criteria, ${ }^{262}$ no significant differences were observed between genders ( $96 \%$ of males and $97 \%$ of females had normal ECG). This contrast could be justified by the fact that the Seattle Criteria are much more rigorous, which increases specificity without sensitivity loss.

Female athletes appear to have a lower prevalence of physiological changes in ECG, especially regarding isolated increases in QRS complex amplitude (in about 10\% of women), incomplete RBBB and early repolarization (four times less than men). ${ }^{263,264}$ However, female athletes had a higher frequency of QT interval increase, as well as inverted T-wave in the V1-V2 leads ( $1 \%$ vs. $0.2 \%$ in male athletes), ${ }^{265}$ such findings are considered non-pathological adaptations. Inverted T-waves in the inferior and/or lateral walls are more prevalent in male athletes, being more commonly associated with underlying structural heart disease. ${ }^{266}$ On the other hand, anterior precordial T wave inversion is more common in women and, when limited to V1-V3 leads, does not appear to be related to structural heart disease. ${ }^{267,268}$ However, ventricular repolarization changes in lateral leads are less common and should always serve as a warning for a possible pathology. ${ }^{269}$

One important point to consider is that the international guidelines for interpreting ECG in athletes do not differ according to gender, but are unanimous in stipulating a higher
QTC interval cut-off point for women than men, since women, regardless of cardiac remodeling, have longer QTc intervals than men ( $\geq 480 \mathrm{~ms} v \mathrm{~s}$. $\geq 470 \mathrm{~ms}$, respectively). ${ }^{101,270}$

\subsection{Echocardiogram}

The echocardiogram is one tool available for PPS and determining sports eligibility. In a study of 600 female athletes who participated in different sports, it was found that the LV cavity is rarely greater than $54 \mathrm{~mm}$ (a threshold value for normality in women) and never above $66 \mathrm{~mm}$. The thickness of the LV wall rarely measures over $11 \mathrm{~mm}$, reaching a maximum of $13 \mathrm{~mm}$, usually in blacks. ${ }^{225,271}$ Finocchiaro et al. ${ }^{264}$ confirmed these findings: none of the women in their sample had an LV wall thickness > $12 \mathrm{~mm}$, and only $7 \%$ had a LV end-diastolic diameter $>54 \mathrm{~mm}$. In fact, these results are clinically relevant, since a LV cavity $<54 \mathrm{~mm}$ can distinguish, for example, an "athlete's heart" from HCM with excellent sensitivity and specificity. ${ }^{272}$

It has long been known that one adaptation to regular physical training is increased LV mass, observed mainly in endurance athletes. However, when LV wall thickness is accompanied by a reduction in cavity size, a pathological process such as HCM should be suspected. LV wall thickness $>12 \mathrm{~mm}$ in men or $>10 \mathrm{~mm}$ in women is considered abnormal in white athletes, and further investigation is necessary. ${ }^{273}$ In black athletes, an LV wall thickness of 11 $\mathrm{mm}$ can be observed, which can reach up to 12 or even 13 $\mathrm{mm}$ in exceptional situations. ${ }^{271}$ Since none of the athletes Finocchiaro et al.'s sample had a LV wall $\geq 13 \mathrm{~mm}$, it would be reasonable to infer that an LV wall thickness of $13 \mathrm{~mm}$ probably represents the upper physiological limit of LV hypertrophy in black and asymptomatic athletes where there is no family history of HCM.

Recent experiments have demonstrated that women with "athlete's heart" have eccentric LV hypertrophy. Initially, there is an increase in the cavity which, although smaller (5\%) than that of a man, is larger when indexed to body surface. LV wall thickness and LV mass do not increase proportionally, being smaller than those of male athletes (23\% and $31 \%$, respectively). It is suggested that a relative LV wall thickness $>0.48$ is a marker of pathology. ${ }^{269}$

D'Ascenzi et al. ${ }^{274}$ investigated the morphology and function of the left and right atria in competitive volleyball athletes, observing a biatrial increase with normal filling pressures and low complacency. In women, these characteristics are typical of athlete's heart and should be thus interpreted as a physiological adaptation to intense physical training.

\subsection{Exercise Testing}

Prior to this decade, the exercise stress testing was considered less accurate when diagnosing CAD in women. However, more recent studies have vindicated its effectiveness, especially for variables besides ST-segment. Women are more likely to have baseline ST-segment and T-wave changes, as well as ST-segment depression, during exercise. This is believed to be a consequence of a "digoxin-like" estrogen effect, since the changes seem 
to vary according to menstrual cycle and postmenopausal hormone replacement. ${ }^{275}$ Unlike men, ST-segment change in asymptomatic women does not correlate with mortality. In many circumstances, due to the relatively higher prevalence of false-positive traits in women, those with ST-segment depression generally receive non-cardiac diagnoses, with no additional exams or subsequent cardiac treatment. ${ }^{276}$

In men and women, a chronotropic index $<0.8$ and $\mathrm{HR}$ recovery $<12 \mathrm{bpm}$ after the first minute correlate with increased mortality and are valuable measures for prognostic evaluation.

Functional capacity, obtained though the exercise stress testing, is especially useful for athletes, besides being an independent predictor of CAD and mortality. For accurate evaluation of exercise capacity, as well as for training adjustments, an association of exercise ECG and expired gas measurements (CPET) is recommended. ${ }^{259}$

\begin{tabular}{lcc}
\hline Recommendation & $\begin{array}{c}\text { Recommendation } \\
\text { grade }\end{array}$ & $\begin{array}{c}\text { Evidence } \\
\text { level }\end{array}$ \\
\hline $\begin{array}{l}\text { Exercise stress testing in initial } \\
\text { assessment for competition or a series of } \\
\text { tests for training load adjustment }\end{array}$ & $\| \mathrm{b}$ & $\mathrm{B}$ \\
CPET (previous item) & $\mathrm{Nla}$ & $\mathrm{B}$ \\
\hline
\end{tabular}

CPET: cardiopulmonary exercise testing.

\subsection{Sudden Death}

Curiously, the occurrence of SD differs between male and female athletes. Several types of evidence indicate that SD is overwhelmingly more prevalent in male athletes. ${ }^{277-280}$ This disproportional occurrence would seem to suggest that women have some "protective factor" against heart disease, in whom $\mathrm{SD}$ is less likely than men under similar conditions. However, little is known about other factors that could be decisive in this outcome. Moreover, it has been shown that $92 \%$ of young athletes with SD were men, and that only $53 \%$ of women had some structural change. ${ }^{281}$

The proportion of women among master athletes ( $>40$ years of age) has grown. There has been much discussion about whether intense exercise over a period of many years has deleterious effects. Myocardial fibrosis, atherosclerotic plaques, and a higher incidence of atrial fibrillation have been found in some groups of athletes. ${ }^{282}$ However, whether the additional risk from very intense exercise applies equally to men and women has also been questioned. A recent metaanalysis involving more than 149,000 women ${ }^{283}$ found that moderate exercise reduces the chance of developing atrial fibrillation, especially in comparison to sedentary women, and that women who exercised intensely on a regular basis had a $28 \%$ lower risk of atrial fibrillation. In contrast, a prospective study suggested that the risk of atrial fibrillation in women followed the same pattern as in men. ${ }^{284}$ According to this study, the risk in more active women was higher than in moderately active women and similar to that of sedentary women. Thus, further investigation is necessary to better understand the relationship between exercise and atrial fibrillation in women.

\section{Basic Life Support for Athletes}

\subsection{Sudden Death among Athletes}

Although rare, SD at a sporting event causes a public commotion, especially when involving elite athletes. Statistics show that in the general population the incidence of SD during exercise is approximately 0.46 cases per 100,000 personyears. ${ }^{285}$ In young athletes this incidence is also low: (a) 0.5 for every 100,000 person-years among athletes in Minnesota; (b) 2.3 per 100,000 person-years among competitive athletes in northern Italy; ${ }^{7}$ (c) 1 to 3 for every 100,000 person-years in professional American football players. ${ }^{286}$ However, the true incidence of cardiac SD in athletes still requires further investigation. More recently, Emery and Kovacs ${ }^{144}$ pointed out that the studies estimating these events vary methodologically, diverging between the number of athletes who suffered SD (numerator) and the number of athletes at risk (denominator). In addition, some included only events that resulted in death, while others also included those who survived cardiorespiratory arrest.

Several structural and non-structural changes (channelopathies) are responsible for most cases of cardiac arrest among athletes. Studies conducted in the 1990s pointed to $\mathrm{HCM}$ as the main cause of $\mathrm{SD}^{287,288}$ and data from another experiment conclusively showed that HCM is the main cause of SD in young athletes, accounting for $26 \%$ of cases. ${ }^{289}$ Nevertheless, a meta-analysis of retrospective cohort studies, registries, and autopsy series by Ullal et al. ${ }^{290}$ challenged these conclusions: in more than 4,000 young SD victims, structurally normal hearts were the most common findings $(26.7 \%)$. Interestingly, the proportion of HCM was much lower among their sample (10.3\%). Irrespective of these controversies, however, vigorous exercise, when associated with heart disease, appears to trigger malignant events.

PPS generally consists of a detailed history, a physical examination and resting 12-lead ECG, although whether ECG should be mandatory has been debated in the international scientific community. ${ }^{5}$ An important Italian study showed that mandatory ECG use reduced the annual incidence of cardiac SD by $90 \%{ }^{291}$ The American Heart Association/American College of Cardiology question the cost-effectiveness of this strategy, the high rate of false-positive results, and the availability of qualified personnel to interpret the results. ${ }^{292}$ On the other hand, the European Society of Cardiology recommends ECG for PPS. ${ }^{35}$ Regardless of this controversy, PPS cannot eliminate SD among athletes. Thus, a second pillar must be further developed: basic life support.

\subsection{Initial Care for Athletes}

The basic emergency care strategy can be summarized as a set of actions taken in the first few minutes following a sudden cardiac event: (1) the organization and planning of an emergency response team at the activity site; (2) training first responders in cardiopulmonary resuscitation and AED use. Places where sports activities occur (e.g., training centers, schools, colleges, gymnasiums, etc.) must have a well-organized emergency care plan, including personnel trained in basic life support and fast and effective 
communication with emergency services who can perform advanced cardiac life support.

Effective treatment for an athlete who has suffered sudden cardiorespiratory arrest depends on a sequence of interdependent actions that, when linked together, form a chain reaction that increases the victim's chance of survival. The American Heart Association calls this a "chain of survival" that consists of the following links: rapid access, early cardiopulmonary resuscitation, early defibrillation and early advanced cardiac life support

Most sudden cardiorespiratory arrest in athletes is due to tachyarrhythmia (ventricular fibrillation), ${ }^{293}$ and can be treated with immediate defibrillation and cardiopulmonary resuscitation (CPR). Reducing mortality among athletes who have suffered sudden cardiorespiratory arrest requires CPR training programs and AED use, as well as personnel who can recognize emergencies, activate the emergency system, provide quality CPR, and use an AED. Current guidelines for sports facilities require the installation of strategically placed defibrillators in those with more than 2,500 patrons or those that host activities for individuals in certain at-risk groups (e.g., heart disease patients or older adults). ${ }^{294,295}$

It is a well-established fact that for each minute without $\mathrm{CPR}$, the cardiorespiratory arrest victim's chance of survival decreases from $7 \%$ to $10 \%$. However, regarding structural diseases, ventricular arrhythmias appear to be more susceptible to minor delays in defibrillation than structurally sound hearts, ${ }^{296}$ which might explain why the survival rate of athletes declines more significantly when AED use is delayed. This highlights the extreme importance of early defibrillation, the third link in the chain.

Numerous studies have documented increased survival rates due to programs promoting public access to defibrillation, including locations such as casinos, ${ }^{297}$ airports ${ }^{298}$ and airplanes. ${ }^{299}$ If resuscitation is delayed until the arrival of emergency services, survival rates are very low, around 1 to $2 \%{ }^{300}$ The use of AED in public places has led to survival rates of up to $74 \%$ for out-of-hospital cardiac arrests. ${ }^{301}$ However, due to the rarity of such events among athletes, little is known about this initiative's specific impact on them.

An important risk marker, PPS should be mandatory, since it can detect cardiovascular changes that predispose an athlete to SD. Despite differing international recommendations, there is consensus that the assessment of every athlete should include clinical history, a physical examination and 12-lead ECG, being complemented with other exams according to the degree of suspicion.

Athletes who experience SD require immediate highquality cardiopulmonary resuscitation to provide vital blood flow to the brain and heart. Defibrillation should be performed, ideally, 3 to 5 minutes after collapse to increase the chance of success. If, as in most cases, the post-shock rhythm cannot achieve effective perfusion, CPR should be restarted immediately.

Finally, periodic medical evaluation, an effective local emergency protocol, and personnel trained in basic life support can ensure high-quality CPR and early defibrillation. This, plus quick access to centers with advanced cardiac life support are fundamental for decreasing the number of SD cases in athletes and increasing their chance of survival.

\subsection{Special Aspects in Preventing Exercise/Sports-Related} Sudden Death

\subsubsection{Doping: Illicit Substances in Sports}

Some substances used for doping can have deleterious repercussions especially on the cardiovascular system, including SD. Among the most commonly used substances, we highlight anabolic steroids, ephedrine and amphetamines. Among recreational drugs, we will address the use of cocaine and 3 , 4-methylenedioxymethamphetamine, also known as ecstasy.

\subsubsection{Anabolic Steroids}

Anabolic steroids cause a number of side effects, including undesirable cardiovascular effects. Anabolic steroids can induce secondary hypertension and nephrosclerosis. Testosterone may increase the vascular response to norepinephrine and, as a consequence, promote fluid retention and elevated peripheral vascular resistance, leading to increased blood pressure.

Tagarakis et al. ${ }^{302}$ were the first to describe another important effect of steroids at the microscopic level: the adaptation of cardiac capillaries and myocytes to concomitant steroid use and physical training, which leads to a disproportionate increase of in myocardial mass in relation to the cardiac capillaries. The results of this study suggest that anabolic steroids could cause an imbalance between oxygen supply and consumption, especially during exercise. Recently, it has been shown that the long-term administration of nandrolone decanoate to rats affects the physiology of the cardiac autonomic system, resulting in a greater predisposition to cardiovascular risk and SD. In addition, discontinued usage did not result in an immediate return to normality. ${ }^{303}$ In humans, anabolic steroids may be associated with a shortened QT interval, thus negatively impacting cardiac electrical activity. ${ }^{304}$ In addition, indiscriminate use of anabolic steroids seems to be an independent risk factor for morbidity and premature death. ${ }^{305}$

\subsubsection{Ephedrine}

In general, stimulants lead to tachycardia and increased myocardial oxygen consumption, which may lead to arrhythmias and acute myocardial infarction in susceptible individuals. Ephedrine may cause symptomatic ventricular tachycardia, frequent ventricular extrasystoles, atrial fibrillation, and SD. It is important to point out that many products called "natural" or "herbal" contain ephedrine-like substances that go unmentioned in the product description.

\subsubsection{Amphetamines}

Amphetamines are the prototype central nervous system stimulants. They come in a great variety of formulas and presentations, with the most commonly used being dextroamphetamine sulfate. This substance directly stimulates adrenergic receptors at the cortical level and the 
ascending reticular activating system, and its indirect action includes displacing endogenous catecholamines from their sites in nerve endings. Its most pronounced general side effects are insomnia, dizziness, profuse sweating, tremors and euphoria; the cardiovascular effects are palpitations, tachycardia and precordial discomfort; cerebral hemorrhage is the neurological effect.

\subsubsection{Cocaine}

Cocaine causes generalized vasoconstriction, with the main consequence being hypertension. Although cocaine use causes more intense vasoconstriction in the central nervous system, it can also affect other organs such as the kidneys, resulting in glomerular, tubular, vascular and interstitial changes that lead to renal damage. ${ }^{306,307}$ Cocaine may also cause acute myocardial infarction, cardiac arrhythmias, congestive cardiomyopathy, myocarditis, subarachnoid hemorrhage, aortic rupture, rhabdomyolysis, arterial hypertension, spontaneous or exercise-induced myocardial ischemia, and cardiac SD.

\subsubsection{Ecstasy}

Ecstasy is a hallucinogen similar to amphetamine. Due to its low cost and availability in tablet form, its popularity and consumption have increased significantly. Ecstasy increases the release of serotonin, dopamine and norepinephrine by presynaptic neurons. It also prevents the metabolism of these neurotransmitters by inhibiting monoamine oxidase. Its main cardiovascular effects are hypertension, tachycardia and arrhythmias, which can lead to SD. ${ }^{308-310}$

\subsection{Evaluating Athletes and the Organization and Planning of Emergency Care}

Sports-related SD is a dramatic event, and some measures can (and should) be taken by doctors to try to prevent this rare but tragic complication of sports/exercise.

\subsubsection{Aspects Related to the Athlete}

\subsubsection{Pre-participation Screening}

Considering that, in most cases, sports-related SD is caused by known or undiagnosed heart disease, everyone who intends to participate in sports should undergo PPS, regardless of age. This clinical examination should be preceded by a thorough anamnesis with particular attention paid to family history of cardiovascular disease and SD.

PPS, in attempting to detect these pathologies, is the most efficient way to prevent a fatal cardiovascular event. ${ }^{311}$ In 2009, the International Olympic Committee published a paper on the importance of periodic medical evaluation in elite athletes. ${ }^{312,313}$

Although isolated clinical examination may fail to detect all forms of heart disease with the potential to cause SD, this procedure, whose emphasis on examining the cardiovascular system is preceded by a thorough anamnesis and previous pathological history (including family history), is nevertheless the first step in proper evaluation of the athlete.

The clinical examination should ideally include a resting 12lead ECG. Although there is disagreement between U.S. (who recommend only anamnesis and physical examination) and European authorities (who recommend adding 12-lead ECG to anamnesis and clinical examination), ${ }^{314}$ the Brazilian Society of Cardiology considers 12-lead ECG as mandatory at the first cardiological examination. ${ }^{315}$ Resting ECG can diagnose numerous heart diseases that can lead to SD, including long QT syndrome, ${ }^{316}$ Brugada syndrome, ${ }^{193}$ Wolf-ParkinsonWhite syndrome ${ }^{317}$ and HCM. ${ }^{318}$ The European protocol, which includes anamnesis, physical examination and ECG, is currently used by the International Olympic Committee, the Italian Olympic Committee, FIFA and the Union of European Football Associations. ${ }^{292,319,320}$ The clinical examination should include family and personal history and specific screening for Marfan syndrome. ${ }^{312} \mathrm{~A}$ more detailed approach to PPS is available in another section of this Guideline.

\subsubsection{Regarding the Athlete's Preparation}

Follow-up for athletes must be thorough. To prevent clinical and cardiovascular events, basic preventive measures, such as adequate nutrition and hydration are also important, respecting rest periods and avoiding training and competition during the hottest periods of the day. Athletes in training and competition must be monitored and observed by qualified medical staff, preferably who have experience in sports medicine and first aid in case of emergency.

\subsubsection{Aspects Related to Training Venues and Competition}

\subsubsection{Emergency Care and Medical Contingency Planning}

In addition to procuring the necessary equipment for cases of cardiorespiratory arrest, training and competition venues should develop a medical contingency plan that includes personnel trained in cardiorespiratory resuscitation and optimized transport to a hospital with advanced cardiac life support when applicable. ${ }^{286,321}$

\subsubsection{Automatic External Defibrillators}

The AED is a computerized device that can identify the occurrence of ventricular fibrillation and tachycardia, the cardiac abnormalities that respond to shock. These devices should be available for use in less than 5 minutes at training venues and competitions, clubs, arenas, stadiums, gyms and cardiovascular rehabilitation clinics, which should also have a team trained in cardiopulmonary resuscitation. ${ }^{145,322}$

Among young athletes, CPR arrest usually occurs after intense training sessions or during a competition. Although the occurrence of these events is rare (corresponding to $1 \%$ of those occurring in middle-aged or older adults), prompt care and successful resuscitation increase long-term survival. ${ }^{323,324}$ 


\section{Erratum}

In the "The Brazilian Society of Cardiology and Brazilian Society of Exercise and Sports Medicine Updated Guidelines for Sports and Exercise Cardiology - 2019", the following names have been omitted from the publication: Japy Angelini Oliveira Filho, associate editor and fifth name in the authorship, from the Universidade Federal de São Paulo (UNIFESP); Antonio Claudio Lucas da Nobrega, from the Universidade Federal Fluminense; Luiz Gustavo Marin Emed, from the Hospital Cardiológico Costantini; and Roberto Vital, from the Comitê Paralímpico Brasileiro (CPB) and Universidade Federal do Rio Grande Do Norte (UFRN), inserted at the end of the authorship, in this order, and their respective institutions.

\section{References}

1. Caspersen CJ, Powell KE, Christenson GM. Physical activity, exercise, and physical fitness: definitions and distinctions for health-related research. Public Health Rep. 1985;100(2):126-31

2. Araujo CG, Scharhag J. Athlete: a working definition for medical and health sciences research. Scand J Med Sci Sports. 2016;26(1):4-7.

3. Ghorayeb N, Costa RV, Castro I, Daher DJ, Oliveira Filho JA, Oliveira MA; Sociedade Brasileira de Cardiologia. [Guidelines on exercise and sports cardiology from the Brazilian Society of Cardiology and the Brazilian Society of Sports Medicine]. Arq Bras Cardiol. 2013;100(1 Suppl 2):1-41. Erratum in: Arq Bras Cardiol. 2013;100(5):488.

4. Maron BJ, Levine BD, Washington RL, Baggish AL, Kovacs RJ, Maron MS; American Heart Association Electrocardiography and Arrhythmias Committee of Council on Clinical Cardiology, Council on Cardiovascular Disease in Young, Council on Cardiovascular and Stroke Nursing, Council on Functional Genomics and Translational Biology, and American College of Cardiology. Eligibility and Disqualification Recommendations for Competitive Athletes With Cardiovascular Abnormalities: Task Force 2: Preparticipation Screening for Cardiovascular Disease in Competitive Athletes: A Scientific Statement From the American Heart Association and American College of Cardiology. Circulation. 2015;132(22):e267-72.

5. Mosterd A. Pre-participation screening of asymptomatic athletes: "don't do stupid stuff". Neth Heart J. 2018;26(3):123-6.

6. Corrado D, Basso C, Pavei A, Michieli P, Schiavon M, Thiene G. Trends in sudden cardiovascular death in young competitive athletes after implementation of a preparticipation screening program. JAMA. 2006;296(13):1593-601.

7. Corrado D, Zorzi A. Sudden death in athletes. Int J Cardiol. 2017 Jun $15 ; 237: 67-70$.

8. Schmied C, Borjesson M. Sudden cardiac death in athletes. J Intern Med. 2014;275(2):93-103.

9. De Wolf D, Matthys D. Sports preparticipation cardiac screening: what about children? Eur J Pediatr. 2014;173(6):711-9.

10. Lehman PJ, Carl RL. The preparticipation physical evaluation. Pediatr Ann. 2017;46(3):e85-e92.

11. Ackerman M, Atkins DL, Triedman JK. Sudden cardiac death in the young. Circulation. 2016;133(10):1006-26.

12. Riebe D, Franklin BA, Thompson PD, Garber CE, Whitfield GP, Magal M, et al. Updating ACSM's recommendations for exercise preparticipation health screening. Med Sci Sports Exerc. 2015;47(11):2473-9. Erratum in: Med Sci Sports Exerc. 2016;48(3):579.

13. Whitfield GP, Riebe D, Magal M, Liguori G. Applying the ACSM preparticipation screening algorithm to U.S. adults: National Health and Nutrition Examination Survey 2001-2004. Med Sci Sports Exerc. 2017;49(10):2056-63

14. Mirabelli MH, Devine MJ, Singh J, Mendoza M. The preparticipation sports evaluation. Am Fam Physician. 2015;92(5):371-6.

15. Oxborough D, Augustine D, Gati S, George K, Harkness A, Mathew T, et al. A guideline update for the practice of echocardiography in the cardiac screening of sports participants: a joint policy statement from the British Society of Echocardiography and Cardiac Risk in the Young. Echo Res Pract. 2018:5(1):G1-G10.
16. Maiorana AJ, Williams AD, Askew CD, Levinger I, Coombes J, Vicenzino $B$, et al. Exercise professionals with advanced clinical training should be afforded greater responsibility in pre-participation exercise screening: a new collaborative model between exercise professionals and physicians. Sports Med. 2018;48(6):1293-1302.

17. Corrà U, Giannuzzi P. Role of cardiopulmonary exercise testing in today's cardiovascular prevention and rehabilitation. Eur J Cardiovasc Prev Rehabil. 2006;13(4):473-4.

18. Beaumont A, Grace F, Richards J, Hough J, Oxborough D, Sculthorpe $\mathrm{N}$. Left ventricular speckle tracking-derived cardiac strain and cardiac twist mechanics in athletes: a systematic review and meta-analysis of controlled studies. Sports Med. 2017;47(6):1145-70.

19. Agir A, Bozyel S, Celikyurt U, Argan O, Yilmaz I, Karauzum K, et al. Arrhythmogenic right ventricular cardiomyopathy in pregnancy. Int Heart J. 2014;55(4):372-6.

20. Corrado D, Zorzi A, Cerrone M, Rigato I, Mongillo M, Bauce B, et al. Relationship between arrhythmogenic right ventricular cardiomyopathy and Brugada Syndrome: new insights from molecular biology and clinical implications. Circ Arrhythm Electrophysiol. 2016;9(4):e003631.

21. Halabchi F, Seif-Barghi T, Mazaheri R. Sudden cardiac death in young athletes; a literature review and special considerations in asia. Asian J Sports Med. 2011;2(1):1-15.

22. Carbone A, D'Andrea A, Riegler L, Scarafile R, Pezzullo E, Martone F, et al. Cardiac damage in athlete's heart: When the "supernormal" heart fails! World J Cardiol. 2017;9(6):470-80.

23. Bille K, Figueiras D, Schamasch P, Kappenberger L, Brenner J Meijboom FJ, et al. Sudden cardiac death in athletes: the Lausanne Recommendations. Eur J Cardiovasc Prev Rehabil. 2006;13(6):859-75.

24. Martin U, Holder R, Hodgkinson J, McManus R. Inter-arm blood pressure differences compared with ambulatory monitoring: a manifestation of the 'white-coat' effect? Br J Gen Pract. 2013;63(607):e97-103. Erratum in: Br J Gen Pract. 2013;63(610):240.

25. Grazioli G, Sanz de la Garza M, Vidal B, Montserrat S, Sarquella Brugada G, Pi R, et al. Prevention of sudden death in adolescent athletes: Incremental diagnostic value and cost-effectiveness of diagnostic tests. Eur J Prev Cardiol. 2017;24(13):1446-54.

26. Lippi G, Favaloro EJ, Sanchis-Gomar F. Sudden cardiac and noncardiac death in sports: epidemiology, causes, pathogenesis, and prevention. Semin Thromb Hemost. 2018 Jun 4. [Epub ahead of print].

27. Bohm P, Scharhag J, Meyer T. Data from a nationwide registry on sports-related sudden cardiac deaths in Germany. Eur J Prev Cardiol. $2016 ; 23(6): 649-56$

28. Riding NR, Sheikh N, Adamuz C, Watt V, Faroog A, Whyte GP, et al Comparison of three current sets of electrocardiographic interpretation criteria for use in screening athletes. Heart. 2015;101(5):384-90.

29. Sharma S, Drezner JA, Baggish A, Papadakis M, Wilson MG, Prutkin JM, et al. International recommendations for electrocardiographic interpretation in athletes. Eur Heart J. 2018;39(16):1466-80.

30. Scharhag J, Löllgen H, Kindermann W. Competitive sports and the heart: benefit or risk? Dtsch Arztebl Int. 2013;110(1-2):14-23. 
31. Panhuyzen-Goedkoop NM, Jørstad HT, Smeets JL. A new consensus document on electrocardiographic interpretation in athletes: does it help to prevent sudden cardiac death in athletes? Neth Heart J. 2018;26(3):127-32.

32. Sharma S, Papadakis M. Interpreting the Athlete's EKG: are all repolarization anomalies created equal? Circulation. 2015;131(2):12830.

33. Bessem B, De Bruijn MC, Nieuwland W, Zwerver J, Van Den Berg M. The electrocardiographic manifestations of athlete's heart and their association with exercise exposure. Eur J Sport Sci. 2018;18(4):587-93.

34. Guasch E, Mont L, Sitges M. Mechanisms of atrial fibrillation in athletes: what we know and what we do not know. Neth Heart J. 2018;26(3):13345 .

35. Dhutia H, Malhotra A, Gabus V, Merghani A, Finocchiaro G, Millar L, et al. Cost implications of using different ECG criteria for screening young athletes in the United Kingdom. J Am Coll Cardiol. 2016;68(7):702-11.

36. Thiene G, Corrado D, Basso C. Revisiting definition and classification of cardiomyopathies in the era of molecular medicine. Eur Heart J. $2008 ; 29(2): 144-6$.

37. Löllgen H, Leyk D. Exercise testing in sports medicine. Dtsch Arztebl Int 2018;115(24):409-416.

38. Meneghelo RS, Araújo CG, Stein R, Mastrocolla LE, Albuquerque PF, Serra SM, et al; Sociedade Brasileira de Cardiologia. [III Guidelines of Sociedade Brasileira de Cardiologia on the exercise test]. Arq Bras Cardiol. 2010;95(5 Suppl 1):1-26

39. Beltz NM, Gibson AL, Janot JM, Kravitz L, Mermier CM, Dalleck LC. Graded exercise testing protocols for the determination of VO2max: historical perspectives, progress, and future considerations. J Sports Med (Hindawi Publ Corp). 2016;2016:3968393.

40. Jemni M, Prince MS, Baker JS. Assessing cardiorespiratory fitness of soccer players: is test specificity the issue?-A review. Sports Med Open. 2018;4(1):28.

41. Garner KK, Pomeroy W, Arnold JJ. Exercise stress testing: indications and common questions. Am Fam Physician. 2017;96(5):293-9.

42. Myers J, Prakash M, Froelicher V, Do D, Partington S, Atwood JE. Exercise capacity and mortality among men referred for exercise testing. $\mathrm{N}$ Engl J Med. 2002;346(11):793-801

43. Franklin BA, Brinks J, Berra K, Lavie CJ, Gordon NF, Sperling LS Using metabolic equivalents in clinical practice. Am J Cardiol. 2018;121(3):382-7.

44. Kokkinos P. Physical activity, health benefits, and mortality risk. ISRN Cardiol. 2012;2012:718789.

45. Faselis C, Doumas M, Pittaras A, Narayan P, Myers J, Tsimploulis A, et al. Exercise capacity and all-cause mortality in male veterans with hypertension aged $>70$ years. Hypertension. 2014;64(1):30-5.

46. Löffler AI, Perez MV, Nketiah EO, Bourque JM, Keeley EC. Usefulness of achieving $\geq 10 \mathrm{METs}$ with a negative stress electrocardiogram to screen for high-risk obstructive coronary artery disease in patients referred for coronary angiography after exercise stress testing. Am J Cardiol. 2018;121(3):289-93.

47. Sik EC, Batt ME, Heslop LM. Atypical chest pain in athletes. Curr Sports Med Rep. 2009;8(2):52-8.

48. Moran B, Bryan S, Farrar T, Salud C, Visser G, Decuba R, et al. Diagnostic Evaluation of Nontraumatic Chest Pain in Athletes. Curr Sports Med Rep. 2017;16(2):84-94.

49. Puymirat E, Simon T, Cayla G, Cottin Y, Elbaz M, Coste P, et al; USIK, USIC 2000, and FAST-MI investigators. Acute myocardial infarction: changes in patient characteristics, management, and 6-month outcomes over a period of 20 years in the FAST-MI Program (French Registry of Acute ST-Elevation or Non-ST-Elevation Myocardial Infarction) 1995 to 2015. Circulation. 2017;136(20):1908-19.

50. Vaidya GN. Application of exercise ECG stress test in the current high cost modern-era healthcare system. Indian Heart J. 2017;69(4):551-5.
51. Katritsis GD, Katritsis DG. The electrocardiogram in athletes revisited. Arrhythm Electrophysiol Rev. 2013;2(2):99-104.

52. Ibrahim M, Hasan R, Pitonak P. Exercise-induced ST-segment elevation during the recovery phase of an exercise stress test. Exp Clin Cardiol. $2013 ; 18(2): e 92-4$

53. Azarbal B, Hayes SW, Lewin HC, Hachamovitch R, Cohen I, Berman DS. The incremental prognostic value of percentage of heart rate reserve achieved over myocardial perfusion single-photon emission computed tomography in the prediction of cardiac death and all-cause mortality: superiority over $85 \%$ of maximal age-predicted heart rate. J Am Coll Cardiol. 2004;44(2):423-30.

54. Cole CR, Foody JM, Blackstone EH, Lauer MS. Heart rate recovery after submaximal exercise testing as a predictor of mortality in a cardiovascularly healthy cohort. Ann Intern Med. 2000;132(7):552-5.

55. Frolkis JP, Pothier CE, Blackstone EH, Lauer MS. Frequent ventricular ectopy after exercise as a predictor of death. N Engl J Med. 2003;348(9):781-90. Erratum in: N Engl J Med. 2003;348(15):1508.

56. Dhoble A, Lahr BD, Allison TG, Kopecky SL. Cardiopulmonary fitness and heart rate recovery as predictors of mortality in a referral population. J Am Heart Assoc. 2014;3(2):e000559.

57. Lessa I. Medical care and deaths due to coronary artery disease in Brazil, 1980-1999. Arq Bras Cardiol. 2003;81(4):336-42.

58. Huston TP, Puffer JC, Rodney WM. The athletic heart syndrome. N Engl J Med. 1985;313(1):24-32.

59. Ulucan S, Kaya Z, Keser A, Katlandur H, Karanfil M, Ateși. Deterioration of heart rate recovery index in patients with erectile dysfunction. Anatol J Cardiol. 2016;16(4):264-9.

60. Herdy AH, Ritt LE, Stein R, Araújo CG, Milani M, Meneghelo RS, et al. Cardiopulmonary exercise test: background, applicability and interpretation. Arq Bras Cardiol. 2016;107(5):467-81.

61. Reeves T, Bates S, Sharp T, Richardson K, Bali S, Plumb J, et al Perioperative Exercise Testing and Training Society (POETTS). Cardiopulmonary exercise testing (CPET) in the United Kingdom-a national survey of the structure, conduct, interpretation and funding. Perioper Med (Lond). 2018 Jan 26;7:2. Erratum in: Perioper Med (Lond). 2018 May $4 ; 7: 8$.

62. Nadruz W Jr, West E, Sengeløv M, Santos M, Groarke JD, Forman DE, et al. Prognostic value of cardiopulmonary exercise testing in heart failure with reduced, midrange, and preserved ejection fraction. J Am Heart Assoc. 2017;6(11). pii: e006000.

63. Kleber FX, Köln PJ. Oxygen consumption trajectory flattening-yet another cardiopulmonary exercise testing parameter in chronic heart failure. Eur J Heart Fail. 2018;20(7):1125-7.

64. Morosin M, Farina S, Vignati C, Spadafora E, Sciomer S, Salvioni E, et al. Exercise performance, haemodynamics, and respiratory pattern do not identify heart failure patients who end exercise with dyspnoea from those with fatigue. ESC Heart Fail. 2018;5(1):115-9.

65. Malhotra R, Bakken K, D'Elia E, Lewis GD. Cardiopulmonary exercise testing in heart failure. JACC Heart Fail. 2016;4(8):607-16.

66. Keteyian SJ, Patel M, Kraus WE, Brawner CA, McConnell TR, Piña IL, et al; HF-ACTION Investigators. Variables measured during cardiopulmonary exercise testing as predictors of mortality in chronic systolic heart failure. J Am Coll Cardiol. 2016;67(7):780-9.

67. Bhagwat M, Paramesh K. Cardio-pulmonary exercise testing: an objective approach to pre-operative assessment to define level of perioperative care. Indian J Anaesth. 2010;54(4):286-91.

68. Belardinelli R, Lacalaprice F, Tiano L, Muçai A, Perna GP. Cardiopulmonary exercise testing is more accurate than ECG-stress testing in diagnosing myocardial ischemia in subjects with chest pain. Int J Cardiol. 2014;174(2):337-42.

69. Leischik R, Dworrak B, Foshag P, Strauss M, Spelsberg N, Littwitz H, et al. Pre-participation and follow-up screening of athletes for endurance sport. J Clin Med Res. 2015;7(6):385-92. 
70. Corrado D, Pelliccia A, Bjørnstad HH, Vanhees L, Biffi A, Borjesson M, et al; Study Group of Sport Cardiology of the Working Group of Cardiac Rehabilitation and Exercise Physiology and the Working Group of Myocardial and Pericardial Diseases of the European Society of Cardiology. Cardiovascular pre-participation screening of young competitive athletes for prevention of sudden death: proposal for a common European protocol. Consensus Statement of the Study Group of Sport Cardiology of the Working Group of Cardiac Rehabilitation and Exercise Physiology and the Working Group of Myocardial and Pericardial Diseases of the European Society of Cardiology. Eur Heart J. 2005;26(5):516-24.

71. Sharma S, Merghani A, Gati S. Cardiac screening of young athletes prior to participation in sports: difficulties in detecting the fatally flawed among the fabulously fit. JAMA Intern Med. 2015;175(1):125-7.

72. Thompson PD, Franklin BA, Balady GJ, Blair SN, Corrado D, Estes NA 3rd, et al; American Heart Association Council on Nutrition, Physical Activity, and Metabolism; American Heart Association Council on Clinical Cardiology; American College of Sports Medicine. Exercise and acute cardiovascular events placing the risks into perspective: a scientific statement from the American Heart Association Council on Nutrition, Physical Activity, and Metabolism and the Council on Clinical Cardiology. Circulation. 2007;115(17):2358-68.

73. Pelliccia A, Culasso F, Di Paolo FM, Accetura D, Cantore R, Castagna W, et al. Prevalence of abnormal electrocardiograms in a large, unselected population undergoing pre-participation cardiovascular screening. Eur Heart J. 2007;28(16):2006-10.

74. Campuzano O, Sanchez-Molero O, Fernandez A, Mademont-Soler I, Coll M, Perez-Serra A, et al. Sudden arrhythmic death during exercise: a post-mortem genetic analysis. Sports Med. 2017;47(10):2101-15.

75. Priori SG, Blomström-Lundqvist C, Mazzanti A, Blom N, Borggrefe M, Camm J, et al; ESC Scientific Document Group. 2015 ESC Guidelines for the management of patients with ventricular arrhythmias and the prevention of sudden cardiac death: The Task Force for the Management of Patients with Ventricular Arrhythmias and the Prevention of Sudden Cardiac Death of the European Society of Cardiology (ESC). Endorsed by: Association for European Paediatric and Congenital Cardiology (AEPC). Eur Heart J. 2015;36(41):2793-867.

76. Mont L, Pelliccia A, Sharma S, Biffi A, Borjesson M, BrugadaTerradellas J, et al. Pre-participation cardiovascular evaluation for athletic participants to prevent sudden death: position paper from the EHRA and the EACPR, branches of the ESC. Endorsed by APHRS, HRS, and SOLAECE. Eur J Prev Cardiol. 2017;24(1):41-69

77. Stein R, Trujillo JP, Silveira AD, Lamounier Júnior A, Iglesias LM Genetic evaluation, familial screening and exercise. Arq Bras Cardiol. 2017;108(3):263-70.

78. Marcondes L, Crawford J, Earle N, Smith W, Hayes I, Morrow P, et al; Cardiac Inherited Disease Group New Zealand. Long QT molecular autopsy in sudden unexplained death in the young (1-40 years old): Lessons learnt from an eight year experience in New Zealand. PLoS One. 2018:13(4):e0196078.

79. Rueda M, Wagner JL, Phillips TC, Topol SE, Muse ED, Lucas JR, et al. Molecular autopsy for sudden death in the young: is data aggregation the key? Front Cardiovasc Med. 2017;4:72.

80. Cooper DN, Krawczak M, Polychronakos C, Tyler-Smith C, KehrerSawatzki H. Where genotype is not predictive of phenotype: towards an understanding of the molecular basis of reduced penetrance in human inherited disease. Hum Genet. 2013;132(10):1077-130.

81. Galderisi M, Cardim N, D'Andrea A, Bruder O, Cosyns B, Davin L, et al. The multi-modality cardiac imaging approach to the Athlete's heart: an expert consensus of the European Association of Cardiovascular Imaging. Eur Heart J Cardiovasc Imaging. 2015;16(4):353.

82. Varnava A, Baboonian C, Davison F, de Cruz L, Elliott PM, Davies MJ, et al. A new mutation of the cardiac troponin T gene causing familial hypertrophic cardiomyopathy without left ventricular hypertrophy. Heart. 1999:82(5):621-4

83. Christiaans I, Lekannedit Deprez RH, van Langen IM, Wilde AA. Ventricular fibrillation in MYH7-related hypertrophic cardiomyopathy before onset of ventricular hypertrophy. Heart Rhythm. 2009;6(9):1366-9.
84. Tabib A, Loire R, Chalabreysse L, Meyronnet D, Miras A, Malicier D, et al. Circumstances of death and gross and microscopic observations in a series of 200 cases of sudden death associated with arrhythmogenic right ventricular cardiomyopathy and/or dysplasia. Circulation. 2003;108(24):3000-5.

85. Bauce B, Rampazzo A, Basso C, Mazzotti E, Rigato I, Steriotis A, et al Clinical phenotype and diagnosis of arrhythmogenic right ventricular cardiomyopathy in pediatric patients carrying desmosomal gene mutations. Heart Rhythm. 2011;8(11):1686-95.

86. Ehlermann P, Lehrke S, Papavassiliu T, Meder B, Borggrefe M, Katus HA et al. Sudden cardiac death in a patient with lamin $\mathrm{A} / \mathrm{C}$ mutation in the absence of dilated cardiomyopathy or conduction disease. Clin Res Cardiol. 2011;100(6):547-51.

87. Corrado D, Wichter T, Link MS, Hauer R, Marchlinski F, Anastasakis A et al. Treatment of arrhythmogenic right ventricular cardiomyopathy dysplasia: an international task force consensus statement. Eur Heart J. 2015:36(46):3227-37.

88. Finocchiaro G, Papadakis M, Robertus JL, Dhutia H, Steriotis AK, Tome M, et al. Etiology of sudden death in sports: insights from a United Kingdom Regional Registry. J Am Coll Cardiol. 2016;67(18):2108-15.

89. Maron BJ, Udelson JE, Bonow RO, Nishimura RA, Ackerman MJ, Estes NA 3rd, etal; American Heart Association Electrocardiography and Arrhythmias Committee of Council on Clinical Cardiology, Council on Cardiovascular Disease in Young, Council on Cardiovascular and Stroke Nursing, Council on Functional Genomics and Translational Biology, and American College of Cardiology. Eligibility and disqualification recommendations for competitive athletes with cardiovascular abnormalities: Task Force 3: Hypertrophic cardiomyopathy, arrhythmogenic right ventricular cardiomyopathy and other cardiomyopathies, and myocarditis: a Scientific Statement from the American Heart Association and American College of Cardiology. Circulation. 2015;132(22):e273-80.

90. Bagnall RD, Weintraub RG, Ingles J, Duflou J, Yeates L, Lam L, et al. A prospective study of sudden cardiac death among children and young adults. N Engl J Med. 2016;374(25):2441-52.

91. LiewAC, Vassiliou VS, Cooper R, Raphael CE. Hypertrophic cardiomyopathypast, present and future. J Clin Med. 2017;6(12). pii: E118

92. Maron BI, Haas TS, Ahluwalia A, Murphy Cl, Garberich RF. Demographics and epidemiology of sudden deaths in young competitive athletes: from the United States National Registry. Am J Med. 2016;129(11):1170-7.

93. Inciardi RM, Galderisi M, Nistri S, Santoro C, Cicoira M, Rossi A. Echocardiographic advances in hypertrophic cardiomyopathy: threedimensional and strain imaging echocardiography. Echocardiography. 2018:35(5):716-26

94. Espinola-Zavaleta N, Vega A, Basto DM, Alcantar-Fernández AC Guarner Lans V, Soto ME. Survival and clinical behavior of hypertrophic cardiomyopathy in a Latin American cohort in contrast to cohorts from the developed world. J Cardiovasc Ultrasound. 2015;23(1):20-6.

95. Geske JB, Ommen SR, Gersh BJ. Hypertrophic cardiomyopathy: clinical update. JACC Heart Fail. 2018;6(5):364-75.

96. Pasquale F, Syrris P, Kaski JP, Mogensen J, McKenna WJ, Elliott P. Long-term outcomes in hypertrophic cardiomyopathy caused by mutations in the cardiac troponin T gene. Circ Cardiovasc Genet. 2012;5(1):10-7.

97. Zhou N, Qin S, Liu Y, Tang L, Zhao W, Pan C, et al. Whole-exome sequencing identifies rare compound heterozygous mutations in the MYBPC3 gene associated with severe familial hypertrophic cardiomyopathy. Eur J Med Genet. 2018 Mar 8. [Epub ahead of print].

98. Burke MA, Cook SA, Seidman JG, Seidman CE. Clinical and mechanistic insights into the genetics of cardiomyopathy. J Am Coll Cardiol. 2016;68(25):2871-86

99. Lu QW, Wu XY, Morimoto S. Inherited cardiomyopathies caused by troponin mutations. J Geriatr Cardiol. 2013;10(1):91-101.

100. Zorzi A, Calore C, Vio R, Pelliccia A, Corrado D. Accuracy of the ECG for differential diagnosis between hypertrophic cardiomyopathy and athlete's heart: comparison between the European Society of Cardiology (2010) and International (2017) criteria. Br J Sports Med. 2018;52(10):667-673. 
101. Drezner JA, Sharma S, Baggish A, Papadakis M, Wilson MG, Prutkin JM, et al. International criteria for electrocardiographic interpretation in athletes: Consensus statement. Br J Sports Med. 2017;51(9):704-31.

102. Semsarian C; CSANZ Genetics Council Writing Group. Update on the diagnosis and management of hypertrophic cardiomyopathy. Heart Lung Circ. 2018;27(3):276-9.

103. Dominguez F, González-López E, Padron-Barthe L, Cavero MA, GarciaPavia P. Role of echocardiography in the diagnosis and management of hypertrophic cardiomyopathy. Heart. 2018;104(3):261-73.

104. Biffi A, Maron BJ, Culasso F, Verdile L, Fernando F, Di Giacinto B, et al. Patterns of ventricular tachyarrhythmias associated with training, deconditioning and retraining in elite athletes without cardiovascular abnormalities. Am J Cardiol. 2011;107(5):697-703.

105. Al-Khatib SM, Stevenson WG, Ackerman MJ, Bryant WJ1, Callans DJ, Curtis AB, et al. 2017 AHA/ACC/HRS Guideline for Management of Patients With Ventricular Arrhythmias and the Prevention of Sudden Cardiac Death: Executive Summary. Circulation. 2018;138(13):e210-e271. Erratum in: Circulation. 2018;138(13):e415-e418.

106. Kobayashi S, Sakai Y, Taguchi I, Utsunomiya H, Shiota T. Causes of an increased pressure gradient through the left ventricular outflow tract: a West Coast experience. J Echocardiogr. 2018;16(1):34-41.

107. Quarta G, Aquaro GD, Pedrotti P, Pontone G, Dellegrottaglie S, lacovoni A. Cardiovascular magnetic resonance imaging in hypertrophic cardiomyopathy: the importance of clinical context. Eur HeartJ Cardiovasc Imaging. 2018;19(6):601-10.

108. Marchesini M, Uguccioni L, Parisi R, Mattioli G, Terzi F, Olivieri R. The role of cardiac magnetic resonance imaging in hypertrophic cardiomyopathy. Rev Cardiovasc Med. 2016;17(1-2):57-64.

109. Magrì D, Santolamazza C. Cardiopulmonary exercise test in hypertrophic cardiomyopathy. Ann Am Thorac Soc. 2017; 14(Supplement_1):S102-S109.

110. Coats CJ, Rantell K, Bartnik A, Patel A, Mist B, McKenna WJ, et al. Cardiopulmonary exercise testing and prognosis in hypertrophic cardiomyopathy. Circ Heart Fail. 2015;8(6):1022-31.

111. Sharma S, Elliott P, Whyte G, Jones S, Mahon N, Whipp B, et al. Utility of cardiopulmonary exercise in the assessment of clinical determinants of functional capacity in hypertrophic cardiomyopathy. Am J Cardiol. 2000;86(2):162-8

112. Rowin EJ, Maron BJ, Olivotto I, Maron MS. Role of exercise testing in hypertrophic cardiomyopathy. JACC Cardiovasc Imaging. 2017;10(11):1374-86.

113. Hindieh W, Adler A, Weissler-Snir A, Fourey D, Harris S, Rakowski H. Exercise in patients with hypertrophic cardiomyopathy: a review of current evidence, national guideline recommendations and a proposal for a new direction to fitness. J Sci Med Sport. 2017;20(4):333-8.

114. Norrish G, Cantarutti N, Pissaridou E, Ridout DA, Limongelli G, Elliott PM, et al. Risk factors for sudden cardiac death in childhood hypertrophic cardiomyopathy: A systematic review and meta-analysis. Eur J Prev Cardiol. 2017;24(11):1220-30.

115. Weissler-Snir A, Adler A, Williams L, Gruner C, Rakowski H. Prevention of sudden death in hypertrophic cardiomyopathy: bridging the gaps in knowledge. Eur HeartJ. 2017;38(22):1728-37.

116. Maron MS, Rowin EJ, Olivotto I, Casey SA, Arretini A, Tomberli B, et al. Contemporary natural history and management of nonobstructive hypertrophic cardiomyopathy. J Am Coll Cardiol. 2016;67(12):1399-409.

117. Dejgaard LA, Haland TF, Lie OH, Ribe M, Bjune T, Leren IS, et al. Vigorous exercise in patients with hypertrophic cardiomyopathy. Int J Cardiol. 2018 Jan 1;250:157-63.

118. Tsatsopoulou A. Arrhythmogenic right ventricular cardiomyopathy and pregnancy. Int J Cardiol. 2018 May 1;258:199-200.

119. Wang W, James CA, Calkins H. Diagnostic and therapeutic strategies for arrhythmogenic right ventricular dysplasia/cardiomyopathy patient. Europace. 2018 Apr 23. [Epub ahead of print].
120. Calkins H, Corrado D, Marcus F. Risk stratification in arrhythmogenic right ventricular cardiomyopathy. Circulation. 2017;136(21):206882 .

121. Corrado D, Link MS, Calkins H. Arrhythmogenic right ventricular cardiomyopathy. N Engl J Med. 2017;376(1):61-72.

122. Tsatsopoulou A, Bossone E. Common presentation of rare diseases: arrhythmogenic right ventricular cardiomyopathy and its mimics. Int J Cardiol. 2018 Apr 15;257:371-7.

123. Etoom Y, Govindapillai S, Hamilton R, Manlhiot C, Yoo SJ, Farhan $M$, et al. Importance of CMR within the Task Force Criteria for the diagnosis of ARVC in children and adolescents. J Am Coll Cardiol. 2015;65(10):987-95

124. Zaidi A, Sheikh N, Jongman JK, Gati S, Panoulas VF, Carr-White G. Clinical differentiation between physiological remodeling and arrhythmogenic right ventricular cardiomyopathy in athletes with marked electrocardiographic repolarization anomalies. J Am Coll Cardiol. 2015;65(25):2702-11.

125. Paul M, Meyborg M, Boknik P, Gergs U, Gerss J, Schmitz W, et al. Autonomic dysfunction in patients with arrhythmogenic right ventricular cardiomyopathy: biochemical evidence of altered signaling pathways. Pacing Clin Electrophysiol. 2014;37(2):173-8.

126. La Gerche A. Defining the interaction between exercise and arrhythmogenic right ventricular cardiomyopathy. Eur J Heart Fail. 2015;17(2):128-31.

127. Haugaa KH, Bundgaard H, Edvardsen T, Eschen O, Gilljam T, Hansen J, et al. Management of patients with Arrhythmogenic Right Ventricular Cardiomyopathy in the Nordic countries. Scand Cardiovasc J. 2015;49(6):299-307

128. James CA, Bhonsale A, Tichnell C, Murray B, Russell SD, Tandri H, et al. Exercise increases age-related penetrance and arrhythmic risk in arrhythmogenic right ventricular dysplasia/cardiomyopathyassociated desmosomal mutation carriers. I Am Coll Cardiol. 2013;62(14):1290-7.

129. Wang W, Orgeron G, Tichnell C, Murray B, Crosson J, Monfredi O, et al. Impact of exercise restriction on arrhythmic risk among patients with arrhythmogenic right ventricular cardiomyopathy. J Am Heart Assoc. 2018;7(12). pii: e008843.

130. Lie OH, Dejgaard LA, Saberniak I, Rootwelt C, Stokke MK, Edvardsen T, et al. Harmful effects of exercise intensity and exercise duration in patients with arrhythmogenic cardiomyopathy. JACC Clin Electrophysiol. 2018;4(6):744-53.

131. Shah N, Phelan DM. Myocarditis in the athlete. Am Coll Cardiol. 2018 Jan 31. [Epub ahead of print].

132. Trachtenberg BH, Hare JM. Inflammatory cardiomyopathic syndromes. Circ Res. 2017;121(7):803-18.

133. Chandra N, Bastiaenen R, Papadakis M, Sharma S. Sudden cardiac death in young athletes: practical challenges and diagnostic dilemmas. J Am Coll Cardiol. 2013;61(10):1027-40.

134. Caforio AL, Pankuweit S, Arbustini E, Basso C, Gimeno-Blanes J, Felix SB, et al; European Society of Cardiology Working Group on Myocardial and Pericardial Diseases. Current state of knowledge on aetiology, diagnosis, management, and therapy of myocarditis: a position statement of the European Society of Cardiology Working Group on Myocardial and Pericardial Diseases. Eur Heart J. 2013;34(33):2636-48.

135. Sagar S, Liu PP, Cooper LT Jr. Myocarditis. Lancet. 2012;379(9817):73847.

136. Ukena C, Mahfoud F, Kindermann I, Kandolf R, Kindermann M, Bohm M. Prognostic electrocardiographic parameters in patients with suspected myocarditis. Eur J Heart Fail. 2011;13(4):398-405

137. Zorzi A, Pelliccia A, Corrado D. Inherited cardiomyopathies and sports participation. Neth Heart J. 2018;26(3):154-65.

138. Weintraub RG, Semsarian C, Macdonald P. Dilated cardiomyopathy. Lancet. 2017;390(10092):400-14. 
139. McNally EM, Mestroni L. Dilated cardiomyopathy: genetic determinants and mechanisms. Circ Res. 2017;121(7):731-48.

140. Pi SH, Kim SM, Choi JO, Kim EK, Chang SA, Choe YH, et al. Prognostic value of myocardial strain and late gadolinium enhancement on cardiovascular magnetic resonance imaging in patients with idiopathic dilated cardiomyopathy with moderate to severely reduced ejection fraction. J Cardiovasc Magn Reson. 2018;20(1):36.

141. Merlo M, Cannatà A, Gobbo M, Stolfo D, Elliott PM, Sinagra G. Evolving concepts in dilated cardiomyopathy. Eur J Heart Fail. 2018;20(2):228-39.

142. Asif IM, Harmon KG. Incidence and etiology of sudden cardiac death: new updates for athletic departments. Sports Health. 2017;9(3):268-79.

143. Asatryan B, Vital C, Kellerhals C, Medeiros-Domingo A, Gräni C, Trachsel LD, et al. Sports-related sudden cardiac deaths in the young population of Switzerland. PLoS One. 2017;12(3):e0174434.

144. Emery MS, Kovacs RJ. Sudden cardiac death in athletes. JACC Heart Fail. 2018;6(1):30-40.

145. Herdy AH, López-Jimenez F, Terzic CP, Milani M, Stein R, Carvalho T, et al; Sociedade Brasileira de Cardiologia. South American Guidelines for Cardiovascular Disease Prevention and Rehabilitation. Arq Bras Cardiol. 2014;103(2 Supl.1):1-31.

146. Towbin JA, Lorts A, Jefferies JL. Left ventricular non-compaction cardiomyopathy. Lancet. 2015;386(9995):813-25.

147. Sedaghat-Hamedani F, Haas J, Zhu F, Geier C, Kayvanpour E, Liss M, et al. Clinical genetics and outcome of left ventricular non-compaction cardiomyopathy. Eur Heart J. 2017;38(46):3449-60.

148. Hotta VT, Tendolo SC, Rodrigues AC, Fernandes F, Nastari L, Mady C Limitations in the diagnosis of noncompaction cardiomyopathy by echocardiography. Arq Bras Cardiol. 2017;109(5):483-8.

149. Finsterer J, Stöllberger C, Towbin JA. Left ventricular noncompaction cardiomyopathy: cardiac, neuromuscular, and genetic factors. Nat Rev Cardiol. 2017; 14(4):224-37.

150. Thavendiranathan P, Dahiya A, Phelan D, Desai MY, Tang WH. Isolated left ventricular non-compaction controversies in diagnostic criteria, adverse outcomes and management. Heart. 2013;99(10):681-9.

151. Ganga HV, Thompson PD. Sports participation in non-compaction cardiomyopathy: a systematic review. Br J Sports Med. 2014;48(20):1466-71.

152. Coris EE, Moran BK, De Cuba R, Farrar T, Curtis AB. Left ventricular non-compaction in athletes: to play or not to play. Sports Med. 2016;46(9):1249-59.

153. Gati S, Chandra N, Bennett RL, Reed M, Kervio G, Panoulas VF, et al Increased left ventricular trabeculation in highly trained athletes: do we need more stringent criteria for the diagnosis of left ventricular noncompaction in athletes? Heart. 2013;99(6):401-8. Erratum in: Heart. 2013;99(7):506

154. Caselli S, Ferreira D, Kanawati E, Di Paolo F, Pisicchio C, Attenhofer Jost $\mathrm{C}$, et al. Prominent left ventricular trabeculations in competitive athletes: a proposal for risk stratification and management. Int J Cardiol. $2016 \mathrm{Nov}$ $15 ; 223: 590-5$.

155. Monge-Maillo B, López-Vélez R. Challenges in the management of Chagas disease in Latin-American migrants in Europe. Clin Microbiol Infect. 2017;23(5):290-5.

156. Cucunubá ZM, Okuwoga O, Basáñez MG, Nouvellet P. Increased mortality attributed to Chagas disease: a systematic review and meta-analysis. Parasit Vectors. 2016 Jan 27;9:42.

157. Traina MI, Hernandez S, Sanchez DR, DufaniJ, Salih M, Abuhamidah AM, et al. Prevalence of Chagas Disease in a U.S. population of Latin American immigrants with conduction abnormalities on electrocardiogram. PLoS Negl Trop Dis. 2017;11(1):e0005244.

158. Merejo Peña CM, Reis MS, Pereira BB, Nascimento EM, Pedrosa RC. Dysautonomy in different death risk groups (Rassi score) in patients with Chagas heart disease. Pacing Clin Electrophysiol. 2018;41(3):238-45.
159. Gadioli LP, Miranda CH, Pintya AO, de Figueiredo AB, Schmidt A, Macie $\mathrm{BC}$, et al. The severity of ventricular arrhythmia correlates with the extent of myocardial sympathetic denervation, but not with myocardial fibrosis extent in chronic Chagas cardiomyopathy: Chagas disease, denervation and arrhythmia. J Nucl Cardiol. 2018;25(1):75-83.

160. Costa HS, Nunes MC, Souza AC, Lima MM, Carneiro RB, Sousa GR, et al Exercise-induced ventricular arrhythmias and vagal dysfunction in Chagas disease patients with no apparent cardiac involvement. Rev Soc Bras Med Trop. 2015;48(2):175-80.

161. Tassi EM, Continentino MA, do Nascimento EM, Pereira BB, Pedrosa RC. Relationship between fibrosis and ventricular arrhythmias in Chagas heart disease without ventricular dysfunction. Arq Bras Cardiol. 2014;102(5):456-64.

162. Matos LD, Azevedo LF, Brum PC, Sosa EA, Martinelli M, Negrão CE. Long distance runner with dilated cardiomyopathy and excellent performance. Arq Bras Cardiol. 2011;96(1):e3-6.

163. Panhuyzen-Goedkoop NM, Wilde AA. Athletes with channelopathy may be eligible to play. Neth Heart J. 2018;26(3):146-53.

164. Garg P, Garg V, Shrestha R, Sanguinetti MC, Kamp TJ, Wu JC. Human induced pluripotent stem cell-derived cardiomyocytes as models for cardiac channelopathies: a primer for non-electrophysiologists. Circ Res. 2018;123(2):224-43

165. Despa S, Vigmond E. From single myocyte to whole heart: the intricate dance of electrophysiology and modeling. Circ Res. 2016;118(2):184-6.

166. Fonseca DJ, Vaz da Silva MJ. Cardiac channelopathies: the role of sodium channel mutations. Rev Port Cardiol. 2018;37(2):179-99.

167. Lazzerini PE, Capecchi PL, Laghi-Pasini F, Boutjdir M. Autoimmune channelopathies as a novel mechanism in cardiac arrhythmias. Nat Rev Cardiol. 2017;14(9):521-35.

168. Etheridge SP, Saarel EV, Martinez MW. Exercise participation and shared decision-making in patients with inherited channelopathies and cardiomyopathies. Heart Rhythm. 2018;15(6):915-20.

169. Jervell A, Lange-Nielsen F. Congenital deaf-mutism, functional heart disease with prolongation of the Q-T interval and sudden death. Am Heart J. 1957;54(1):59-68.

170. Schwartz PJ, Crotti L, Insolia R. Long-QT syndrome: from genetics to management. Circ Arrhythm Electrophysiol. 2012;5(4):868-77. Erratum in: Circ Arrhythm Electrophysiol. 2012;5(6):e119-20.

171. Garcia-Elias A, Benito B. Ion channel disorders and sudden cardiac death Int J Mol Sci. 2018;19(3). pii: E692.

172. Mazzanti A, Maragna R, Vacanti G, Monteforte N, Bloise R, Marino M, et al . Interplay between genetic substrate, QTc duration, and arrhythmia risk in patients with long QT syndrome. J Am Coll Cardiol. 2018;71(15):1663-71.

173. Moreno C, Oliveras A, Bartolucci C, Muñoz C, de la Cruz A, Peraza DA, et al. D242N, a KV7.1 LQTS mutation uncovers a key residue for IKs voltage dependence. J Mol Cell Cardiol. 2017 Sep;110:61-69.

174. Liu L, Tian J, Lu C, Chen X, Fu Y, Xu B, et al. Electrophysiological Characteristics of the LQT2 Syndrome Mutation KCNH2-G572S and Regulation by Accessory Protein KCNE2. Front Physiol. 2016 Dec $27 ; 7: 650$.

175. Jackson HA, Accili EA. Evolutionary analyses of KCNQ1 and HERC voltagegated potassium channel sequences reveal location-specific susceptibility and augmented chemical severities of arrhythmogenic mutations. BMC Evol Biol. 2008 Jun 30;8:188.

176. Zimmer T, Surber R. SCN5A channelopathies--an update on mutations and mechanisms. Prog Biophys Mol Biol. 2008;98(2-3):120-36.

177. Wilde AA, Moss AJ, Kaufman ES, Shimizu W, Peterson DR, Benhorin J, et al Clinical aspects of type 3 long-QT syndrome: an International Multicenter Study. Circulation. 2016;134(12):872-82.

178. Priori SG, Schwartz PJ, Napolitano C, Bloise R, Ronchetti E, Grillo $M$, et al. Risk stratification in the long-QT syndrome. N Engl J Med. 2003;348(19):1866-74 
179. Aziz PF, Sweeten T, Vogel RL, Bonney WJ, Henderson J, Patel AR, et al. Sports participation in genotype positive children with long QT syndrome. JACC Clin Electrophysiol. 2015;1(1-2):62-70.

180. Ackerman MJ, Zipes DP, Kovacs RJ, Maron BJ. Eligibility and disqualification recommendations for competitive athletes with cardiovascular abnormalities: task force 10: the cardiac channelopathies: a scientific statement from the American Heart Association and American College of Cardiology. J Am Coll Cardiol. 2015;66(21):2424-8.

181. Steinberg C. Diagnosis and clinical management of long-QT syndrome. Curr Opin Cardiol. 2018;33(1):31-41.

182. Ahn J, Kim HJ, Choi JI, Lee KN, Shim J, Ahn HS, et al. Effectiveness of betablockers depending on the genotype of congenital long-QT syndrome: a meta-analysis. PLoS One. 2017;12(10):e0185680.

183. Pérez-Riera AR, Barbosa-Barros R, Daminello Raimundo R, da Costa de Rezende Barbosa MP, Esposito Sorpreso IC, de Abreu LC. The congenital long QT syndrome Type 3: an update. Indian Pacing Electrophysiol J. 2018;18(1):25-35

184. Shah SR, Park K. Long QT syndrome: a comprehensive review of the literature and current evidence. Curr Probl Cardiol. 2018 May 10. pii: S0146-2806(18)30051-3.

185. Bjerregaard P. Diagnosis and management of short QT syndrome. Heart Rhythm. 2018;15(8):1261-7.

186. Sharma S, Drezner JA, Baggish A, Papadakis M, Wilson MG, Prutkin JM, et al. International recommendations for electrocardiographic interpretation in athletes. J Am Coll Cardiol. 2017;69(8):1057-75.

187. Cubeddu LX. Drug-induced inhibition and trafficking disruption of ion channels: pathogenesis of QT abnormalities and drug-induced fatal arrhythmias. Curr Cardiol Rev. 2016;12(2):141-54.

188. El-Battrawy I, Lan H, Cyganek L, Zhao Z, Li X, Buljubasic F, et al. Modeling short QT syndrome using human-induced pluripotent stem cell-derived cardiomyocytes. J Am Heart Assoc. 2018;7(7). pii: e007394.

189. Gaita F, Giustetto C, Bianchi F, Schimpf R, Haissaguerre M, Calò L, et al. Short QT syndrome: pharmacological treatment. J Am Coll Cardiol. 2004:43(8):1494-9.

190. Mondoly P, Cardin C, Rollin A, Duparc A, Maury P. Use of a subcutaneous ICD in a patient with short QT syndrome. Clin Case Rep. 2015;4(1):35-8.

191. Schimpf R, Wolpert C, Bianchi F, Giustetto C, Gaita F, Bauersfeld U, et al. Congenital short QT syndrome and implantable cardioverter defibrillator treatment: inherent risk for inappropriate shock delivery. J Cardiovasc Electrophysiol. 2003;14(12):1273-7.

192. Gourraud JB, Barc J, Thollet A, Le Marec H, Probst V. Brugada syndrome: diagnosis, risk stratification and management. Arch Cardiovasc Dis. 2017;110(3):188-95.

193. Argenziano M, Antzelevitch C. Recent advances in the treatment of Brugada syndrome. Expert Rev Cardiovasc Ther. 2018;16(6):387-404.

194. Antzelevitch C, Yan GX, Ackerman MJ, Borggrefe M, Corrado D, Guo J, et al. J-Wave syndromes expert consensus conference report: emerging concepts and gaps in knowledge. Europace. 2017;19(4):665-694.

195. Ghouse J, Have CT, Skov MW, Andreasen L, Ahlberg G, Nielsen JB, et al. Numerous Brugada syndrome-associated genetic variants have no effect on J-point elevation, syncope susceptibility, malignant cardiac arrhythmia, and all-cause mortality. Genet Med. 2017;19(5):521-8.

196. Gray B, Hasdemir C, Ingles J, Aiba T, Makita N, Probst V, et al. Lack of genotype-phenotype correlation in Brugada syndrome and sudden arrhythmic death syndrome families with reported pathogenic SCN1B variants. Heart Rhythm. 2018;15(7):1051-1057.

197. Wu W, Tian L, Ke J, Sun Y, Wu R, Zhu J, et al. Risk factors for cardiac events in patients with Brugada syndrome: a PRISMA-compliant meta-analysis and systematic review. Medicine (Baltimore). 2016;95(30):e4214.

198. Antzelevitch C, Brugada P, Borggrefe M, Brugada J, Brugada R, Corrado $\mathrm{D}$, et al. Brugada syndrome: report of the second consensus conference. Heart Rhythm. 2005;2(4):429-40.
199. Pérez-Riera AR, Barbosa-Barros R, de Rezende Barbosa MP, DaminelloRaimundo R, de Lucca AA Jr, de Abreu LC. Catecholaminergic polymorphic ventricular tachycardia, an update. Ann Noninvasive Electrocardiol. 2018;23(4):e12512.

200. Kannankeril PJ, Moore JP, Cerrone M, Priori SG, Kertesz NJ, Ro PS, et al Efficacy of flecainide in the treatment of catecholaminergic polymorphic ventricular tachycardia: a randomized clinical trial. JAMA Cardiol. 2017;2(7):759-66.

201. Li N, Wang Q, Sibrian-Vazquez M, Klipp RC, Reynolds JO, Word TA, et al. Treatment of catecholaminergic polymorphic ventricular tachycardia in mice using novel RyR2-modifying drugs. Int J Cardiol. 2017 Jan 15;227:668-73.

202. Sumitomo N. Current topics in catecholaminergic polymorphic ventricular tachycardia. J Arrhythm. 2016;32(5):344-51.

203. Wall JJ, lyer RV. Catecholaminergic polymorphic ventricular tachycardia. Pediatr Emerg Care. 2017;33(6):427-431.

204. Roston TM, Vinocur JM, Maginot KR, Mohammed S, Salerno JC, Etheridge $\mathrm{SP}$, et al. Catecholaminergic polymorphic ventricular tachycardia in children: analysis of therapeutic strategies and outcomes from an international multicenter registry. Circ Arrhythm Electrophysiol. 2015;8(3):633-42.

205. Priori SG, Napolitano C, Memmi M, Colombi B, Drago F, Gasparini M, et al Clinical and molecular characterization of patients with catecholaminergic polymorphic ventricular tachycardia. Circulation. 2002;106(1):69-74.

206. Imberti JF, Underwood K, Mazzanti A, Priori SG. Clinical challenges in catecholaminergic polymorphic ventricular tachycardia. Heart Lung Circ. 2016;25(8):777-83.

207. Liu N, Ruan Y, Priori SG. Catecholaminergic polymorphic ventricular tachycardia. Prog Cardiovasc Dis. 2008;51(1):23-30.

208. Xiong J, Liu X, Gong Y, Zhang P, Qiang S, Zhao Q, et al. Pathogenic mechanism of a catecholaminergic polymorphic ventricular tachycardia causing-mutation in cardiac calcium release channel RyR2. J Mol Cell Cardiol. 2018 Apr;117:26-35.

209. Ackerman MJ, Priori SG, Dubin AM, Kowey P, Linker NJ, Slotwiner D, et al. Beta-blocker therapy for long QT syndrome and catecholaminergic polymorphic ventricular tachycardia: Are all beta-blockers equivalent? Heart Rhythm. 2017;14(1):e41-e44.

210. Nishimura RA, Otto CM, Bonow RO, Carabello BA, Erwin JP 3rd, Guyton RA, et al; American College of Cardiology/American Heart Association Task Force on Practice Guidelines. 2014 AHA/ACC guideline for the management of patients with valvular heart disease: a report of the American College of Cardiology/American Heart Association Task Force on Practice Guidelines. J Am Coll Cardiol. 2014;63(22):2438-88. Erratum in: J Am Coll Cardiol. 2014;63(22):2489.

211. Siu SC, Silversides CK. Bicuspid aortic valve disease. J Am Coll Cardiol. 2010;55(25):2789-800.

212. Taniguchi T, Morimoto T, Shiomi H, Ando K, Kanamori N, Murata K, et al; CURRENT AS Registry Investigators. Sudden death in patients with severe aortic stenosis: observations from the CURRENT AS registry. J Am Heart Assoc. 2018;7(11). pii: e008397.

213. Kanwar A, Thaden JJ, Nkomo VT. Management of patients with aortic valve stenosis. Mayo Clin Proc. 2018;93(4):488-508.

214. Maron BJ. Sudden death in young athletes. N Engl J Med. 2003;349(11):1064-75.

215. Tarasoutchi F, Montera MW, Ramos Al, Sampaio RO, Rosa VE, Accorsi TA, et al. Atualização das Diretrizes Brasileiras de Valvopatias: Abordagem das Lesões Anatomicamente Importantes. Arq Bras Cardiol. 2017;109(6 Supl. 2):1-34.

216. Baumgartner $\mathrm{H}$, Otto $\mathrm{CM}$. Aortic stenosis severity: do we need a new concept? J Am Coll Cardiol. 2009;54(11):1012-3

217. Mantini C, Di Giammarco G, Pizzicannella J, Gallina S, Ricci F, D'Ugo E, et al. Grading of aortic stenosis severity: a head-to-head comparison between cardiac magnetic resonance imaging and echocardiography. Radiol Med. $2018 ; 123(9): 643-54$. 
218. Saeed S, Rajani R, Seifert R, Parkin D, Chambers JB. Exercise testing in patients with asymptomatic moderate or severe aortic stenosis. Heart. 2018 Apr 13. [Epub ahead of print].

219. Nadeau-Routhier C, Marsit O, Beaudoin J. Current management of patients with severe aortic regurgitation. Curr Treat Options Cardiovasc Med. 2017;19(2):9.

220. Zoghbi WA, Enriquez-Sarano M, Foster E, Grayburn PA, Kraft CD, Levine RA, et al; American Society of Echocardiography. Recommendations for evaluation of the severity of native valvular regurgitation with twodimensional and Doppler echocardiography. J Am Soc Echocardiogr. 2003;16(7):777-802.

221. Cawley PJ, Hamilton-Craig C, Owens DS, Krieger EV, Strugnell WE, Mitsumori L, et al. Prospective of valve regurgitation quantitation by cardiac magnetic resonance imaging and transthoracic echocardiography. Circ Cardiovasc Imaging. 2013;6(1):48-57.

222. Gabriel RS, Renapurkar R, Bolen MA, Verhaert D, Leiber M, Flamm SD, et al. Comparison of severity of aortic regurgitation by cardiovascular magnetic resonance versus transthoracic echocardiography. Am J Cardiol. 2011;108(7):1014-20.

223. Pelliccia A, Culasso F, Di Paolo FM, Maron BJ. Physiologic left ventricular cavity dilatation in elite athletes. Ann Intern Med. 1999;130(1):23-31.

224. Pelliccia A, Kinoshita N, Pisicchio C, Quattrini F, Dipaolo FM, Ciardo R, et al. Long-term clinical consequences of intense, uninterrupted endurance training in Olympic athletes. J Am Coll Cardiol. 2010;55(15):1619-25.

225. Pelliccia A, Maron BJ, Culasso F, Spataro A, Caselli G. Athlete's heart in women: echocardiographic characterization of highly trained elite female athletes. JAMA. 1996;276(3):211-5.

226. Dujardin KS, Enriquez-Sarano M, Schaff HV, Bailey KR, Seward JB, Tajik AJ. Mortality and morbidity of aortic regurgitation in clinical practice: a long-term follow-up study. Circulation. 1999;99(14):1851-7.

227. Bonow RO, Lakatos E, Maron BJ, Epstein SE. Serial long-term assessment of the natural history of asymptomatic patients with chronic aortic regurgitation and normal left ventricular systolic function. Circulation. 1991;84(4):1625-35.

228. Yoon SH, Maeno Y, Kawamori H, Miyasaka M, Nomura T, Ochiai T, et al. Diagnosis and outcomes of transcatheter aortic valve implantation in bicuspid aortic valve stenosis. Interv Cardiol. 2018;13(2):62-5

229. Martín M, Lorca R, Rozado J, Alvarez-Cabo R, Calvo J, Pascual I, et al. Bicuspid aortic valve syndrome: a multidisciplinary approach for a complex entity. J Thorac Dis. 2017;9(Suppl 6):S454-S464

230. Svensson LG, Kim KH, Lytle BW, Cosgrove DM. Relationship of aortic crosssectional area to height ratio and the risk of aortic dissection in patients with bicuspid aortic valves. J Thorac Cardiovasc Surg. 2003;126(3):892-3.

231. Parker MW, Thompson PD. Exercise in valvular heart disease: risks and benefits. Prog Cardiovasc Dis. 2011;53(6):437-46

232. Harb SC, Griffin BP. Mitral valve disease: a comprehensive review. Curr Cardiol Rep. 2017;19(8):73.

233. Rahimtoola SH, Durairaj A, Mehra A, Nuno I. Current evaluation and management of patients with mitral stenosis. Circulation. 2002;106(10):1183-8

234. Sandoval Y, Sorajja P, Harris KM. Contemporary management of ischemic mitral regurgitation: a review. Am J Med. 2018;131(8):887-95

235. Bonow RO. Chronic mitral regurgitation and aortic regurgitation: have indications for surgery changed? J Am Coll Cardiol. 2013;61(7):693-701.

236. Parwani P, Avierinos JF, Levine RA, Delling FN. Mitral valve prolapse: multimodality imaging and genetic insights. Prog Cardiovasc Dis. 2017;60(3):361-9.

237. Thacoor A. Mitral valve prolapse and Marfan syndrome. Congenit Heart Dis. $2017: 12(4): 430-4$

238. Freed LA, Levy D, Levine RA, Larson MG, Evans JC, Fuller DL, et al. Prevalence and clinical outcome of mitral-valve prolapse. N Engl J Med. 1999;341(1):1-7.
239. Narayanan K, Uy-Evanado A, Teodorescu C, Reinier K, Nichols GA Gunson K, et al. Mitral valve prolapse and sudden cardiac arrest in the community. Heart Rhythm. 2016;13(2):498-503.

240. Delling FN, Rong J, Larson MG, Lehman B, Fuller D, Osypiuk E, et al Evolution of mitral valve prolapse: insights from the Framingham heart study. Circulation. 2016;133(17):1688-95.

241. Basso C, Perazzolo Marra M, Rizzo S, De Lazzari M, Giorgi B, Cipriani A, et al. Arrhythmic mitral valve prolapse and sudden cardiac death. Circulation. 2015;132(7):556-66

242. Caselli S, Mango F, Clark J, Pandian NG, Corrado D, Autore C, et al Prevalence and clinical outcome of athletes with mitral valve prolapse. Circulation. 2018:137(19):2080-2.

243. Corrado D, Basso C, Nava A, Rossi L, Thiene G. Sudden death in young people with apparently isolated mitral valve prolapse. G Ital Cardiol. 1997;27(11):1097-105.

244. Glesby MJ, Pyeritz RE. Association of mitral valve prolapse and systemic abnormalities of connective tissue: a phenotypic continuum. JAMA $1989 \cdot 262(4): 523-8$

245. Rippe M, De Backer J, Kutsche K, Mosquera LM, Schüler H, Rybczynski $M$, et al. Mitral valve prolapse syndrome and MASS phenotype: Stability of aortic dilatation but progression of mitral valve prolapse. Int J Cardiol Heart Vasc. 2016 Jan 21;10:39-46

246. Graffunder FP, Sties SW, Gonzáles AI, de Carvalho T. Differential diagnosis of Marfan syndrome in a teenage volleyball athlete. Int J Cardiovasc Sci. 2017;30(2):181-4.

247. Cevasco M, Shekar PS. Surgical management of tricuspid stenosis. Ann Cardiothorac Surg. 2017;6(3):275-82.

248. Arsalan M, Walther T, Smith RL 2nd, Grayburn PA. Tricuspid regurgitation diagnosis and treatment. Eur Heart J. 2017;38(9):634-8.

249. Badano LP, Agricola E, Perez de Isla L, Gianfagna P, Zamorano JL. Evaluation of the tricuspid valve morphology and function by transthoracic real-time threedimensional echocardiography. Eur J Echocardiogr. 2009;10(4):477-84

250. Unger P, Clavel MA, Lindman BR, Mathieu P, Pibarot P. Pathophysiology and management of multivalvular disease. Nat Rev Cardiol. 2016;13(7):429-40.

251. Rahimtoola SH. Choice of prosthetic heart valve for adult patients. J Am Coll Cardiol. 2003;41(6):893-904.

252. Cahill TJ, Chen M, Hayashida K, Latib A, Modine T, Piazza N, et al Transcatheter aortic valve implantation: current status and future perspectives. Eur Heart J. 2018;39(28):2625-34

253. Pressler A, Christle JW, Lechner B, Grabs V, Haller B, Hettich I, et al. Exercise training improves exercise capacity and quality of life after transcathete aortic valve implantation: a randomized pilot trial. Am Heart J. 2016 Dec;182:44-53.

254. Völler H, Salzwedel A, Nitardy A, Buhlert H, Treszl A, Wegscheider K. Effect of cardiac rehabilitation on functional and emotional status in patients after transcatheter aortic-valve implantation. Eur J Prev Cardiol. 2015;22(5):568-74.

255. Tarro Genta F, Tidu M, Bouslenko Z, Bertolin F, Salvetti I, Comazzi F, et al. Cardiac rehabilitation after transcatheter aortic valve implantation compared to patients after valve replacement. J Cardiovasc Med (Hagerstown). 2017;18(2):114-20.

256. Russo N, Compostella L, Tarantini G, Setzu T, Napodano M, Bottio T, et al. Cardiac rehabilitation after transcatheter versus surgical prosthetic valve implantation for aortic stenosis in the elderly. Eur J Prev Cardiol. 2014;21(11):1341-8.

257. Abdul-Jawad Altisent O, Puri R, Regueiro A, Chamandi C, RodriguezGabella T, Del Trigo M, et al. Predictors and association with clinical outcomes of the changes in exercise capacity after transcatheter aortic valve replacement. Circulation. 2017;136(7):632-43.

258. Thein-Nissenbaum J, Hammer E. Treatment strategies for the female athlete triad in the adolescent athlete: current perspectives. Open Access J Sports Med. 2017 Apr 4;8:85-95. 
259. Sharma S. Athlete's heart - effect of age, sex, ethnicity and sporting discipline. Exp Physiol. 2003;88(5):665-9.

260. Finochiaro G, Sharma S. Do endurance sports affect female hearts differently from male hearts? Future Cardiol. 2016;12(2):105-8.

261. Pelliccia A, Maron BJ, Culasso F, Di Paolo FM, Spataro A, Biffi A, et al. Clinical significance of abnormal electrocardiographic patterns in trained athletes. Circulation. 2000;102(3):278-84.

262. Drezner JA, Ackerman MJ, Anderson J, Ashley E, Asplund CA, Baggish AL, et al. Electrocardiographic interpretation in athletes: the 'Seattle criteria'. Br J Sports Med. 2013;47(3):122-4

263. Wasfy MM, DeLuca J, Wang F, Berkstresser B, Ackerman KE, Eisman $A$, et al. ECG findings in competitive rowers: normative data and the prevalence of abnormalities using contemporary screening recommendations. Br J Sports Med. 2015;49(3):200-6.

264. Finocchiaro G, Dhutia H, D'Silva A, Malhotra A, Steriotis A, Millar L, et al. Effect of sex and sporting discipline on LV adaptation to exercise. JACC Cardiovasc Imaging. 2017;10(9):965-72.

265. Serratosa-Fernández L, Pascual-Figal D, Masiá-Mondéjar MD, Sanzde laGarza M, Madaria-Marijuan Z, Gimeno-Blanes JR, et al; Grupo de Cardiología del Deporte de la Sociedad Española de Cardiología. Comments on the New International Criteria for Electrocardiographic Interpretation in Athletes. Rev Esp Cardiol (Engl Ed). 2017;70(11):983-90.

266. Malhotra A, Dhutia H, Gati S, Yeo TJ, Dores H, Bastiaenen R, et al. Anterior T-wave inversion in young white athletes and nonathletes: prevalence and significance. J Am Coll Cardiol. 2017;69(1):1-9.

267. Petek BJ, Wasfy MM. Cardiac adaption to exercise training: the female athlete. Curr Treat Options Cardiovasc Med. 2018;20(8):68.

268. Sheikh N, Papadakis M, Schnell F, Panoulas V, Malhotra A, Wilson M, et al. Clinical profile of athletes with hypertrophic cardiomyopathy. Circ Cardiovasc Imaging. 2015;8(7):e003454.

269. Malhotra A, Dhutia H, Gati S, Dores H, Meller L, Merghani R, et al. Prevalence and significance of anterior $\mathrm{T}$ wave inversion in females. Heart. 2014;100(Suppl 3):A60.

270. Pickham D, Zarafshar S, Sani D, Kumar N, Froelicher V. Comparison of three ECG criteria for athlete pre-participation screening. J Electrocardiol. 2014;47(6):769-74.

271. Rawlins J, Carre F, Kervio G, Papadakis M, Chandra N, Edwards C, et al. Ethnic differences in physiological adaptation to intense physical exercise in highly trained female athletes. Circulation. 2010;121(9):1078-85.

272. Caselli S, Maron MS, Urbano-Moral JA, Pandian NG, Maron B] Pelliccia A. Differentiating left ventricular hypertrophy in athletes from that in patients with hypertrophic cardiomyopathy. Am J Cardiol. 2014;114(9):1383-9.

273. Brosnan MJ, Rakhit D. Differentiating athlete's heart from cardiomyopathies: the left side. Heart Lung Circ. 2018;27(9):1052-62.

274. D'Ascenzi F, Pelliccia A, Natali BM, Zacà V, Cameli M, Alvino F, et al. Morphological and functional adaptation of left and right atria induced by training in highly trained female athletes. Circ Cardiovasc Imaging. 2014;7(2):222-9.

275. Gulati M, Pratap P, Kansal P, Calvin JE Jr, Hendel RC. Gender differences in the value of ST-segment depression during adenosine stress testing. Am J Cardiol. 2004;94(8):997-1002.

276. Sharma S, Mehta PK, Arsanjani R, Sedlak T, Hobel Z, Shufelt C, et al. False-positive stress testing: Does endothelial vascular dysfunction contribute to ST-segment depression in women? A pilot study. Clin Cardiol. 2018;41(8):1044-8.

277. Mathews SC, Narotsky DL, Bernholt DL, Vogt M, Hsieh YH, Pronovost PJ, et al. Mortality among marathon runners in the United States, 20002009. Am J Sports Med. 2012;40(7):1495-500.

278. Maron BJ, Haas TS, Murphy CJ, Ahluwalia A, Rutten-Ramos S. Incidence and causes of sudden death in U.S. college athletes. J Am Coll Cardiol. 2014;63(16):1636-43.
279. Harmon KG, Asif IM, Maleszewski JJ, Owens DS, Prutkin JM, Salerno $\mathrm{JC}$, et al. Incidence and etiology of sudden cardiac arrest and death in high school athletes in the United States. Mayo Clin Proc. 2016;91(11):1493-502.

280. Harris KM Creswell LL, Haas TS, Thomas T, Tung M, Isaacson E, et al. Death and cardiac arrest in U.S. triathlon participants, 1985 to 2016: a case series. Ann Intern Med. 2017;167(8):529-35.

281. Finocchiaro G, Papadakis M, Robertus JL, Mellor G, Behr E, Sharma S, et al. Sudden death in sport: insights from a national pathology referral center. Eur Heart J. 2015;36(Suppl 1):332.

282. Estes NA 3rd, Madias C. Atrial fibrillation in athletes: a lesson in the virtue of moderation. JACC Clin Electrophysiol. 2017;3(9):921-8.

283. Mohanty S, Mohanty P, Tamaki M, Natale V, Gianni C, Trivedi C, et al. Differential Association of Exercise Intensity With Risk of Atrial Fibrillation in Men and Women: Evidence from a Meta-Analysis. J Cardiovasc Electrophysiol. 2016;27(9):1021-9.

284. Morseth B, Graff-Iversen S, Jacobsen BK, Jørgensen L, Nyrnes A, Thelle DS, et al. Physical activity, resting heart rate, and atrial fibrillation: the Tromsø Study. Eur Heart J. 2016;37(29):2307-13.

285. Landry CH, Allan KS, Connelly KA, Cunningham K, Morrison LJ, Dorian P. Sudden cardiac arrest during participation in competitive sports. $\mathrm{N}$ Engl J Med. 2017;377(20):1943-53.

286. Siebert DM, Drezner JA. Sudden cardiac arrest on the field of play: turning tragedy into a survivable event. Neth Heart J. 2018;26(3):115-9.

287. Burke AP, Farb A, Virmani R, Goodin J, Smialek JE. Sports-related and non-sports-related sudden cardiac death in young adults. Am Heart J. 1991;121(2 Pt 1):568-75.

288. Van Camp SP, Bloor CM, Mueller FO, Cantu RC, Olson HG. Nontraumatic sports death in high school and college athletes. Med Sci Sports Exerc. 1995;27(5):641-7.

289. Saberi S, Day SM. Exercise and hypertrophic cardiomyopathy: time for a change of heart. Circulation. 2018;137(5):419-21.

290. Ullal AJ, Abdelfattah RS, Ashlev EA, Froelicher VF. Hypertrophic cardiomyopathy as a cause of sudden cardiac death in the young: a meta-analysis. Am J Med. 2016;129(5):486-96.

291. Schmehil C, Malhotra D, Patel DR. Cardiac screening to prevent sudden death in young athletes. Transl Pediatr. 2017;6(3):199-206.

292. Fuller C, Scott C, Hug-English C, Yang W, Pasternak A. Fiveyear experience with screening electrocardiograms in National Collegiate Athletic Association Division I Athletes. Clin J Sport Med. 2016;26(5):369-75

293. Panhuyzen-Goedkoop NM, Wellens HJ, Piek JJ. Early recognition of sudden cardiac arrest in athletes during sports activity. Neth Heart J. $2018 ; 26(1): 21-25$.

294. Saberi S, Day SM. Exercise prescription for the athlete with cardiomyopathy. Cardiol Clin. 2016;34(4):591-601.

295. Drezner JA, Asif IM, Harmon KG. Automated external defibrillators in health and fitness facilities. Phys Sportsmed. 2011;39(2):114-8.

296. Gu W, Li CS. What is more important: defibrillation or compression? J Thorac Dis. 2016;8(8):E778-80.

297. Bækgaard JS, Viereck S, Møller TP, Ersbøll AK, Lippert F, Folke F. The effects of public access defibrillation on survival after out-of-hospital cardiac arrest: a systematic review of observational studies. Circulation. 2017;136(10):954-65.

298. Garcia EL, Caffrey-Villari S, Ramirez D, Caron JL, Mannhart P, Reuter PG, et al. [Impact of onsite or dispatched automated external defibrillator use on early survival after sudden cardiac arrest occurring in international airports]. Presse Med. 2017;46(3):e63-e68.

299. Mark DB, Hansen SM, Starks ML, Cummings ML. Drone-based automatic external defibrillators for sudden death? do we need more courage or more serenity? Circulation. 2017;135(25):2466-9. 
300. Hung KK, Graham CA, Chan LK, Poon WK, Rainer TH, Cocks RA. Performance of automated external defibrillators under conditions of inflight turbulence. Resuscitation. 2018 Sep;130:41-3.

301. Hansen SM, Hansen CM, Folke F, Rajan S, Kragholm K, Ejlskov L, et al. Bystander defibrillation for out-of-hospital cardiac arrest in public vs residential locations. JAMA Cardiol. 2017;2(5):507-14.

302. Tagarakis CV, Bloch W, Hartmann G, Hollmann W, Addicks K. Anabolic steroids impair the exercise-induced growth of the cardiac capillary bed. Int J Sports Med. 2000;21(6):412-8.

303. Marocolo M, Silva-Neto JA, Barbosa Neto O. Acute interruption of treatment with nandrolone decanoate is not sufficient to reverse cardiac autonomic dysfunction and ventricular repolarization disturbances in rats. Steroids. 2018 Apr;132:12-7.

304. Angell P, Chester N, Green D, Somauroo J, Whyte G, George K. Anabolic steroids and cardiovascular risk. Sports Med. 2012;42(2):119-34.

305. Thiblin I, Garmo H, Garle M, Holmberg L, Byberg L, Michaëlsson K, et al. Anabolic steroids and cardiovascular risk: A national population-based cohort study. Drug Alcohol Depend. 2015 Jul 1;152:87-92.

306. Novick T, Liu Y, Alvanzo A, Zonderman AB, Evans MK, Crews DC. Lifetime cocaine and opiate use and chronic kidney disease. Am J Nephrol. 2016:44(6):447-53.

307. Goel N, Pullman JM, Coco M. Cocaine and kidney injury: a kaleidoscope of pathology. Clin Kidney J. 2014;7(6):513-7.

308. Vizeli P, Liechti ME. Safety pharmacology of acute MDMA administration in healthy subjects. J Psychopharmacol. 2017;31(5):576-88.

309. Suarez RV, Riemersma R. "Ecstasy" and sudden cardiac death. Am J Forensic Med Pathol. 1988;9(4):339-41.

310. Chandra YG, Shetty AR, Jayanth SH, Hugar BS, Praveen S, Harish S. A death due to ecstasy - a case report. Med LegJ. 2016;84(1):46-8.

311. Mont L, Pelliccia A, Sharma S, Biffi A, Borjesson M, Terradellas JB, et al Pre-participation cardiovascular evaluation for athletic participants to prevent sudden death: position paper from the EHRA and the EACPR, branches of the ESC. Endorsed by APHRS, HRS, and SOLAECE. Europace. 2017;19(1):139-63.

312. Ljungqvist A, Jenoure PJ, Engebretsen L, Alonso JM, Bahr R, Clough AF, et al. The International Olympic Committee (IOC) consensus statement on periodic health evaluation of elite athletes, March 2009.Clin J Sport Med. 2009;19(5):347-65.
313. Hainline B, Drezner J, Baggish A, Harmon KG, Emery MS, Myerburg RJ, et al. Interassociation Consensus Statement on Cardiovascular Care of College Student-Athletes. J Athl Train. 2016;51(4):344-57.

314. van der Wall EE. ECG screening in athletes: optional or mandatory? Neth Heart J. 2015;23(7-8):353-5.

315. Barbosa ET. Critérios para solicitação de exames complementares do aparelho cardiovascular. Arq Bras Cardiol. 1997;68(3):1-9.

316. Lane CM, Bos JM, Rohatgi RK, Ackerman MJ. Beyond the length and look of repolarization: defining the non-QTc electrocardiographic profiles of patients with congenital long QT syndrome. Heart Rhythm. 2018 Sep;15(9):1413-9.

317. Lyon A, Ariga R, Mincholé A, Mahmod M, Ormondroyd E, Laguna $P$, et al. Distinct ECG phenotypes identified in hypertrophic cardiomyopathy using machine learning associate with arrhythmic risk markers. Front Physiol. 2018 Mar 13;9:213

318. Olen MM, Baysa SJ, Rossi A, Kanter RJ, Fishberger SB. WolffParkinson-White syndrome: a stepwise deterioration to sudden death. Circulation. 2016;133(1):105-6.

319. Heron N, Cupples M. The health profile of football/soccer players in Northern Ireland - a review of the uefa pre-participation medical screening procedure. BMC Sports Sci Med Rehabil. 2014;6(1):5

320. Dvorak J, Kramer EB, Schmied CM, Drezner JA, Zideman D Patricios J, et al. The FIFA medical emergency bag and FIFA 11 steps to prevent sudden cardiac death: setting a global standard and promoting consistent football field emergency care. Br J Sports Med. 2013;47(18):1199-202.

321. Kramer EB, Botha M, Drezner J, Abdelrahman Y, Dvorak J. Practical management of sudden cardiac arrest on the football field. Br J Sports Med. 2012;46(16):1094-6

322. Leusveld E, Kleijn S, Umans VA. Usefulness of emergency medical teams in sport stadiums. Am J Cardiol. 2008;101(5):712-4.

323. Moretti MA, Cesar LA, Nusbacher A, Kern KB, Timerman S, Ramires JA. Advanced cardiac life support training improves long-term survival from in-hospital cardiac arrest. Resuscitation. 2007;72(3):458-65.

324. Capucci A, Aschieri D, Guerra F, Pelizzoni V, Nani S, Villani GQ et al. Community-based automated external defibrillator only resuscitation for out-of-hospital cardiac arrest patients. Am Heart J. 2016 Feb;172:192-200. 
The Brazilian Society of Cardiology and Brazilian Society of Exercise and Sports Medicine

Updated Guidelines for Sports and Exercise Cardiology - 2019

Updated

367

Arg Bras Cardio. 2019; 112(3):326-368 
